University of Louisville

ThinkIR: The University of Louisville's Institutional Repository

$12-2017$

\title{
Moving mountains : a study examining long-term impacts of mountaintop removal coal mining on mortality in the Appalachian region using geographic information sciences techniques.
}

James Howard Kent Pugh

University of Louisville

Follow this and additional works at: https://ir.library.louisville.edu/etd

Part of the Demography, Population, and Ecology Commons, Environmental Public Health Commons, Environmental Studies Commons, Epidemiology Commons, Geographic Information Sciences Commons, Human Geography Commons, Medicine and Health Commons, Place and Environment Commons, Regional Sociology Commons, Rural Sociology Commons, and the Spatial Science Commons

\section{Recommended Citation}

Pugh, James Howard Kent, "Moving mountains : a study examining long-term impacts of mountaintop removal coal mining on mortality in the Appalachian region using geographic information sciences techniques." (2017). Electronic Theses and Dissertations. Paper 2847.

https://doi.org/10.18297/etd/2847

This Doctoral Dissertation is brought to you for free and open access by ThinkIR: The University of Louisville's Institutional Repository. It has been accepted for inclusion in Electronic Theses and Dissertations by an authorized administrator of ThinkIR: The University of Louisville's Institutional Repository. This title appears here courtesy of the author, who has retained all other copyrights. For more information, please contact thinkir@louisville.edu. 
MOVING MOUNTAINS: A STUDY EXAMINING LONG-TERM IMPACTS OF MOUNTAINTOP REMOVAL COAL MINING ON MORTALITY IN THE APPALACHIAN REGION USING GEOGRAPHIC INFORMATION SCIENCES TECHNIQUES

\author{
by \\ James Howard Kent Pugh \\ B.A., Berea College, 2012 \\ M.A., University of Louisville, 2014
}

\begin{abstract}
A Dissertation
Submitted to the Faculty of the

College of Arts and Sciences of the University of Louisville In Partial Fulfillment of the

For the Degree of Requirements
\end{abstract}

Doctor of Philosophy

In Applied Sociology in the

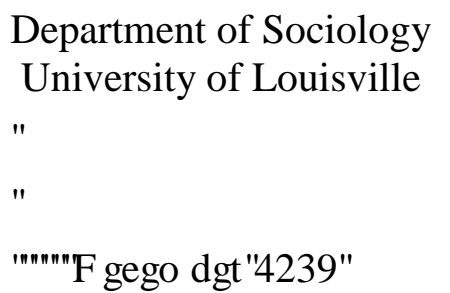


Copyright 2017 by James Howard Kent Pugh 

MOVING MOUNTAINS: A STUDY EXAMINING LONG-TERM IMPACTS OF MOUNTAINTOP REMOVAL COAL MINING ON MORTALITY IN THE APPALACHIAN REGION USING GEOGRAPHIC INFORMATION SCIENCES TECHNIQUES

By

James Howard Kent Pugh

B.A., Berea College, 2012

M.A., University of Louisville, 2014

A Dissertation Approved on

November $21^{\text {st }}, 2017$

By the following Dissertation Committee:

Dissertation Chair, Dr. Latrica E. Best

Department of Sociology \& Pan-African Studies

Dr. David Roelfs

Department of Sociology

Dr. Lauren Heberle

Department of Sociology

Dr. Ryan Schroeder

Department of Sociology

Dr. Kristina Zierold

Department of Epidemiology\& Population Health 


\section{DEDICATION}

This work is dedicated to all those who helped me along this way. I want especially thank

my mother Jeanie D. Pugh, my father James Scott Pugh (R.I.P.) and my mamaws Ilene Hardy Pugh (R.I.P.) and Geneva Tolson Murphy (R.I.P.). They all believed in me from the beginning. Without them, I would not be here. 


\section{ACKNOWLEDGMENTS}

I want to acknowledge the endless patience, caring and support of my wonderful chair, Dr. Latrica E. Best. Dr. Best has been my anchor through this whole process, the good and the bad.

I want to acknowledge the hard work of Dr. Carol L. Hanchette (R.I.P.). A void was left on campus that will be never replaced. Dr. Hanchette touched so many at the University of Louisville.

A thank you to Dr. Derrick Brooms who inspired me to keep working even in the darkest moments and for his mentorship through graduate school. Thank you to Dr. Dave Roelfs for his tireless support during my dissertation process. A special thanks to Dr. Patricia Gagne on her untiring support, not only of me, but every graduate student in Sociology at the University of Louisville. Dr. Mark Austin for always being there when the chips were down. Thank you to Dr. Lauren Heberle, who believed in me when few did.

Last but not least, thank you for the support from my best friend, my ally and the one person who made graduate school so much fun and enjoyable, Dr. Jelisa Clark. Thank you to Brandon McReynold, Adam Sizemore, Heidi Williams, Christa Moore, Eric Jordan, Megan Robinson, Trey Allen, Brittany Buttry-Watson, Brandon Schmidt and so many more for all the laughs, the cries and the joys. 


\title{
ABSTRACT \\ MOVING MOUNTAINS: A STUDY EXAMINING LONG-TERM IMPACTS OF MOUNTAINTOP REMOVAL COAL MINING ON MORTALITY IN THE APPALACHIAN REGION USING GEOGRAPHIC INFORMATION SCIENCES TECHNIQUES
}

\author{
James Kent Pugh
}

November $21^{\text {st }}, 2017$

Over the last hundred years, the Appalachian region has been dominated by the coal industry. It has also been and currently is one of the unhealthiest regions in the United States. Recent scholarship has examined the relationship between coal mining and health and mortality rates in the Appalachian region. The first study incorporates air quality and pollution data to examine if coal mining counties have higher levels of pollution and if this pollution contributes to mortality disadvantage. In the second study, I construct a population-based coal-exposure measure to better evaluate the relationship between coal mining and health I find that coal mining is a poor predictor of air quality and air pollution. However, there appears to be strong links between air pollution and particulate matter pollution. In the second study, I find that the coal-exposure measure for some types of mortality (all-cause, all-cancer, lung cancer, respiratory disease, cardiovascular disease) is more predictive than dichotomous county-level coal mining measures, particularly in explaining cross-county differences in mortality rates. However, I find limited support for the effectiveness of coal-exposure measures when examining links between coal mining and mortality rates. 


\section{TABLE Of CONTENTS}

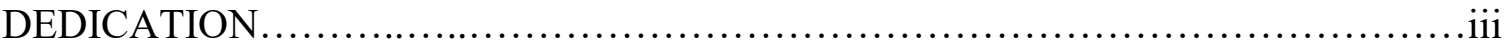

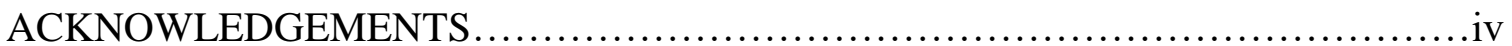

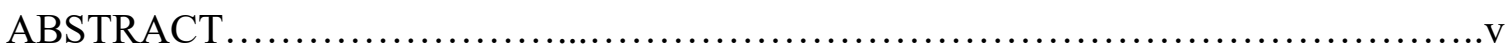

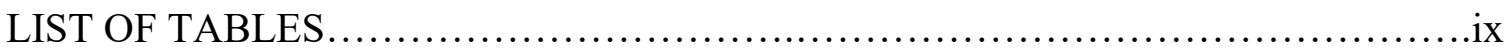

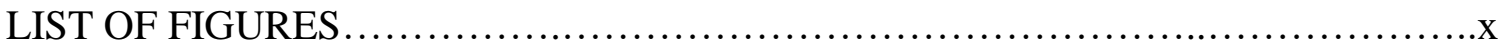

INTRODUCTION ................................................................

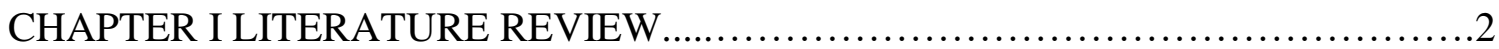

Coal Mining in Appalachia........................................................................ 2

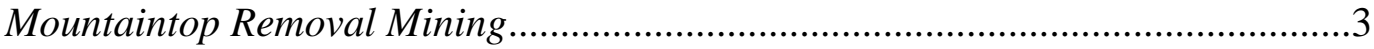

Natural Resource Curse and the Appalachian Region...........................5

Health in Appalachia...........................................................99

Mortality \& Coal Mining........................................................13

Self-reported health, Hospitalizations \& other coal mining-related health outcomes...............................................................16

Coal Mining Pollution Risks..............................................19

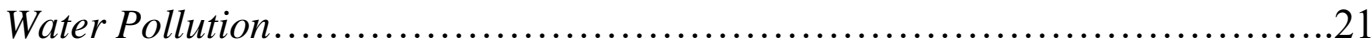

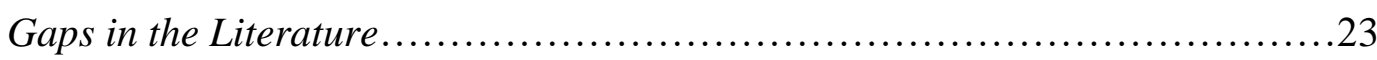

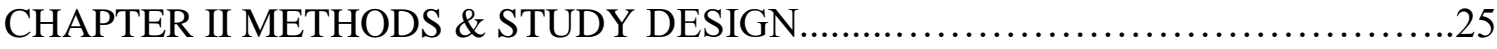

Air Quality Research Questions.............................................25

Coal-exposure Research Questions........................................26

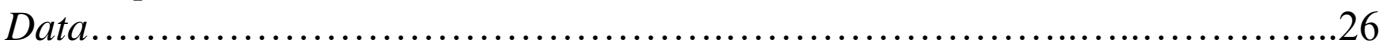

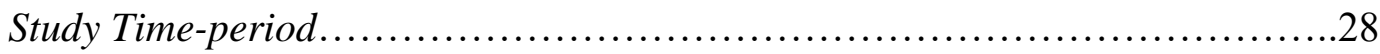

Geographic Location................................................ 28

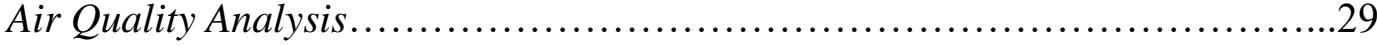

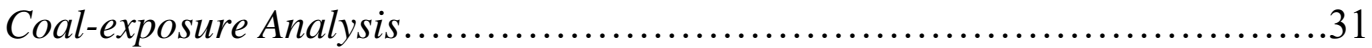

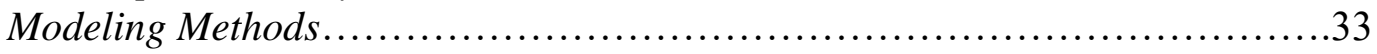

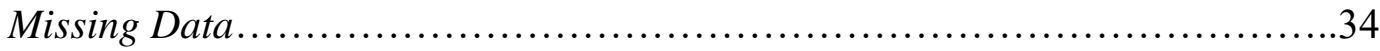

Longitudinal Trends in Coal Production.....................................35

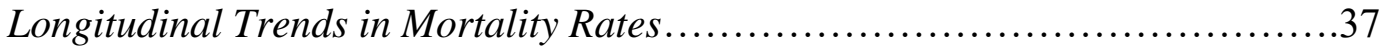

CHAPTER III AIR POLLUTION STUDY......................................40

Univariate Results....................................................40

Geographic Distribution of Air Quality....................................41

Coal Mining \&Air Quality Models.........................................44

Particulate Matter \& Mortality Models.....................................45

Air Quality Index \& Mortality Models.......................................53

Discussion..............................................................60

CHAPTER IV: COAL-EXPOSURE STUDY ....................................67

Univariate Results...................................................67

Geographic Distribution of Coal-exposure measure..........................69

All-cause mortality models............................................. 74

All-cancer mortality models.............................................78

Lung cancer mortality models ..........................................81

Respiratory disease mortality models ....................................84 
Neurodegenerative disease mortality models.............................87

Cardiovascular disease mortality models..................................91

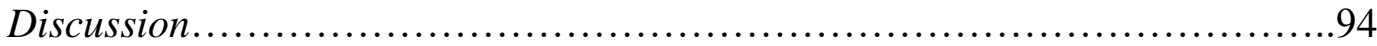

Study Limitations.......................................................... 97

CHAPTER V: IMPLICATIONS \& CONCLUSIONS .............................. 100

Appalachian Coal Mining in Context........................................101

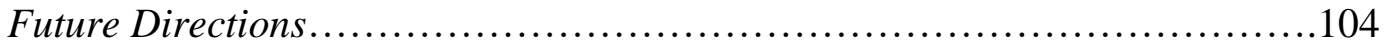

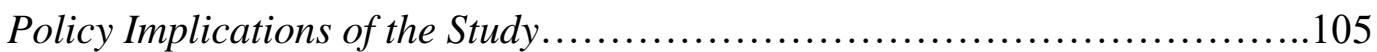

REFERENCES ............................................................... 110

CURRICULUM VITA ..................................................... 139 


\section{LIST OF TABLES}

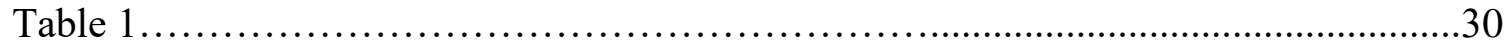

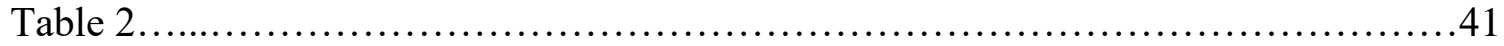

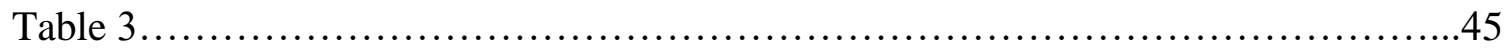

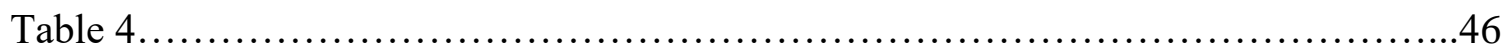

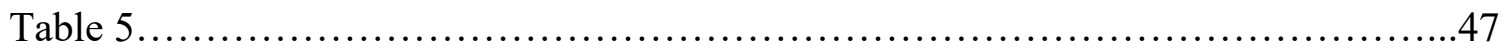

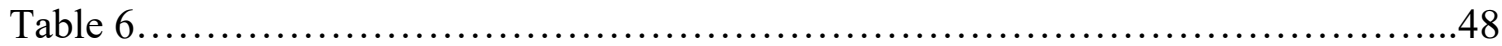

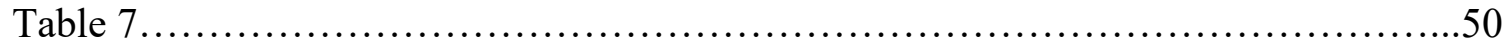

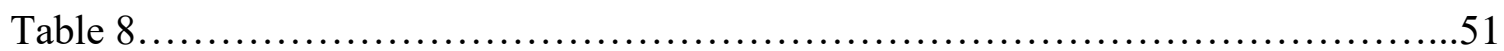

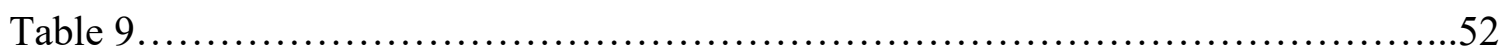

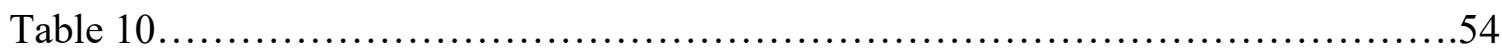

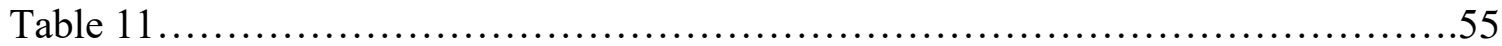

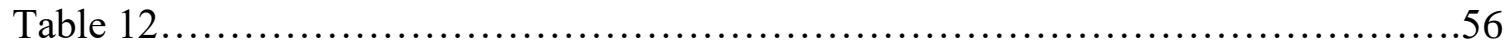

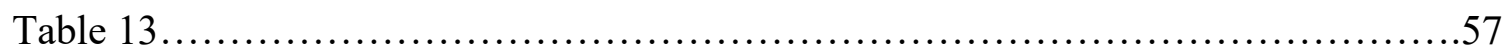

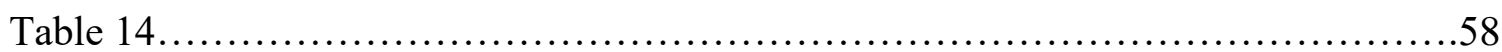

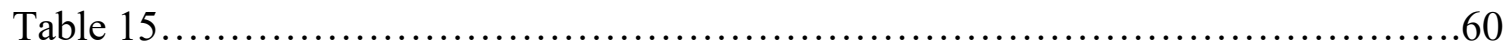

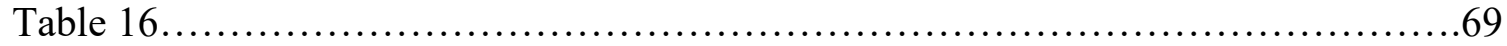

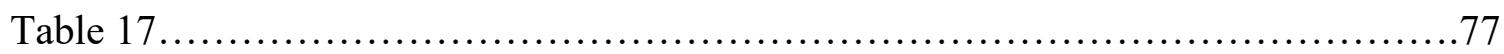

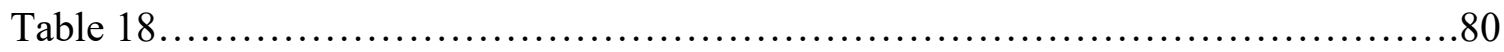

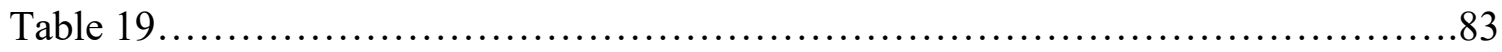

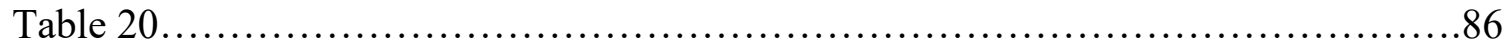

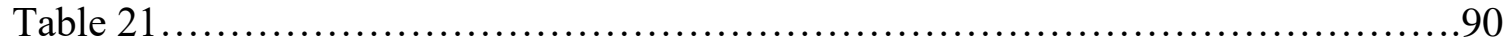

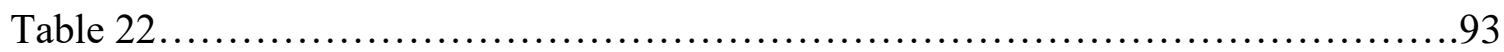




\section{LIST OF FIGURES}

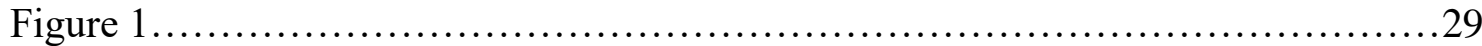

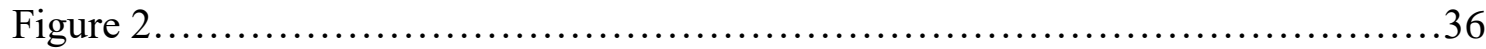

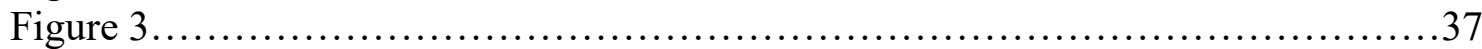

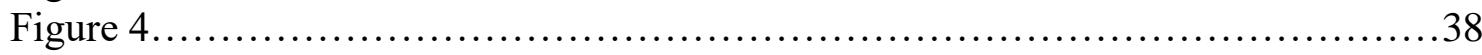

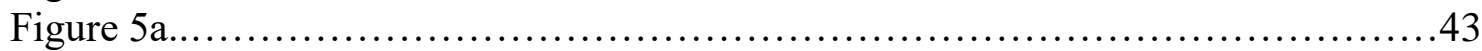

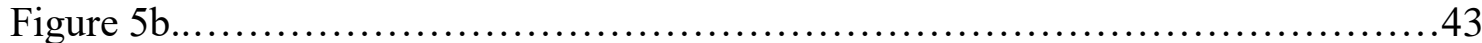

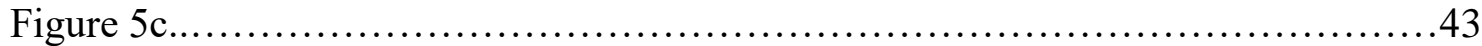

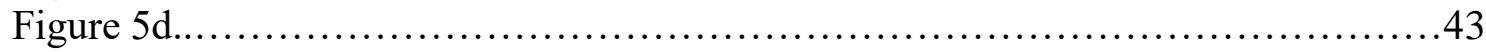

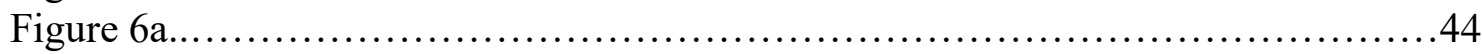

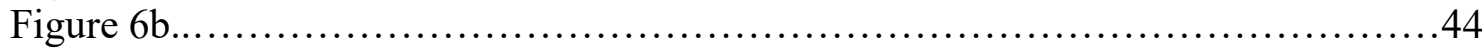

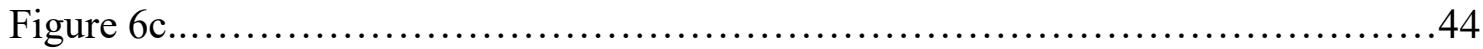

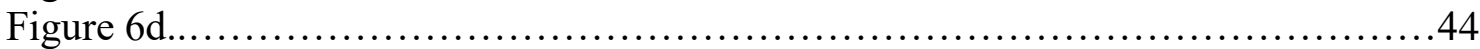

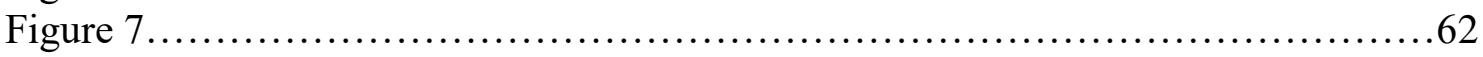

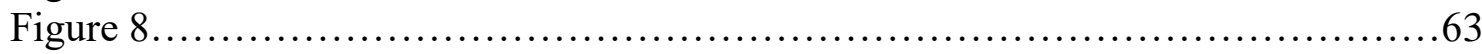

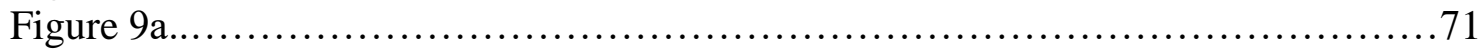

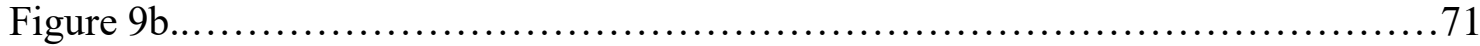

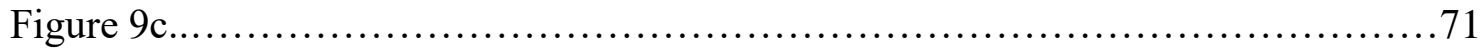

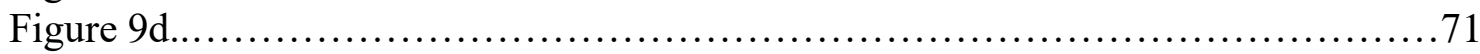

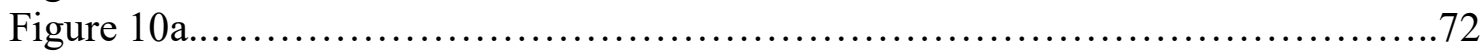

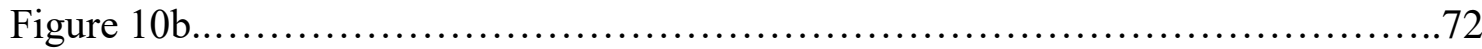

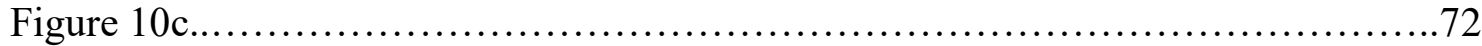

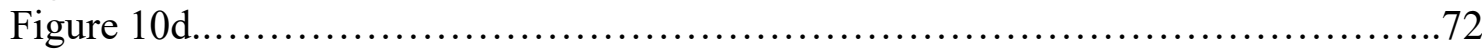

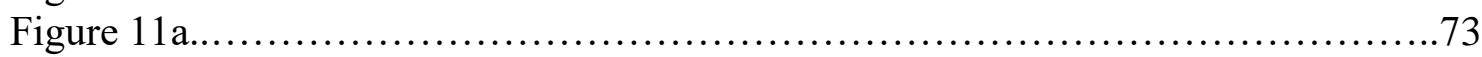

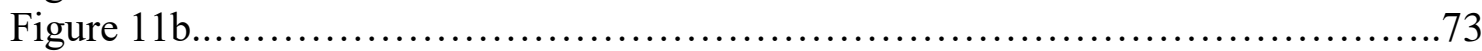

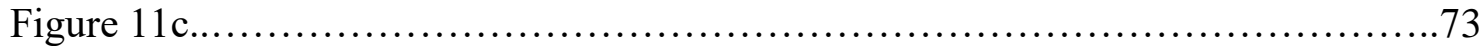

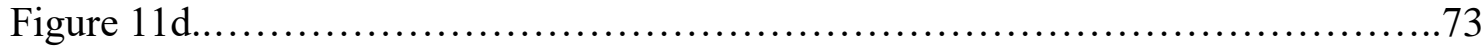

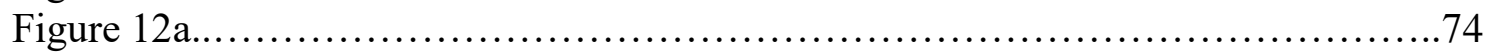

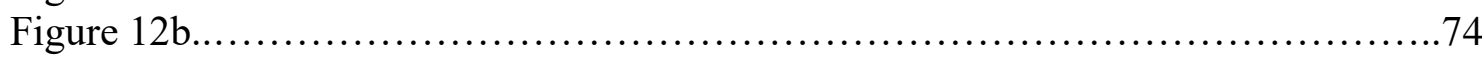

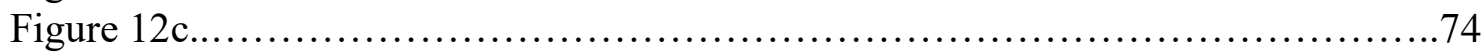

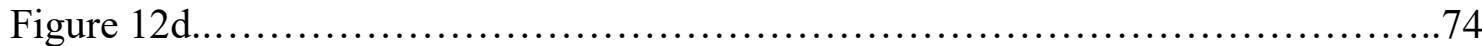




\section{INTRODUCTION}

Appalachia stretches from as far north as southern New York and as far south as northeast Mississippi. However, when one imagines the region, they think of the central Appalachian coalfields of eastern Kentucky, West Virginia, and southwest Virginia. Appalachia has been and still is one of the largest coal producing regions in the world, let alone in the United States. In 2014, the Appalachian region accounted for nearly $25 \%$ of total US coal production, down from over a third just a decade prior (Annual Coal Report 2015). Coal mining and its related industries have had an impact on the Appalachia region. From the early days of union organizing and conflict to the modern era "War on Coal," the black mineral remains at the heart of the Appalachian region (Eller 2008).

Increasingly scholars have focused on the region's health outcomes and its potential association with coal mining. The Appalachian region lags behind the nation in improvements in health and health-related outcomes. The region has high rates of cardiovascular and heart disease (Barnett et a. 2000; Halverson, Barnett \& Casper 2002; Michimi 2010), high rates of cancer (Wingo et al. 2007; Wilson 2016) and a high prevalence of known negative health behavioral risk factors such as smoking (Mensah et al. 2005; King, Dube, \& Tynan 2012). While much of the previous research has focused on the links between low socioeconomic status and health outcomes in populations within the Appalachian region, a growing number of scholars are starting to examine the role coal mining may play in the health status of people in the region. This dissertation builds upon the work of other scholars in this regard. 
Within this burgeoning research area, scholars disagree about the extent to which coal mining may impact health outcomes, namely mortality. For example, Michael Hendryx and colleagues consistently find higher mortality rates, both all-cause and for a variety of other diseases, in coal mining communities (e.g., Hendryx 2008; Hendryx and Ahern 2009). However, other scholars find limited support for non-significant results when attempting to replicate the Hendryx studies (e.g., Boark et al. 2012; Buchanich et al. 2014). Many of the population-based studies have used dichotomous measures of coal production (yes/no, does the county have coal mining sites) and have found contradictory results, with Borak et al. (2012) and Buchanich et al. (2014) finding limited support for coal mining counties having higher mortality rates than non-coal mining counties, counter to the Hendryx (2008) and Hendryx and Ahern (2009) studies. A key limitation of these prior studies is there use of the county-level coal mining dichotomous measure. Such measures remove gradient differences between coal mining counties and serve as a poor measure of environmental pollution exposure related to coal mining sites. I fill in the gaps in the literature by approaching the relationship between coal mining and mortality with new techniques and methods. In this project, I seek to use new geographic and environmental models and techniques to address the questions around the relationship between coal mining and mortality in the Appalachian region. 


\section{LITERATURE REVIEW}

\section{Coal Mining in Appalachia}

The Appalachian region has a long history of coal mining. Coal reserves have been plentiful over the past century and have fueled the American industrial revolution (Williams 2002). Before the discovery of coal in the region in the late 1800's, the Appalachian economy had remained a largely agrarian society of small subsistence forest farms (Williams 2002). At the onset of WWII, the mines were booming and employing hundreds of thousands of miners throughout the Appalachian region. However, the industrial boom during World War II would lead to a crash in the price of coal once the war ended. Miners were laid off en masse in the late 1940's and 1950's, as the demand for coal collapsed, the use of oil began to take off. Additionally, advances in mining technologies such as the continuous miner ${ }^{1}$ further reduced employment in the mines. These technological advancements would continue a trend of reduced employment in mining that would last until the present day. Coal would continue to go through boom and bust cycles in the late 20th century (Eller 2008).

\section{Mountaintop removal mining}

The United States is referred to as the Saudi Arabia of coal (Goodell 2006). The central Appalachian region, consisting of West Virginia, Kentucky, Virginia, Tennessee, and Ohio, is one of the most productive coal producing regions in the United States. After the end of WWII, coal began to lose its dominance among America's energy needs, as

\footnotetext{
${ }^{1}$ A machine that includes a drill-bit to dig coal and a conveyor belt to transport it out of the mine (Eller 2008).
} 
cheap oil and gas fueled the growth of suburban America (Goodell 2006; Eller 2008). The oil embargo and resulting shocks of the 1970's brought renewed interest in domestic sources of energy and coal once again became a dominant player in America's energy needs. The passage of new environmental regulations in the 1960's and 1970's, particularly controls on emissions from power plants enacted through the Clean Air Act, fueled an increased demand for Appalachian coal (Goodell 2006; Eller 2008; Hendryx \& Holland 2016). Appalachian coal has lower levels of sulfur compared to coal mined in the other major producing regions (such as the Powder River Basin in Wyoming) in the United States (Goodell 2006; Hendryx \& Holland 2016). As power plants were required to reduce emissions of sulfur and other pollutants, cleaner burning Appalachian coal began to rise in demand (Copeland 2015; Hendryx \& Holland 2016). However, by the late 1960's and early 1970's the easiest to reach coal reserves were depleted. This required technological innovation to get at the last seams of coal. Beginning in the 1960's and 1970's a new mining technique was incorporated to reach harder to mine coal with a new technology called mountaintop removal mining.

One technological advancement that has had a meaningful effect on both employment, and potential health, is mountaintop coal removal. Mountaintop removal coal mining is a form of surface coal mining that requires the blasting and removal of the tops of mountains. The resulting rock and rubble is pushed into the valley below the mountain. This process is used to extract thin seams of coal from the center of mountaintops that would otherwise not be retrievable using underground mining techniques (Copeland 2015). This mining process has serious ecological ramifications on the surrounding environment, including changes in the flows of streams and waterways (Vengosh et al. 2013; Evans et 
al. 2015), polluting of surrounding groundwater (McAuley \& Kazor 2006; Lindberg et al. 2011), reduced air quality (Aneja, Isherwood \& Morgan 2012; Kruth et al. 2014) and drastic changes in the topography of the land (Wickham et al. 2013; Ross, McGlynn \& Bernhardt 2016). In addition to the environmental issues, scholars have find links between mining-related environmental concerns and population health in the Appalachian region. The environmental health concerns associated with mining is discussed in further detail in a later section.

\section{Natural Resource Curse and the Appalachian Region}

There is a fundamental paradox about the Appalachian region of the United States. The region hosts some of the largest reserves of natural resources in the United States, from forest timbers to coal and natural gas (Goodell 2006; Eller 2008). However, the Appalachian region remains one of the poorest in the United States (Pollard \& Jacobsen 2015). Studies find that some, but not all, of the health disparities in the Appalachian region, can be explained by high levels of socioeconomic inequality (Halverson \& Bischak 2008). Thus, much scholarship has focused on the causes of socio-economic inequality in the Appalachian region. Some scholars point to the vast natural resource wealth of the Appalachian region as a potential cause of its plight. A vein of scholarly thought has brought attention to the "Natural Resource Curse" in the Appalachian region.

The term "Natural Resource Curse" was first coined by Richard M. Autry in his 1993 book "Sustainable Development in Mineral Economies: The Resource Curse Thesis." Autry (1993) argues that countries, particularly former colonies that have bountiful natural resources, are "cursed" by poor economic performance. Autry pays attention to the nature of the natural resource economy, which is a "boom and bust" cycle (Autry 1993). Natural 
resource economies are capital intensive and have low levels of investment in social capital, and most infrastructure and resource investments are used primarily to serve the extractive industry (Autry 1993; Morice \& Colagiuri 2012).

One of the key components of a "Natural Resource Curse" is a lack of investment in non-resource related industries (Autry 1993). When the prices rise, and income from natural resources is high, there is a significant lack of demand to invest in other, more diverse, industries. Thus, economies become dependent upon primary extractive industries. A central characteristic of the central Appalachian regional economy is the dominance of the coal industry (Goodell 2006; Eller 2008; Center for Regional Economic Competitiveness 2014). Appalachian scholars Helen Lewis and Edward Knipe (1978) note in their work "The Colonialism Model: The Appalachian Case" of the colonial nature of the Appalachian coal-based economy and describe it as an "internal colony" of the United States. Scholars suggest the dominance of the coal industry has impacted the development of social capital in the region.

Black, McKinnish, and Sanders (2005) used high school enrollment and coal price data to test if times of high coal prices led to decreased enrollment in school during the 1970 to 1990 period. They find that in Kentucky and Pennsylvania during the 1970's, school enrollment rates in coal mining counties declined and then increased in the 1980's relative to the rates of non-mining counties. They find that a $10 \%$ increase in the wages of low-skilled workers (particularly coal miners) is associated with a 5-7\% decline in school enrollment rates during the period studied. In a study conducted by Douglas and Walker (2015) using economic panel data from 1970 to 2012, they find that up to $25 \%$ of the drop in annual per capita income growth rates in coal mining counties between 1970 to 2010 
were associated with decreased educational attainment. In an assessment of poverty and mining employment in the region, Deaton and Niman (2012) find that coal mining employment associated with immediate reductions in poverty rates, but a long-term increase in poverty rates. If a coal mining resource curse exists in the Appalachian region, how does this phenomenon affect the health and well-being of those in the Appalachian region?

Poverty and income inequality are the biggest drivers of health inequality both in the developing and the developed world (Marmot 2005). Research consistently finds that those with the most economic resources in society have better access to healthcare, reduced rates of disease, increased life expectancy and higher rated quality of life (Marmot 2005). In the case of regions like Appalachia, that experience with high rates of poverty and health inequality is important to understand fully how economic and health inequalities continue to be reproduced. Appalachia's "Natural Resource Curse" serves as a mechanism by which to understand how power concentrates in the coal mining industry. Investments in education, economic opportunity, and infrastructure are focused on the needs of the mining industry. As a result, health inequality and high rates of poverty are externalities that are produced by coal mining. These externalities help to feed what Allan Schaiberg (1980) calls the "Treadmill of Production."

Coal mining and its externalities in the Appalachian region are symptomatic of a larger problem associated with increased industrial production suggested by Schnaiberg's 'Treadmill of Production" thesis. In his 1980 book "The Environment: From Surplus to Scarcity" Allan Schnaiberg argues that capitalist societies seek to increase their rate of growth at the expense of the natural and social world. Schnaiburg argues that capitalist 
societies seek to expand production of goods and services, monopolize production processes within the society, and increase capital intensity of production (Schnaiberg 1980). According to Schnaiberg (1980) as capital increases in industrialized Western countries during the middle of the twentieth century, the capital was put into replacing labor production with more resource intensive new technologies. These new technologies required the more intense use of natural resources, chemicals, and other industrial byproducts (Schnaiberg 1980). Unlike labor capital, this new technological capital represented large sunk costs, thus to gain the most use of the new technologies, capitalists sought to constantly increase production and expand the marketplace for such products (Schnaiberg 1980). Increased industrial production growth includes the increased demand and use of chemicals, pesticides, oil, coal, gas and other natural resources to drive the increased production, which in turn increases the amount of ecological devastation produced in the economy (Schaniberg 1980). Capitalist societies thus produce externalities such as pollution, poverty, and other environmental, social, and economic issues through increased growth in production.

In the Appalachian context, the increased and continued use of coal for electricity production in the 20th century led to environmental (surface and MTR coal mining pollution), socioeconomic (increased poverty, reduced employment in coal industry) and health externalities (Coal workers' pneumococcus, environmental pollution risk). The treadmill of production in the Appalachian context uses coal as a mechanism to increase economic growth, via increased electricity use. Natural Resource Curse and the Treadmill of Production both provide useful theoretical insight into the larger context in which Appalachia exists. Mountaintop removal coal mining is a capital-intensive process that 
reduces the labor production of coal miners, while dramatically increasing the amount of coal mined. This form of mining thus increases production at the expense of ecological ramifications. However, as recent literature suggests the treadmill of production that mountaintop removal coal mining produces may lead to externalities beyond the ecological, but into health and socioeconomics.

Scholars find mountaintop removal (MTR)MTR coal mining to be highly destructive to the environment (Palmer et al. 2010; Aneja, Isherwood \& Morgan 2012; Vengosh et al. 2013; Kruth et al. 2014; Evans et al. 2015) and is linked to negative health outcomes, including increased mortality rates and reduced self-rated health (Hitt \& Hednryx 2010; Hendryx, Fedorko \& Anesetti 2010; Zullig \& Hendryx 2010; Zullig \& Hendryx 2011). While acknowledging that the role of socioeconomic status on coal mining in the region remains important, socioeconomic status may not be the only mechanism through which coal mining affects the health and wellbeing of the Appalachian region.

In this project, I seek to examine the potential impact of mountaintop removal coal mining beyond its socio-economic aspects of health and mortality by using both direct environmental measures and geographic derived spatial measures of coal mining population exposure. However, as I argue in this project, in addition to the socio-economic impact of coal mining on the region's health, there are additional issues related to environmental pollution, particularly for mountaintop removal coal mining.

\section{Health in Appalachia}

Scholars have documented persistent health disparities in the Appalachian region (Behringer \& Friedell 2006; Crossman et al. 2007; Lane et al. 2012). These disparities are noted across a variety of physical and psychological health conditions including dental 
health (e.g., Gorsuch, Sanders \& Wu 2014), mental health (e.g. Zhang et al. 2008), mortality from cardiovascular diseases and incidences of high blood pressure (e.g. Halverson, Barnett \& Casper 2002), cancers, both mortality and incidence rates (e.g. Wilson et al. 2016) among others. Scholars have focused particular attention on cancer incidence, mortality, and survivorship.

Overall cancer incidence in the Appalachian region is higher than the United States (Wingo et al. 2007; Wilson et al. 2016). Trend data show that over the past quarter of a century the incidence rates of cancer in Appalachia have decreased; however, the gap between the region and the nation remains high (Wilson et al. 2016). While rates continue to decline, survivorship remains poor for cancer in the Appalachian region (Yao et al. 2016). Rural and urban disparities in cancer incidence and mortality rates persist within the Appalachian region. Cancer incidence rates have risen since 2009 in rural Appalachian counties, while mortality has continued to decline (Yao et al. 2016). Urban Appalachian counties have incidence and mortality rates closer to the national rates (Yao et al. 2016). Certain types of cancers are elevated in the Appalachian region compared to the nation, particularly breast and lung cancers.

Anderson et al. (2014) find higher incidence rates of later-stage breast cancer in the Appalachian region compared to the nation, and that later-stage breast cancer rates cluster in the poorest counties in the region. Hall et al. (2000) find that breast cancer mortality rates in the Appalachian region rose during the 1980's but had declined through the 1990's considerably. Yao, Lengerich, and Hillemeier (2012) find that between 1969 to 2000, Appalachian women had lower levels of mortality from breast cancer. However, by the 2003-2007 period, mortality trends had reversed, and women in Appalachian counties had 
higher rates of breast cancer mortality than the nation (Yao, Lengerich \& Hillemeier 2012). Scholars suggest the disparities between urban and rural counties in Appalachia may be related to lower breast cancer screening rates among residents in rural Appalachian counties (Hall et al. 2000; Yao et al. 2016). Breast cancer disparities remain a significant concern in the Appalachian region.

Increased tobacco consumption among residents in the Appalachian region makes lung cancer a particular concern (Jermal et al. 2008; King, Dube \& Tynan 2012). Lung and bronchial cancer incidence rates are higher in Appalachian counties than in nonAppalachian counties (Fisher et al. 2008; Christian et al. 2011; Blackley, Behringer \& Zheng 2012). Lung cancer incidence rates are highest in the central Appalachian regions of West Virginia, Kentucky, Virginia, and Tennessee (Wingo et al. 2007; Christian et al. 2011). Scholars suggest that concentrated poverty in the central Appalachian region may be associated with the higher incidence and lower survivorship from cancer more generally (Lengerich et al. 2005; Blackley, Behringer \& Zheng 2012). Increased levels of poverty and social stress may also account for increased incidence and mortality rates from stressrelated ailments such as cardiovascular diseases.

The Appalachian region has higher rates of cardiovascular and heart diseases (Barnett et a. 2000; Halverson, Barnett \& Casper 2002; Michimi 2010) and a higher occurrence of risk factors such as smoking (Mensah et al. 2005; King, Dube, \& Tynan 2012) than the rest of the United States. Appalachian states such as Kentucky, West Virginia, Tennessee, and Mississippi have higher rates of hospitalization for stroke, heart failure and myocardial infraction (Mensah et al. 2005). Barnett et al. (2000) find that mortality rates for coronary heart disease are significantly higher in non-metropolitan 
(rural) Appalachian counties for all-age African Americans and younger whites. They suggest the lack of medical facilities and resources in rural Appalachia make management of heart disease and comorbidities (such as obesity, diabetes, etc.) more difficult, leading to increased mortality rates (Barnett et al. 2000). In addition to mortality rates for heart disease and cancers, oral and dental health disparities exist as well.

Dental and oral health is of particular concern for the Appalachian region due to the high rate of tobacco use, both smoke and smokeless, and lack of dental health facilities (Mensh, et al. 2005; Krause et al. 2011; King, Dube \& Tynan 2012; Gorsuch, Sanders \& Wu 2014). Krause et al. (2011) find that the Appalachians had higher levels of tooth decay than the United States' general population. Appalachian adults have higher rates of loss of six or more teeth than the national population (Krause et al. 2011). Krause et al. (2011) find that seniors in the Appalachian region are particularly vulnerable, as they report higher levels of tooth loss than non-Appalachian seniors. Gorscuch, Sanders, and Wu (2014) also identify the Appalachian region as a place of high disparity in tooth loss. They find that between 1999 and 2010, the rate of tooth loss had decreased in the Appalachian region by a similar rate as the nation; however, the region has a higher proportion of the population that experience tooth loss (Gorsuch, Sanders \& Wu 2014). Some scholarship finds strong links between incidence and mortality from other comorbidities, particularly from heart and cardiovascular diseases, and oral health (e.g., Mattila et al. 1989; DeStefano et al. 1993). Thus, there may be strong links between oral health and overall well-being in the Appalachian region.

The state of health in the Appalachian region is one of the historical and persistent disparities in disease incidence, mortality, and risk factors. Scholars point to the problems 
of geographic isolation and persistent poverty as possible sources of health disparities in the region. Others examine links between pollution, particularly coal mining pollution, and population health outcomes in the Appalachian region.

\section{Mortality \& Coal Mining}

In the first of a series of ecological studies conducted by a research team out of West Virginia University (WVU), Michael Hendryx (2008) examines the impacts of coal production on all-cause mortality in the Appalachian region. Hendryx finds that Appalachian coal mining counties with the highest levels of annual coal production ( $>4$ million tons) have the highest mortality rates during the 1999-2004 study period. These results remain after additional covariates for socio-economic indicators, demographics and smoking rates are modeled. In a follow-up study by Hendryx and Ahern (2009), they find that Appalachian counties with the highest levels of coal production (higher than median coal production) between 1979 and 2005 have the highest age-adjusted all-cause mortality rates. Hendryx and Ahern (2009) find between 1979 and 2005 coal mining areas of Appalachia had an average of 77.6 excess deaths per 100,000 people, and this mortality

rate increased to 126 excess deaths per 100,000 during the last five years (2001-2005) of the study period. While these initial WVU ecological studies find significant associations between coal production and all-cause mortality, another pair of studies finds limited support for such claims.

Borak et al. (2012) attempt to replicate several of the studies conducted by the team at WVU. Using all-cause mortality rates from 2000 to 2004 and similar covariate data for socioeconomic status, demographics, and smoking rates, they find that coal mining is not independently associated with increased all-cause mortality rates in the Appalachia region. 
They test measures of coal production like those used by several of the WVU studies and find little changes in the model. However, they note several changes between the studies. Borak et al. (2012) only use counties identified as part of the Appalachian region by the Appalachian Regional Commission $(n=420)$ compared to several of the Hendryx studies (Hendryx 2008; Hendryx and Ahern 2009) that use all US counties (3,141). Additionally, in several of the Hendryx studies controls are added for regional differences, a variable that marked whether a county is in the American South.

In a third study conducted by Buchanich et al. (2014), the authors find that all-cause mortality rates are not significantly associated with coal production. However, this study's design differs from that of the Boark et al. (2012) study and the studies conducted by the team at WVU. In the Borak study, they pair-match 62 counties based on median income and geographic proximity from eight Appalachian states (West Virginia, Pennsylvania, Maryland, Virginia, North Carolina, Tennessee, Kentucky, and Ohio). They then calculated rate ratios for all-cause mortality rates. After adjusting for covariates, little association remained between coal production levels and mortality rates. A strength of this study design is the semi-experimental nature of the pair-wise matching. However, this does limit the number of counties in the sample size, which can limit the predictive power given that most coal mining clusters in a few counties in the Appalachian region. While all-cause mortality has conflicting results, other cause-specific mortality are closely associated with coal mining in Appalachia.

Mortality from respiratory diseases is higher in the Appalachian region than in the United States. Generally, this can in large part be explained by high rates of smoking (Mensah et al. 2005; King, Dube, \& Tynan 2012). However, recent research suggests that 
coal mining areas have higher rates of respiratory disease mortality than non-coal mining areas. Hendryx (2009) finds that Appalachian counties with more than 4 million tons of coal mined between 2000 and 2004 have the highest rates of mortality from chronic respiratory diseases. However, they do not find higher acute respiratory mortality elevated. These findings suggest that much of the respiratory disease mortality comes from chronic obstructive pulmonary disease (COPD), asthma, lung cancer, cystic fibrosis among other forms of chronic respiratory disease. Additional studies conducted by the WVU team find an increased incidence of lung cancer (Hendryx, O’Donnell \& Horn 2008; Hendryx, Fedorko \& Anesetti-Rothermel 2010; Hendryx \& Holland 2016) and respiratory mortality (Hendryx \& Holland 2016) in Appalachian coal mining counties.

Lung and bronchial cancer incidence rates are higher in Appalachian counties than in non-Appalachian counties (Fisher et al. 2008; Christian et al. 2011; Blackley, Behringer \& Zheng 2012; Wilson et al. 2016). Lung cancer incidence rates are highest in the central Appalachian regions of West Virginia, Kentucky, Virginia, and Tennessee (Wingo et al. 2007; Christian et al. 2011). However, despite overall higher incidence rate of lung cancer in the Appalachian region, studies find the highest mortality rates for lung cancer in coal mining counties (Hendryx, O’Donnell \& Horn 2008; Hendryx, Fedorko \& AnesettiRothermel 2010; Hendryx \& Holland 2016). All studies have controlled for potential risk factors, such as smoking rates within each county. In a GIS-based inverse-distance model, using location data on mines, coal slurry impoundments and processing plants, Hendryx, Fedorko \& Anesetti-Rothermel (2010) find their exposure method to be highly correlated with lung cancer mortality rates in West Virginia. I build upon the work of Hendryx, 
Fedorko \& Anesetti-Rothermel (2010) by constructing a population-exposure based model, which will is discussed in a later chapter.

Heart disease and risk factors for heart disease such as obesity and smoking are higher in the Appalachian region (Sherry et al. 2010; Jemal et al. 2008; King, Dube \& Tynan 2012). However, research suggests that Appalachian coal-producing counties have higher rates of heart disease than non-coal producing Appalachian counties. Hendryx (2009) finds that male and female mortality rates for chronic heart disease are higher in Appalachian coal mining communities after controlling for smoking and other demographic and socio-economic factors. In a follow-up study, Esch \& Hendryx (2011) find that chronic cardiovascular disease mortality rates are highest in coal mining counties containing mountaintop removal coal mining. These findings suggest a strong environmental component to health disparities in the Appalachian region.

\section{Self-reported health, Hospitalizations \& other coal mining-related health outcomes}

Scholars find that measures of self-rated health and illness to be highly predictive of actual disease and illness (Miilunpalo et al. 1997; Idler \& Benyamini 1997; Jylha 2009; Mossey \& Shapiro 2011). Studies have consistently found that self-rated health can predict mortality, that is self-rated poorer health and illness are predictive of future mortality (e.g., Mossey \& Shaprio 2011). Thus, scholars have found consistent evidence that self-rated health is a strong predictor of overall health and potentially serious illness (Idler \& Benyamini 1997; Jylha 2009). In the Appalachian region, researchers find a significant association between residence in coal mining communities and lower self-rated health status. Using a survey of 16,493 residents of West Virginia, Hendryx and Ahern (2008) find coal production to be highly associated with lower levels of self-rated health. As the 
rate of coal production increased, health status ratings decreased, and the reporting of diseases increased. This association remained after additional covariates for health behaviors, socioeconomic status and demographics are included in the model (Hendryx \& Ahern 2008).

Hendryx (2013) surveyed three communities in eastern Kentucky, one that had mountaintop removal coal mining and two that did not. Hendryx (2013) finds that respondents living in the mountaintop mining community have significantly lower selfrated health than those living in the non-mountaintop mining community. Those living in the mountaintop mining community had significantly higher rates of asthma, COPD, and hypertension (Hendryx 2013).

While research by Michael Hendryx and his colleagues find a significant association between coal mining and self-rated health, other scholars find contradictory results. Woolley et al. (2015) used logistic modeling from self-rated responses from 10 counties in West Virginia, Tennessee and North Carolina $(n=415)$, both coal mining and non-coal mining, to model the potential association between coal mining and self-reported health. They find no significant association between the odds of having poor or good health and living in a coal mining county (Woolley et al. 2015). They measured coal mining by employment status or a self-reported question asking if they lived near a coal mining facility. Self-reporting residence near coal mining sites raises the possibility of misreporting if the respondent does not know if they live near a coal facility. Previous research used administrative production records to control for coal mining by employing dichotomous measures of living in a coal mining community or not or linear measures of the level of coal production (e.g., Hendryx \& Ahern 2008; Hendryx 2013). 
Some scholars use self-rated health as part of a measure to assess the healthassociated quality of life. These measures are called health-related quality of life (HRQOL) factors (CDC 2000). HRQOL includes a 5-measure scale for self-rated health, a measure of the number of healthy physical and mental days a person reports each month and a measure of the number of activity limitation days (CDC 2000). Using HRQOL measures, Zullig and Hendryx (2010) find that Appalachian coal mining county residents had significantly fewer healthy days for both physical and mental health and overall poorer self-rated health compared to the U.S. non-coal mining counties. Zullig and Hendryx (2010) find that these associations remained after additional controls for health behaviors, socioeconomic circumstances and demographic characteristics are considered. In a separate analysis conducted by Zullig and Hendryx (2011) they find a similar pattern for respondents living in mountaintop removal mining counties.

Hendryx, Ahern \& Nurkieicz (2007) was one of the first publications to bring attention to the potential impact of coal mining on population health in the Appalachian coalfields. Using 2001 hospitalization data for West Virginia, Kentucky, and Pennsylvania, they find a significant association for increases in coal production and increased odds of hospitalization for hypertension and COPD. Increased odds of hospitalization for hypertension and COPD remained after additional covariates for county socioeconomic and demographic factors were considered. The odds of hospitalization for hypertension increased by $1 \%$ for every 1873 tons of coal mined and the odds for COPD hospitalization increased $1 \%$ for every 1462 tons mined (Hendryx, Ahern \& Nurkieicz 2007). While Hendryx's team finds significant links between coal mining and hospitalization rates, others have found contradictory results. 
Talbott et al. (2015) examined hospitalization rates for circulatory disease in West Virginia and finds that they are not associated with coal mining. Using hospitalization data from 2005 to 2009 for all counties in West Virginia, they constructed a spatial regression model assessing the relationship between coal mining production and hospitalization rates. They find no significant association between a county's coal mining production and hospitalization rates for circulatory disease (Talbott et al. 2015). These results suggest a mixed association between coal mining and hospitalization in the Appalachian region. Coal mining communities are associated with increased hospitalization rates for respiratory diseases (e.g., COPD) (Hendryx, Ahern \& Nurkieicz 2007). However circulatory disease (e.g., cardiovascular disease) do not see higher hospitalization rates (Talbott et al. 2015).

\section{Coal Mining Pollution Risks}

Mountaintop removal coal mining's potential environmental health risks are associated with two main ecological pathways, air pollution, and water pollution. The air quality pathway consists of is two areas of releases, the release of particulate matter in the air and the chemicals and other materials that are in the particulate matter itself. Particulate matter refers to a mixture of liquid droplets and solid particles that are found in air. These particulates can be very large or very small; they can be visible to the naked or invisible ("Particulate Matter," EPA 2016). Particulate matter comes in two sizes, PM10 and PM2.5. PM10 refers to any particulate matter larger than 2.5 micrometers in diameter, PM2.5 refers to particles 2.5 micrometers or less in diameter ("Particulate Matter," EPA 2016).PM2.5 can travel distances far beyond the emission point, sometimes documented farther 30 miles from the source point, PM10 has been noted to have a smaller range ("Particulate Matter," EPA 2016). 
Particulate matter can be dangerous when certain concentrations and sizes are inhaled in the human body (Anderson, Thundiyill \& Stolbach 2011). Particulate matter has been found to increase incidence, mortality, and hospitalizations from respiratory diseases (Zeka et al. 2005; Analitis et al. 2006; Ostro et al. 2006; Zanobetti and Schwartz 2009; Hales et al. 2010), cardiovascular disease (Chapman et al. 1997; Bhatnagar 2006; Dominici et al. 2006; Mastin 2006) and lung cancer (Pope III et al. 2002).

Particulate matter is found in coal dust produced in underground coal mines and is linked to incidence of coal workers' pneumoconiosis (CWP; more commonly called “Black Lung Disease.”) and silicosis in coal miners (Castranova \& Vallathan 2000). Additional scholarship finds that surface coal mining sites release particulate matter into the atmosphere as well. Increased particulate matter concentration has been found in studies of surface coal mines in India (Ghose \& Majee 2000), United Kingdom (Reynolds et al. 2003), China (Liu et al. 2012), Colombia (Huertas et al. 2012) and Australia (Higginbotham et al. 2010). Similar air quality issues are found in West Virginia in the United States (Kurth et al. 2014; Kurth et al. 2014[1]).

In the case of the Appalachian region, surface mining via the mountaintop removal process has been found to produce increased levels of particulate matter and crustal materials in the air. A research team from West Virginia University and the US Geologic Survey sampled air quality in several West Virginia counties with and without mountaintop removal coal mining sites. They find that mountaintop removal mining sites experience between 1.5 to 5.8 times more PM elements than the non-mountaintop removal sites (Kruth et al. 2012). An additional study found that the smallest $\left(\mathrm{PM}<2.5 \mu \mathrm{m}^{3}\right)$ size particles are 
found in high concentrations around the sample mountaintop removal coal mining sites in West Virginia (Kruth et al. 2012 [1]).

The World Health Organization estimates that nearly 800,000 people die each year from diseases and illnesses associated with air pollution (Anderson, Thundiyil \& Stolbach 2011), much of which comes in the form of particulate matter (PM $2.5 \mu \mathrm{m}^{3}$ and PM 10 $\mu \mathrm{m}^{3}$ ). Almost all population health studies examining the impact of particulate matter and air pollution have examined large urban centers (Anderson, Thundivil \& Stolbach 2011). Increases in coarse particulate matter $\left(\mathrm{PM} 10 \mu \mathrm{m}^{3}\right)$ is associated with increased all-cause mortality (Dockery et al. 1993; Pope et al. 1995), cardiopulmonary mortality (Pope et al. 1995) and respiratory mortality (Zeka et al. 2005; Analitis et al. 2006; Hales et al. 2010). Increases in fine and ultrafine particulate matter $\left(\mathrm{PM}<2.5 \mu \mathrm{m}^{3}\right)$ are associated with increased cardiopulmonary (Pope et al. 2002), cardiovascular (Miller et al. 2007), respiratory (Zanobetti et al. 2009; Ostro et al. 2006) and lung cancer mortality (Pope et al. 2002). Particulate matter is a serious environmental health risk, and research suggests it poses a serious risk to the cardiovascular and respiratory systems. This risk posed by particulate matter is due to the potential harm of the cardiopulmonary system, which can cause respiratory, cardiovascular illnesses (Thurston \& Lippmann 2015) and increases the risk of cancer (Hamra et al. 2014). Much of the scholarship on the mortality risks associated with mountaintop removal coal mining in Appalachia suggests air pollution as the most likely pathway for increased mortality.

\section{Water Pollution}

The mountaintop removal mining process does extensive harm to the environment (Palmer et al. 2010). When the physical terrain changes, the hydrological geography 
changes as well. Streams are buried beneath rubble from the mountains, in some cases, they may be completely rerouted (Lindberg et al. 2011; Evans et al. 2015). Thus, these streams are susceptible to runoff from the mines when it rains or snows on the large mine site (Evans et al. 2015). Lindberg et al. (2011) find a linear increase in conductivity in the streams near the mountaintop removal mining site. Additionally, they find high concentrations of selenium, sulfate, magnesium, and other inorganic solutes within the geographic extent of the upstream mining operation. Hitt \& Hendryx (2010) find a significant association between the ecological integrity of streams near mountaintop removal coal mining sites and cancer rates in the surrounding counties. They find that respiratory, digestive, urinary and breast cancer rates are significantly elevated and associated with the ecological integrity of streams (Hitt \& Hendryx 2010). While streams are a significant cause of concern for pollution, groundwater appears to be impacted by mountaintop removal mining as well.

An assessment conducted in 1996-98 by the U.S. Geological Survey National Water-Quality Assessment Program finds that ground-water wells down-stream from reclaimed surface coal mines in Pennsylvania, Maryland and West Virginia had higher levels of sulfate, water hardness, calcium, iron, manganese, aluminum than wells in nonmined areas (McAuley \& Kozar 2006). A 2005 study by John Schiber finds high levels of arsenic in 217 groundwater samples from 26 coal mining counties in eastern Kentucky, West Virginia, southeastern Ohio, and northeastern Tennessee. When groundwater is impacting, there is potential for pollution to enter public drinking water sources. Another study conducted by Hendryx, Fulk \& McGinley (2012) found mountaintop coal mining counties have significantly higher public drinking water violations than regular coal mining 
counties and non-coal mining counties between 2001 and 2009. Pollution via air, streams, and groundwater all pose significant risks to populations that surround coal mining areas. Scholarship has continued to point toward links between coal mining, mountaintop removal coal mining and negative health outcomes.

\section{Gaps in the Literature}

There have been multiple studies of the environmental impact of mountaintop removal coal mining in Appalachia. Scholars have found that mountaintop removal mining is associated with increased hydrological damage to the watershed and on the land (Lindberg et al. 2011; Evans et al. 2015), increased pollution, including chemical and isotopic compositions in streams (Vengosh et al. 2013), and increased particulate matter in the air (Kruth et al. 2012). There has been little research linking environmental pollution from mountaintop removal coal mining to human mortality rates. A limited study conducted by Hitt and Hendryx (2010) found significant links between stream pollution levels and respiratory, digestive, urinary and breast cancer rates in the surrounding counties. However, other than this study the field remain relatively scarce. In this project, I seek to combine pollution variables (air pollution data from the EPA) and mortality data to assess the impact of air pollution from coal mining areas on mortality rates. I will discuss study design specifics in the next chapter.

Environmental health risks at a population level require a refined measure of exposure. However, except for a study conducted by Hendryx, Fedorko \& AnesettiRothermel (2010), all prior studies use some form of county-level coal production as a proxy for environmental exposure. Hendryx, Fedorko \& Anesetti-Rothermel (2010)'s inverse-distance variable is an imperfect measure, in part because of the geographic nature 
of mountaintop removal coal mining. Population centers and mining sites may vary greatly within the county-level boundaries. As Hendryx, Fedorko \& Anesetti-Rothermel (2010) showed in their study; a more refined and detailed geographic information systems approach can yield some more statistically robust findings. In their study, they used the inverse-distance measure to estimate population exposure at the county-level. I plan to use areal interpolation to create a county-level coal-exposure measure. I will discuss this at length in a later chapter.

As has been noted by scholars (e.g., Borak et al. 2012), much of the scholarship positing a link between coal mining and mortality in Appalachia has been correlational and not causal. It is not clear from prior studies if increases in coal mining production or exposure to coal mining lead to higher mortality rates. I address this problem by employing a longitudinal analysis to measure change over time. I will discuss these in the more detail in the following chapters. 


\section{STUDY DESIGN \& METHODS}

My project will address the gaps in the literature on coal mining and mortality in Appalachia through two different, yet related analyses. The first is an analysis of air quality data from the EPA and mortality rates in the Appalachian region; the second will be constructing a population-based coal-exposure risk measure. I incorporate longitudinal study design elements into both studies.

\section{Air Pollution Analysis}

I create a model to test the association between coal mining production and air quality in the Appalachian region. I use air quality data from the EPA's system of air monitoring networks combined with coal production data and county-level age-adjusted mortality rates. Prior scholarship suggests that coal mining communities will experience more particulate matter emissions than non-coal mining communities. Thus my research questions and hypotheses predict that coal mining counties will have increased average emissions of particulate matter (PM $\left.10 \mu \mathrm{m}^{3}\right)$ and higher average Air Quality Index (AQI) measure than non-coal mining counties.

Research Questions:

- Do coal mining counties have higher PM10 \& overall AQI than non-coal mining counties?

- Are higher levels of PM10 emissions and overall AQI associated with increased mortality?

Hypothesis :

$\mathrm{H}_{1}$ : As coal production increases, the concentration of particulate matter (PM10) and AQI will increase.

$\mathrm{H}_{2}$ : Increases in AQI and particulate matter (PM10) will be significantly associated with increases in mortality from all-causes, all-cancers, lung cancer, respiratory diseases, neurodegenerative and cardiovascular diseases. 


\section{Population Risk Analysis}

I use an aerial interpolation model to create a mountaintop removal coal mining population coal-exposure risk measure. This measure tests if using a GIS model is more predictive than prior non-GIS models (e,g, Hendryx 2008). Additionally, I examine the long-term impact of increases in the population risk measure on mortality.

Research Questions:

- Is coal mining associated with increased mortality rates?

- Does this association remain after the addition of covariates for socioeconomic, demographic and health factors?

- Is the Population Risk Measure associated with increased mortality rates?

- Does this association remain after considering socio-economic, demographic and health covariates?

- Is this association more predictive than prior coal production measures?

- Does the increase in the coal production population risk measure produce significant increases in mortality rates over time?

Hypotheses :

$\mathrm{H}_{3}$ : Coal mining will have a significant positive relationship with mortality rates, and the association will remain after the addition of covariates.

$\mathrm{H}_{4}$ : Population Risk Measure will be more predictive of mortality rates than the coal production measures previously used.

$\mathrm{H}_{5}$ : Increases in coal population risk measure will be significantly associated with increases in mortality rates over time.

\section{Data}

The dependent variable will be the age-adjusted county mortality rate for six classification types. The World Health Organization provides a comprehensive set of classifications for deaths called the International Classification of Diseases and Related Health Problems (ICD) (U.S. Department of Health and Human Services, 1995). The National Center for Health Statistics classifies all mortality data using the ICD codes and provides mortality data for cause of death (U.S. Department of Health and Human Services, 1995). In this project, I use six classification levels. These classifications include all-cause 
mortality, all-cancers (ICD 10 - C00-D49), lung and bronchus cancer (ICD 10 - C34), respiratory diseases (J00-J99), cardiovascular diseases (ICD $10-$ I00-I99) and neurodegenerative diseases (ICD 10-G30-G32). These four categories are picked because either other scholars find significant associations between mortality rates and coal mining or recent research suggests air pollution is connected to increased incidence (e.g., neurodegenerative diseases (Block \& Calderon-Garciduenas 2009)), thus making this study comparable to previous scholarly work (e.g. Hendryx 2008; Hendryx 2009; Hendryx, Fedorko \& Anesetti 2010; Esch and Hendryx 2011; Boark et al. 2012).The disease-specific mortality estimates are provided by the Institute for Health Metrics and Evaluation at the University of Washington (Dwyer-Lingren et al. 2016); they are five-year estimates from 1990 to 2010 (1990-95; 1996-2000; 2001-05; 2006-10).

Dwyer-Lingren et al. (2016) have created robust estimates of disease-specific mortality rates at the county-level. These estimates use redistribution techniques to recode garbage mortality codes (implausible or insufficiently specific cause of death codes) and incorporate small area estimation methods (statistical methods for estimating rates in small subpopulations). They use mortality data from the death recreation system of the National Vital Statistics System from 1980 to 2014 to construct their estimates (Dwyer-Lingren et al. 2016). They construct these county-level estimates for 21 causes of death. I use these estimates because they provide robust estimates for disease-specific mortality in small, rural counties, which the Appalachian region has more than other comparable regions in the country. Thus these data provide a more robust assessment than the more commonly 
used CDC WONDER ${ }^{2}$ disease-specific mortality estimates (Dwyer-Lingren et al. 2016). All-cause mortality comes from the standard CDC WONDER estimate, adjusted for age.

\section{Study Time-Period}

Mountaintop removal coal mining began in the middle of the twentieth century. However, it was not until the 1970's that the practice gained widespread use in the Appalachian region (Eller 2008; Hendryx \& Holland 2016). The ideal analysis would include the time-period before mountaintop removal mining started. However, there is little key data available before the 1992 period for some important covariate data (smoking). Therefore, this study will focus on the 1990 to 2010 period. The 1990's saw an increase in the use of mountaintop removal coal mining. Thus this period works well given the increasing use of this mining practice during the study time frame.

\section{Geographic Location}

While mountaintop removal coal mining has been found as far north as some parts of Pennsylvania and Ohio and in parts of states like Tennessee, the heartland of MTR is the coalfields of eastern Kentucky, southern West Virginia, and southwest Virginia (Hendryx and Holland 2016). This region alone accounts for $62 \%$ of all coal mined in Appalachia and nearly $15 \%$ of all coal produced in the United States in 2015 (Annual Coal Report 2016). This study will focus on the Appalachian counties, as defined by the Appalachian Regional Commission of Kentucky, West Virginia, and Virginia ("Counties in Appalachia," Appalachian Regional Commission 2016). Figure 1 shows all the counties included in the model.

\footnotetext{
${ }^{2}$ CDC WONDER is an online web application that provides $20+$ collections of public-use data for U.S.
} births, deaths, cancer incidence statistics for download (CDC WONDER 2017). 


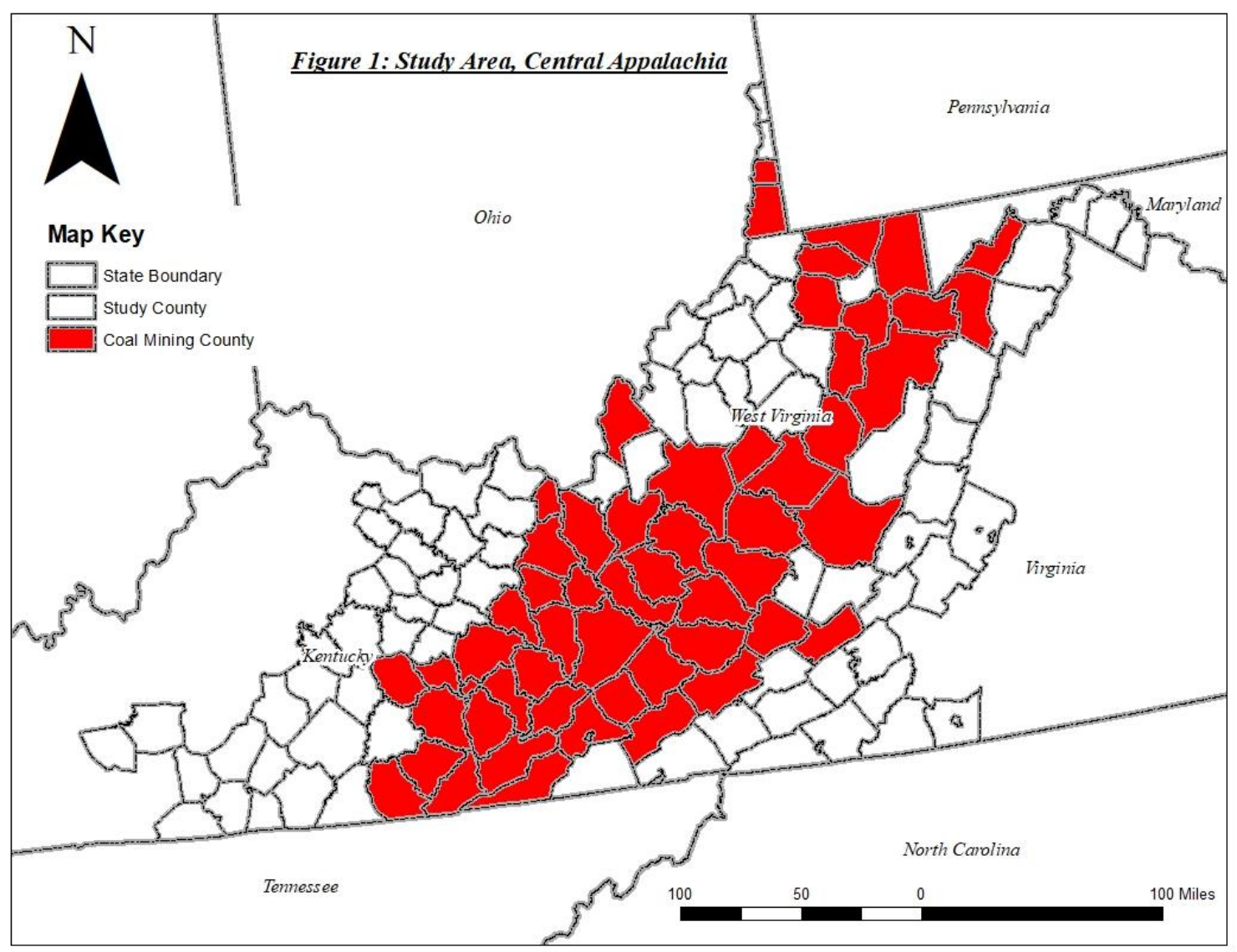

Air Quality Analysis

The passage of the 1990 reauthorization of the Clean Air Act by the U.S. Congress brought new National Ambient Air Quality Standards (NAAQS) for "criteria" pollutants (NAAQS Table 2016). The pollutants included in the new standards are carbon monoxide (CO), nitrogen dioxide $\left(\mathrm{NO}_{2}\right)$, ozone $\left(\mathrm{O}_{3}\right)$, particulate matter $\left(\mathrm{PM} 2.5 \mu \mathrm{m}^{3}\right.$ and PM $\left.10 \mu \mathrm{m}^{3}\right)$, and sulfur dioxide $\left(\mathrm{SO}_{2}\right)$. Each pollutant has a daily, and annual measure that cannot exceed, or the said community in which the pollutant is elevated can face fines and enforcement action by the U.S. EPA. In addition to the "criteria" pollutants, the EPA created a composition measure of air quality called the Air Quality Index (AQI). The AQI is a composition of all pollutants and their potential harm to human health and wellbeing. It ranges from 0 to 500 , with the higher the number, the more hazardous to human health 
(Mintz 2009). See Table 1 below. All are measured at monitoring stations in all 50 states and US territories. However, not all US counties have air monitoring stations, and this is a limitation to the study.

\section{Table 1: Air Quality Index}

\begin{tabular}{|c|c|c|}
\hline $\begin{array}{l}\text { Air Quality Index } \\
\text { Levels of Health } \\
\text { Concern }\end{array}$ & $\begin{array}{l}\text { Numerical } \\
\text { Value }\end{array}$ & Meaning \\
\hline Good & 0 to 50 & $\begin{array}{l}\text { Air quality is considered satisfactory, and air pollution } \\
\text { poses little or no risk. }\end{array}$ \\
\hline Moderate & 51 to 100 & $\begin{array}{l}\text { Air quality is acceptable; however, for some pollutants, } \\
\text { there may be a moderate health concern for a very small } \\
\text { number of people who are unusually sensitive to air } \\
\text { pollution. }\end{array}$ \\
\hline $\begin{array}{l}\text { Unhealthy for } \\
\text { Sensitive Groups }\end{array}$ & 101 to 150 & $\begin{array}{l}\text { Members of sensitive groups may experience health } \\
\text { effects. The general public is not likely to be affected. }\end{array}$ \\
\hline Unhealthy & 151 to 200 & $\begin{array}{l}\text { Everyone may begin to experience health effects; } \\
\text { members of sensitive groups may experience more } \\
\text { serious health effects. }\end{array}$ \\
\hline Very Unhealthy & 201 to 300 & $\begin{array}{l}\text { Health alert: everyone may experience more serious } \\
\text { health effects. }\end{array}$ \\
\hline Hazardous & 301 to 500 & $\begin{array}{l}\text { Health warnings of emergency conditions. The entire } \\
\text { population is more likely to be affected. }\end{array}$ \\
\hline
\end{tabular}

(Source: https://airnow.gov/index.cfm?action=aqibasics.aqi).

In my analysis, I use EPA air quality data for particulate matter. Particulate matter is a concern for mountaintop removal coal mining operations because it comes not only from explosives and debris from mines but also from trucks, trains, and construction equipment in the immediate vicinity. I only use the coarser PM $10 \mu \mathrm{m}^{3}$ standard due to the limited sampling of finer grain $\left(\mathrm{PM} \leq 2.5 \mu \mathrm{m}^{3}\right)$ particulate matter air quality data. The air 
monitoring system does not cover all counties in the United States; however, it uses a sample of counties that are to be representative of various regions of each state. The air monitoring stations can change from year to year as funding for the air monitoring program is changed, thus the sample counties from range from 25 sample counties in the 1990-95 time period to 11 sample counties in the 2006-10 time period. I combine the annual air quality data with annual coal production data for surface and all-coal mines for the timeperiod between 1990 and 2010.

Preliminary analyses of the air monitoring data included looking at air data trends within each county included in the study both longitudinally and each counties' distributions. These initial tests were conducted to test the assumptions that are required for several of the analytical models (e.g., OLS). These tests proved that the air monitoring data was robust and normally distributed both within the counties and combined. While some debate exists in the literature about appropriate measures, we choose to use a mean (average) of the all the measures due to the inconsistency between time measures are taken (Some every week others every three days, depending upon the monitoring site in question). Thus I standardized these measures across the sample counties.

My analysis will consist of several regression models, including ordinary least squares, random-effects, and fixed-effects models. The addition of other covariate data (such as smoking rates, socio-economic status, etc.) will be included in the model. I use these same three modeling techniques in the coal-exposure models, which are discussed below.

\section{Coal-exposure Analysis}


The base of the coal-exposure risk measure will come from the 1992, 2001, 2006 and 2011 National Land Cover Database. The National Land Cover Database is a topographical survey of all land and its use in the United States constructed by the U.S. Geological Survey (Fry et al. 2011). The NLCD uses imagery from Landsat7 Enhanced Thematic Mapper Plus (ETM+) and Landsat 5 Thematic Mapper to monitor change in land cover between the mapping period (Fry et al. 2011). In the 1992 NLCD, there is a code for land areas classified as "surface mining," however, after this year this code is merged with codes for gravel, pavement, etc. I combine the NLCDs with mine permitting data from regulatory agencies in Kentucky, West Virginia, and Virginia. Using these as a guide, I extract all of the coded pavement, gravel areas within permitted mining sites. I conduct random checks comparing against satellite imagery to make sure surface mines are extracted from the data. I construct shapefiles for each year (1992, 2001, 2006, 2011) with crude measures of surface mining in many coal mining counties in three Appalachian states.

I use an areal interpolation method to estimate the population within multiple distance parameters of mountaintop removal coal mines. Areal interpolation is a method used by many geographers and demographers to aggregate data from a small administrative unit to a larger unit. In this project, I aggregate census block population data near mountaintop removal coal mining sites to the county-level (The lowest geographic unit available for mortality rates are only at the country level). I calculate the percentage of the estimated population within each block that is within a defined distance (.25 miles, .50 miles, 1 miles, 2 miles) of the mountaintop removal coal mining site, then add up all the estimated population at risk for each county. Thus, my coal-exposure measure is the total 
estimated population at risk from pollution from mountaintop removal coal mining sites. I will calculate this into the percent of the county population at risk for being exposed to surface/mtr coal mine sites. However, while geographers and demographers commonly use this method, it does have its limitations.

Areal interpolation assumes a uniform distribution of population over administrative units. Thus, all census block groups in my project will be assumed to have uniform population distribution. Given the mountainous geography of the Appalachian region, this could be a potential limitation. However, given the relatively small size of block groups, this limitation may not be as severe as initially expected. This method builds upon the work of others such as Hendrxy, Fedorko, \& Anesetti-Rothermel (2010).

\section{Modeling Methods}

I test the association between AQI and particulate matter and mortality rates and coal-exposure measures and mortality rates using three separate types of models: ordinaryleast-squares regression model, random-effects, and fixed-effects regression models. Each model type brings both advantages and disadvantages that I discuss further in detail. Testing the association between multiple types of models provide a robust analysis of the potential associations.

Ordinary-least squares regression modeling is the workhorse of the social sciences. Linear regression thus provides a very simple model to test the potential association between coal mining and mortality rates. However, OLS regression cannot account for potential heterogeneity caused by non-measured county-level factors. Thus, there may be 
potential errors in the analysis due to unique county-level factors unmeasured in the data available. The next two models attempt to account for these unique factors.

Random-effects models measure variation between and within counties over time while controlling for potential unobserved heterogeneity in the dataset via a combined error term (Allison 2009). Coal mining cluster in a minority of counties in the study area. Thus there is potential for strong variation among county characteristics (Energy Information Administration 2016). Using a random-effects model I can account for potential effects of individual county characteristics, but also unmeasured effects between the counties that are measured. Random-effects differs from the fixed-effects modeling in controlling for potential between-county variation.

Fixed-effects models account for only within-county variation. Thus, individual county characteristics that are not measured in the dataset, but are fixed (geographic features, built environment, etc.) as a constant over the study period. Potential unobserved heterogeneity from county-level factors is taken into consideration. In fixed-effects models, observed variables can correlate. In random-effects models, these are not assumed or allowed to correlate (Allsion 2009). However, fixed-effects models can only account for within-county change over time, but not between county change over time (Allison 2009). The use of both random-effects (both within and between) and fixed-effects (only within) is appropriate for longitudinal analysis. Accounting for only within county-change will allow me to examine the potential longitudinal impact of coal mining on mortality in Appalachia.

\section{Missing Data}


Given the unique data of this project and the multiple sources of data, issues of missing data arise. I deal with missing data on a case-by-case basis. Some data, such as the EPA air quality data, are missing counties in the analyses due to a lack of monitoring stations (air quality data). Those counties without air monitoring stations were not included in the model, thus reducing the sample size to $n=33$ total counties out of a total of $n=133$ counties included in the coal-exposure model. The EPA does construct modeled data for counties in which there are not monitoring stations. However, I choose not to use this data. I wanted to use the raw data and construct my own annual estimates to modify the air quality data based on my own understandings of the structure of the data. I tested several ways of calculating the data (e.g., annual medians, annual means, etc.).

The population, demographic and socio-economic data from the US Census Bureau has very little to no missing data, and all are at the county level. Coal production data is limited to the early 1990 's, as many states do not publicly report coal production data by county and the U.S. Department of Energy did not start reporting coal production data by county-level until the late 1990's. The data limitations around coal mining limit the scope of this study to the two decades between 1990 and 2010.

\section{Longitudinal Trends in Coal Production}

Figure 2 shows the longitudinal trend in coal production in the Central Appalachian region. In the years between 1992 and 2004, coal mining production dropped by a total of 17\% in Central Appalachia. Underground coal mining production had dropped 27\% between this same period, while mountaintop removal coal mining saw a $6 \%$ uptick in production over the same period. The increase of mountaintop removal and surface coal 
mining and decline of underground coal mining points to a depletion of easier to retrieve coal reserves and increased reliance upon smaller coal seams which require MTR to access.

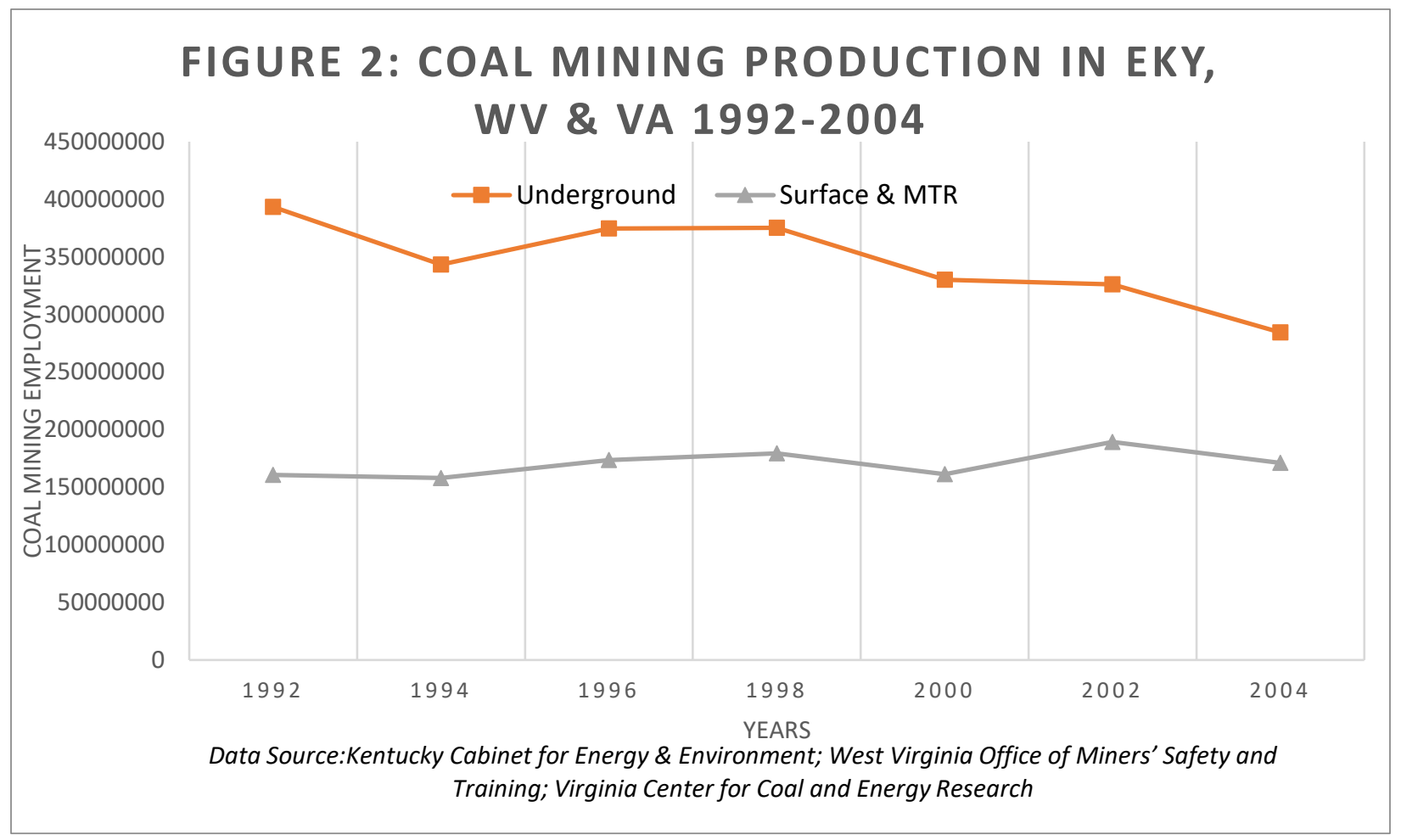

It was during this time-period as coal production overall declined, and underground coal mining, in particular, declined heavily, we see a decrease in coal mining employment. Figure 3 shows the trend line for coal mining employment in the Central Appalachian region. Between 1992 and 2004 Central Appalachia saw a 52\% decrease in coal mining employment. The largest loss was between 1992 and 1994, which saw a 36\% decrease in total coal mining employment in the region. The decrease in coal mining employment figures is not surprising, given the long-term decline in underground coal mining production and the rise of MTR coal mining. Mountaintop removal coal mining requires far fewer employees than traditional underground mines. Thus, increasing production of 
MTR and decreasing underground mining leads to a decrease in overall employment in the mining industry.

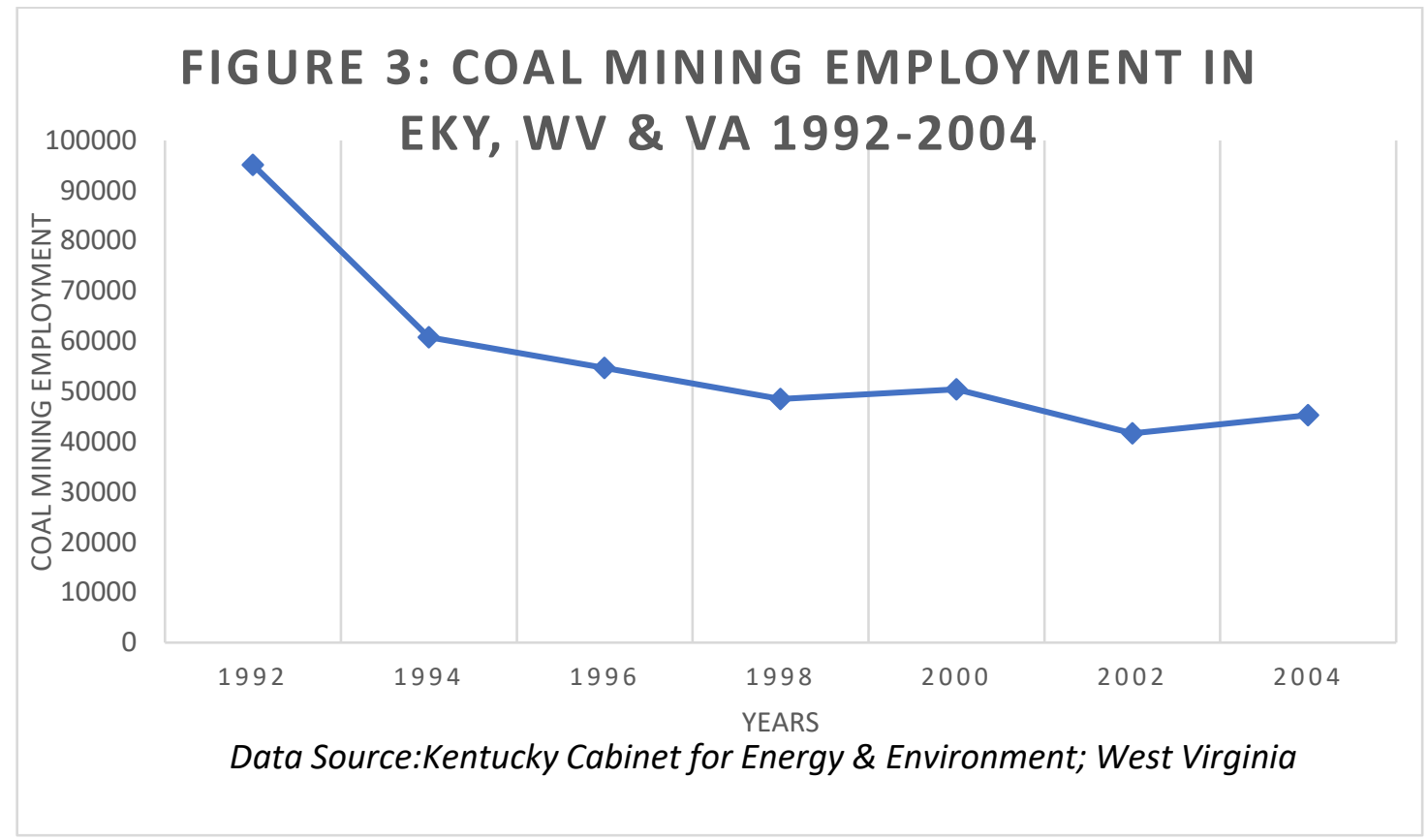

\section{Longitudinal Trends in Mortality Rates}

Figure 4 presents mortality trends for all-cause mortality for states in the study, Appalachian counties in the study, plus coal mining and non-coal mining counties in the study area. Mortality rates declined in six categories; however, the rate of decline varied. Among the states, Virginia consistently has the lowest mortality rates in the region, declining by $11 \%$. Kentucky had the lowest rate of decline in all three states, with a decline of just $2.4 \%$ between 1992 to 2004 .

Appalachia has higher mortality rates than all states in the study. Appalachian counties also have the lowest decline in mortality rates of all regions and states in the study, at a decline of $.16 \%$. Previous scholarship finds the Appalachian region to have higher mortality rates than non-Appalachian counties even within the same state (Halverson 2004). Previous research finds that coal mining regions of Appalachia, both total coal 
mining and mountaintop removal coal mining specifically, have higher mortality rates than the Appalachian region and the respective states in the study. Two of the three slowest declines in mortality rates are in the coal mining regions. These results show that consistently the Appalachian region has higher mortality rates than the non-Appalachian regions of the states included in the study. They also show that coal mining counties, particularly mountaintop removal coal mining counties, have higher mortality rates than Appalachia and the non-Appalachian parts of the states. These findings are consistent with what other scholars have found in Appalachia; mountaintop removal coal mining is associated with higher mortality rates for both all-cause mortality and disease-specific (e.g., Hendryx 2008; Hendryx 2009; Hendryx \& Ahern 2009). I build upon these preliminary results in following two chapters.

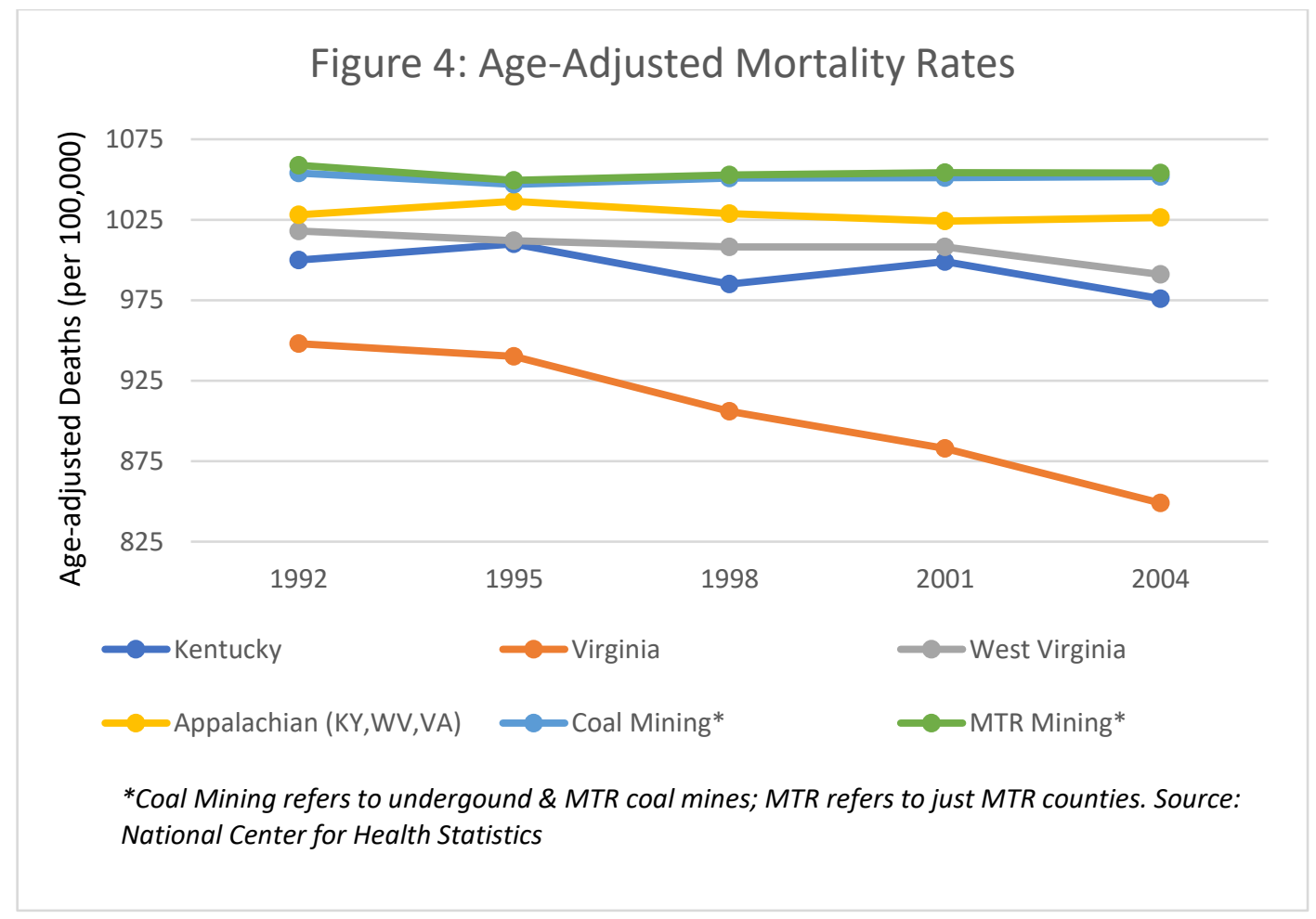




\section{AIR POLLUTION STUDY}

\section{Univariate Results}

Table 2 presents the descriptive statistics for the Air Quality models. Included in the model are the six dependent mortality variables for all county-years. The average mortality for all-cause mortality is 1,056 per 100,000 persons, the average ranges from 85 per 100,000 for neurodegenerative diseases to 389 per 100,00 for cardiovascular disease. Cardiovascular disease has the highest disease-specific mortality rates, while neurodegenerative diseases have the lowest average mortality rates.

The air quality measures consist of two different measurements. The first is the Air Quality Index, created by the passage of 1990 reauthorized Clean Air Act, includes component measurements for carbon monoxide $(\mathrm{CO})$, nitrogen dioxide $\left(\mathrm{NO}_{2}\right)$, ozone $\left(\mathrm{O}_{3}\right)$, particulate matter (PM $2.5 \mu \mathrm{m}^{3}$ and $\mathrm{PM} 10 \mu \mathrm{m}^{3}$ ), and sulfur dioxide $\left(\mathrm{SO}^{2}\right)$. The AQI is a composition of all pollutants and their potential harm to human health and wellbeing. It ranges from 0 to 500 , with the higher the number, the more hazardous to human health (Mintz 2009). The average annual AQI for the counties in the sample is 22, with a range between 10 and 33, this range is within the "Good" category according to the AQI category, this average annual air quality is considered "satisfactory" and air pollution "poses little or no risk" (Mintz 2009). The other measure is the annual particulate matter (PM10) concentration for the sampled counties, which is $21 \mathrm{ug} / \mu \mathrm{m}^{3}$, with a range of $11 \mathrm{ug} / \mu \mathrm{m}^{3}$ and $38 \mathrm{ug} / \mu \mathrm{m}^{3}$. These rates are below the national standard of $150 \mathrm{ug} / \mu \mathrm{m}^{3}$ per twenty-four hour 
period (NAAQS Table 2016). The sample counties are within the national standards for good air quality when averaged into an annual measure.

The average surface/mtr coal production across the counties was 3,234,000 tons, with some counties having a maximum of $86,100,000$ tons coal mined. Underground coal mining has an average coal production double that of surface coal production across the study counties. An average of nearly 6,000,000 tons of underground coal is mined, with a maximum production of 102,000,000 tons of coal mined. In the study counties, coal mining employment averaged 1,253 with a maximum of 21,927 employed in coal mines. Similar to coal production, employment in coal mines cluster in a few coalfield counties in Central Appalachia.

The study's counties are largely white and rural. However, there are pockets of nonwhite populations and urban communities as well. Across the counties, $2.78 \%$ of the population is African American, with a range between 0 and 44.95\%. Other racial groups make up on average $.53 \%$ of study counties population, with a range between $0 \%$ and $5.63 \%$. More than three-fourths of the counties in the study area are rural (77.3\%), while more than a fifth are urban (22.7\%) according to the 1993, 2003, and 2013 USDA ruralurban continuum codes ${ }^{3}$.

The study counties have low levels of educational attainment, with high rates of poverty and smoking rates. An average of nearly one-tenth (9.8\%) of people living in the study counties having less than an eighth-grade education, with a range between $.47 \%$ to $32.49 \%$. One in five residents in the study counties live below the poverty line $(21.2 \%)$, some counties having a poverty rate of over $50 \%$. An average of a third of study county

\footnotetext{
${ }^{3}$ https://www.ers.usda.gov/data-products/rural-urban-continuum-codes/
} 
residents is currently a daily smoker, with counties that range between less than one fifth (18.09\%) and nearly $40 \%$ of the county's population being a current smoker.

\begin{tabular}{|c|c|c|c|c|}
\hline \multirow[b]{2}{*}{ Mortality Rates (per 100,000) } & \multirow{2}{*}{ Mean } & \multirow[t]{2}{*}{ S.D. } & \multirow[t]{2}{*}{ Min } & \multirow[t]{2}{*}{ Max } \\
\hline & & & & \\
\hline All-cause & 1056 & 116 & 794 & 1407 \\
\hline All-cancer & 247 & 28 & 167 & 316 \\
\hline Lung Cancer & 87 & 18 & 43 & 143 \\
\hline Respiratory Diseases & 79 & 21 & 42 & 148 \\
\hline Neurodegenerative Diseases & 85 & 18 & 42 & 142 \\
\hline Cardiovascular Diseases & 389 & 66 & 232 & 570 \\
\hline \multicolumn{5}{|l|}{ Air Quality } \\
\hline Annual Air Quality Index (0-500) & 22 & 4 & 10 & 33 \\
\hline Annual PM10 $\left(\mu \mathrm{g} / \mathrm{m}^{3}\right)$ & 21 & 5 & 11 & 38 \\
\hline \multicolumn{5}{|l|}{ Coal Mining } \\
\hline Underground Production (000's tons) & 5993 & 15100 & 0 & 102000 \\
\hline Surface Production (000's tons) & 3234 & 9153 & 0 & 86100 \\
\hline Employment & 1253 & 2964 & 0 & 21927 \\
\hline \multicolumn{5}{|l|}{ Demographics } \\
\hline African American (\%) & 2.78 & 4.56 & 0 & 45 \\
\hline Non-white (\%) & 0.53 & 0.57 & 0 & 6 \\
\hline Rural $(1=$ Rural; $0=$ Urban $)$ & 0.77 & 0.42 & 0 & 1 \\
\hline \multicolumn{5}{|l|}{ Socioeconomics } \\
\hline Poverty $(\%)$ & 21 & 8 & 5 & 51 \\
\hline$>$ Eight Grade Education (\%) & 10 & 7 & 0.47 & 32 \\
\hline \multicolumn{5}{|l|}{ Health } \\
\hline \multirow[t]{2}{*}{ Smoking (\%) } & 31 & 4 & 18 & 38 \\
\hline & $\mathrm{n}=90$ & & & \\
\hline
\end{tabular}

\section{Geographic Distribution of Air Quality}

In Figure 5a is a map of annual particulate matter (PM10) concentrations in the 1990-95 time period. The highest concentrations of particle matter cluster is in the Kanawha Valley in central West Virginia and northeastern Kentucky along the West Virginia and Ohio border. The lowest concentration is in southwest Virginia. Figure 5b maps the annual particulate matter (PM10) concentration in the 1996-00 time period. PM10 
concentrations have decreased in a majority of the counties, and the highest concentrations are now in northeastern and southeastern Kentucky. Figure 5c shows the concentrations of annual particulate matter in the 2001-05 time period. The number of counties with available data has decreased sharply compared to the two other time periods. The highest concentrations are in Monongalia County (Morgantown), West Virginia, Ohio County, West Virginia, and Boyd County (Ashland), Kentucky. Figure 5d presents the annual particulate matter concentrations in the 2006-10 time period. The number of counties in West Virginia and Virginia is greatly reduced, with only two counties in WV and one county in VA. The highest concentration is in Boyd County, KY. Overall, I find that particulate matter concentrations decline over the 1990 to 2010 time period. Particulate matter (PM10) concentrations cluster in the highest rates in northeastern Kentucky, the Kanawha Valley in central West Virginia and the northern panhandle of West Virginia. However, the number of counties with available data declines, which limits the conclusions that can be drawn from these maps. 

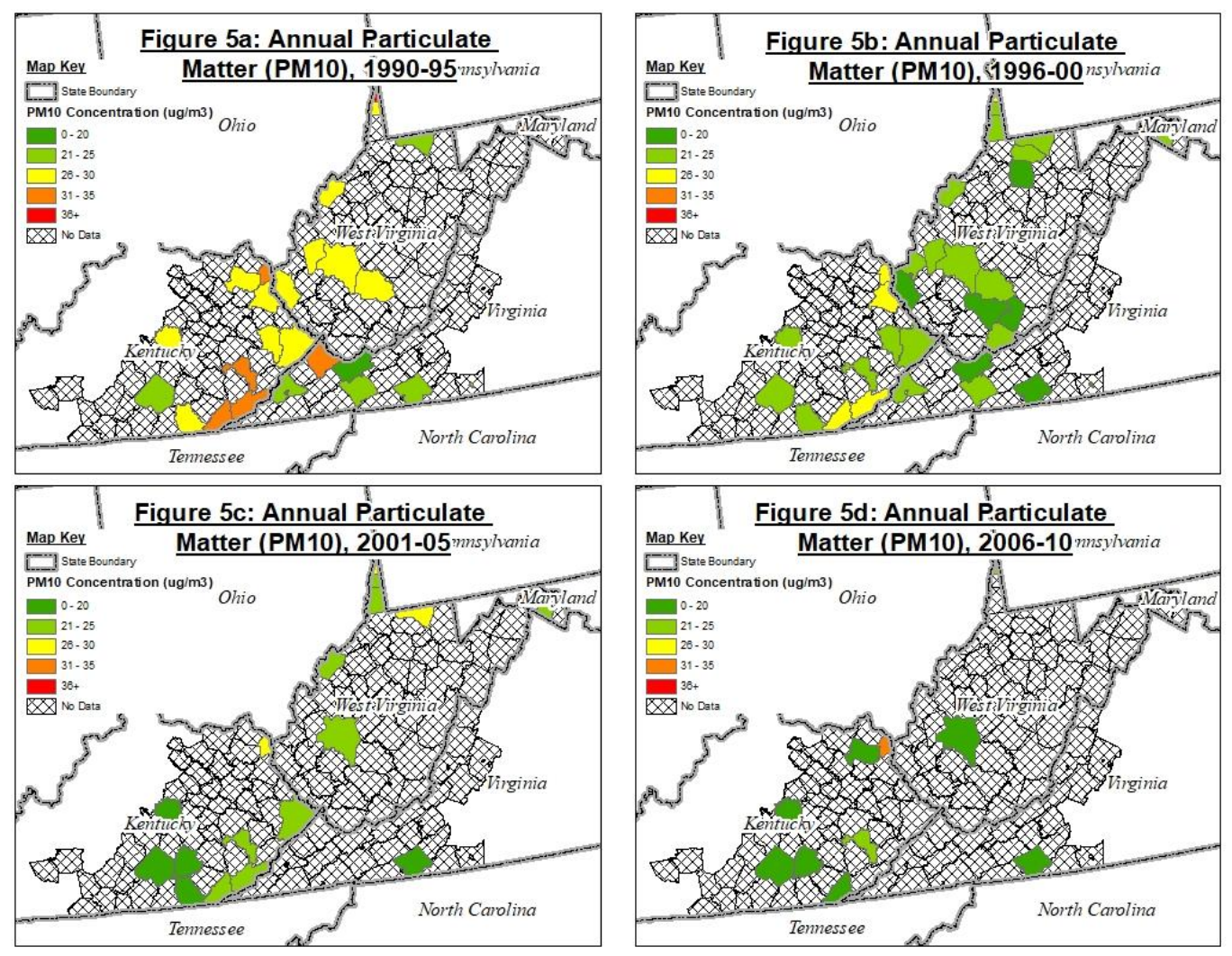

In Figure 6a is a map of the average annual air quality index (AQI) in the 1990-95 time period. The highest concentrations are in northeastern Kentucky, southeastern Kentucky, and the northern panhandle of West Virginia. The lowest concentrations are in southwest Virginia. In Figure 6b is a map of annual AQI in the 1996-00 time period. The lowest AQI concentrations are in the Kanawha Valley in central West Virginia, and the highest AQI concentration is in the northeastern Kentucky and the northern panhandle of West Virginia. Figure 6c is a map of annual AQI in the 2001-05 time period. The number of counties is reduced compared to the two previous time periods. However, similar to the other maps, the highest concentrations are in northeastern Kentucky and the northern panhandle of West Virginia. Figure 6d is a map of the annual AQI in the 2006-10 period. The number of counties decreases in West Virginia (two) and Virginia (one). The highest concentration is in Boyd County, Ky. Overall I find that AQI concentrations decrease over 
the 1990 to 2010 time period. Similar to the maps for particulate matter (PM10), high AQI clusters in northeastern Kentucky, the Kanawha Valley in central West Virginia and the northern panhandle of West Virginia.
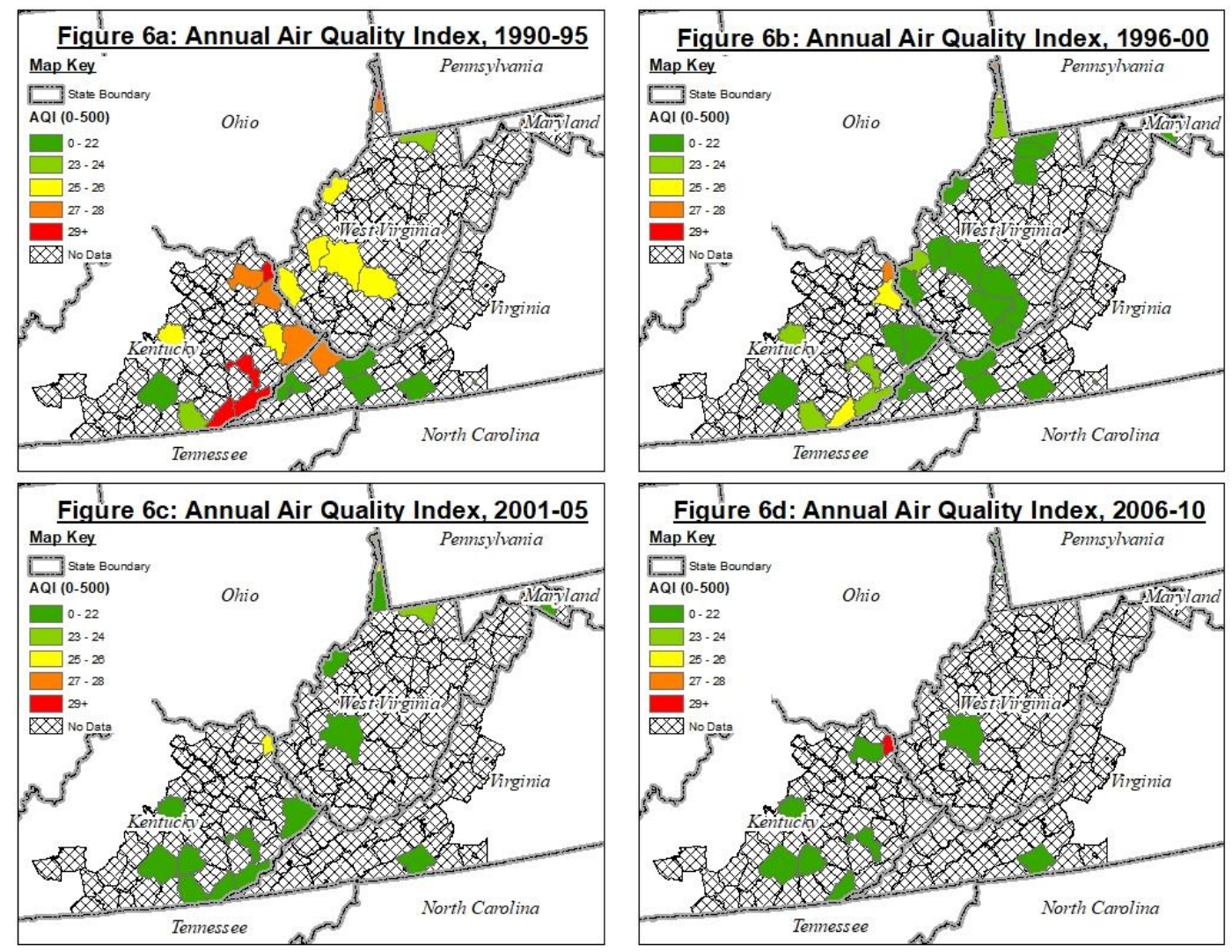

Coal Mining \& Air Quality Models

Table 3 shows the OLS, random-effects and fixed-effects models for air quality (AQI and Particulate Matter) and coal mining production. In the particulate matter, OLS, random-effects, and fixed-effects models coal production (underground or surface/mtr coal production) is not statistically significant and is not associated with annual county-level particulate matter. In the AQI OLS, random-effects and fixed-effects models coal production (underground or surface/mtr coal production) is not statistically significant and 
is not associated with annual county-level AQI measure. These models poorly predict county-level particulate matter concentration or AQI.

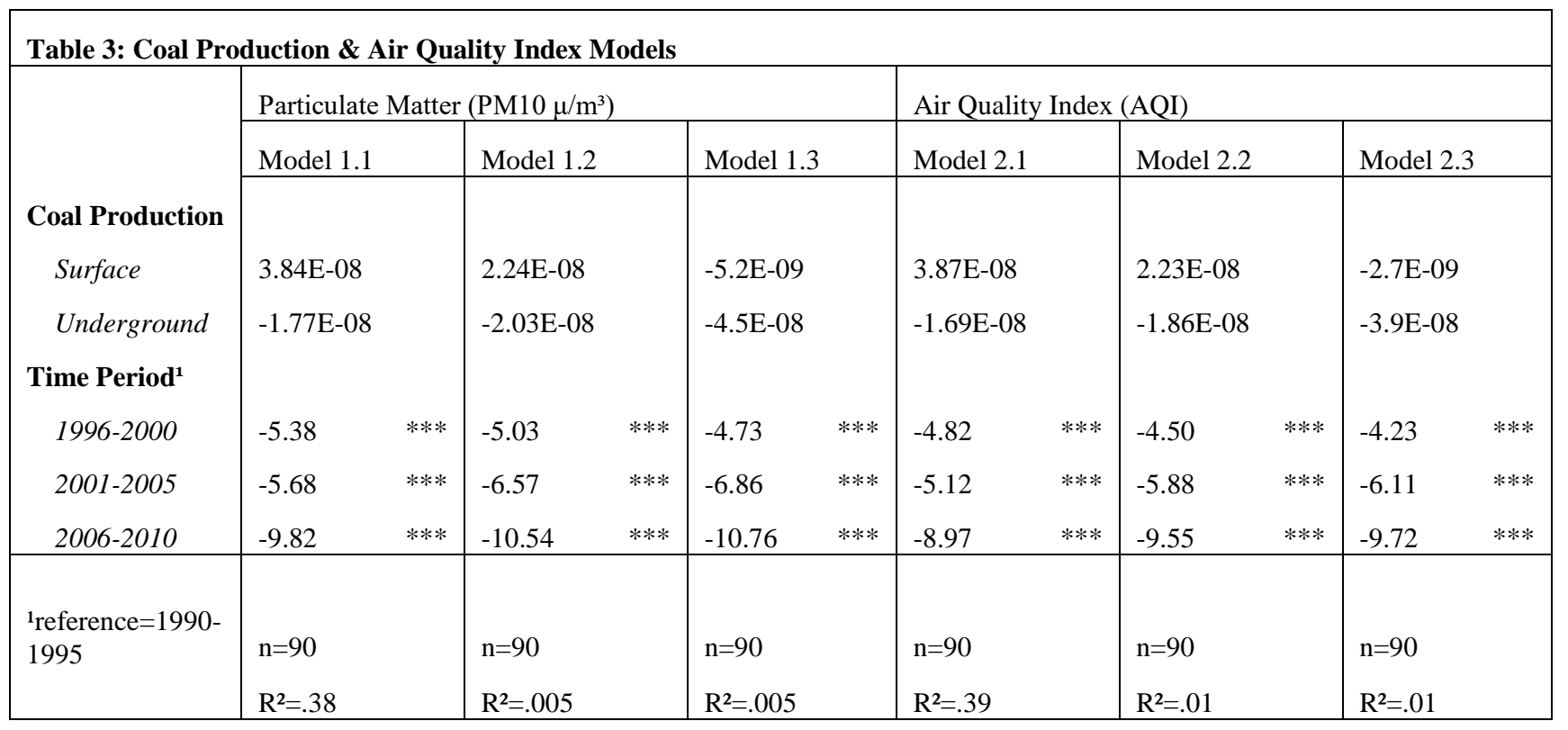

Particulate Matter \& Mortality Models

Table 4 presents the results from the particulate matter and mortality OLS, randomeffects and fixed-effects models. In the all-cause OLS model (M1.1), particulate matter (9.09) is statistically significant and positively associated with all-cause mortality. In the random-effects model (M1.2), particulate matter (6.06) is statistically significant and associated with all-cause mortality, meaning that increases in particulate matter are associated with 6.06 extra deaths. In models M1.1 (5.79) and M1.2 (3.87), the percentage African American is statistically significant and associated with all-cause mortality. In model M1.1 the percentage non-White is statistically significant and negatively associated with all-cause mortality. In models M1.1 (6.97) and M1.2 (3.06), poverty is statistically significant and associated with all-cause mortality. In models M1.1 (18.97) and M1.2 
(18.18), smoking is statistically significant and associated with all-cause mortality. These models suggest that particulate matter concentrations can explain cross-country differences in all-cause mortality rates, but have a limited causal relationship with all-cause mortality.

\begin{tabular}{|c|c|c|c|c|c|c|c|c|c|}
\hline \multirow[b]{3}{*}{ Air Quality } & \multicolumn{6}{|c|}{ Table 4: All-cause Mortality \& PM10 Models } & & & \\
\hline & \multicolumn{3}{|c|}{ Model 1.1} & \multicolumn{3}{|c|}{ Model 1.2} & \multicolumn{3}{|c|}{ Model 1.3} \\
\hline & Coefficient & S.E. & Sig. & Coefficient & S.E. & Sig. & Coefficient & S.E. & Sig. \\
\hline PM10 & 9.09 & 1.82 & $* * *$ & 6.06 & 1.94 & $* *$ & 2.05 & 2.24 & \\
\hline \multicolumn{10}{|l|}{ Coal Mining } \\
\hline Underground Production & $-1.86 \mathrm{E}-07$ & 4.43E-07 & & $-1.32 \mathrm{E}-08$ & 3.47E-07 & & $-1.69 \mathrm{E}-07$ & 3.99E-07 & \\
\hline Surface Production & $8.32 \mathrm{E}-07$ & $1.24 \mathrm{E}-06$ & & $6.23 \mathrm{E}-07$ & $8.55 \mathrm{E}-07$ & & 3.84E-07 & 7.61E-07 & \\
\hline Employment & 0.01 & 0.004 & & 0.005 & 0.003 & & -0.004 & 0.004 & \\
\hline \multicolumn{10}{|l|}{ Demographics } \\
\hline African American (\%) & 5.79 & 1.49 & $* * *$ & 3.87 & 1.49 & $* *$ & -2.36 & 3.30 & \\
\hline Non-white (\%) & -33.67 & 15.89 & $* *$ & -19.69 & 13.09 & & -6.59 & 12.95 & \\
\hline Rural $^{1}$ & -19.47 & 17.99 & & & & & & & \\
\hline \multicolumn{10}{|l|}{ Socioeconomics } \\
\hline Poverty (\%) & 6.97 & 1.55 & $* * *$ & 3.06 & 1.26 & $* *$ & -0.83 & 1.30 & \\
\hline$>$ Eight Grade Education (\%) & -4.33 & 2.70 & & -0.83 & 2.09 & & -4.88 & 2.33 & $*$ \\
\hline \multicolumn{10}{|l|}{ Health } \\
\hline Smoking (\%) & 18.97 & 2.70 & $* * *$ & 18.18 & 2.74 & $* * *$ & -0.36 & 5.29 & \\
\hline \multicolumn{10}{|l|}{ Time Period $^{2}$} \\
\hline $1996-2000$ & 43.84 & 21.96 & $*$ & 31.59 & 17.12 & & -24.16 & 18.85 & \\
\hline $2001-2005$ & 13.99 & 40.65 & & 37.62 & 32.38 & & -71.51 & 38.39 & \\
\hline $2006-2010$ & 46.12 & 35.45 & & 35.40 & 30.59 & & -93.82 & 39.68 & $*$ \\
\hline $\begin{array}{c}\text { 1reference=Urban; } \\
\text { 2reference=1990-1995 }\end{array}$ & & $\begin{array}{l}=90 \\
=.72\end{array}$ & & & $\begin{array}{l}1=90 \\
2=.74\end{array}$ & & & $\begin{array}{l}1=90 \\
2=.10\end{array}$ & \\
\hline
\end{tabular}

In Table 5 are the OLS, random-effects and fixed-effects models for all-cancer mortality and particulate matter. In the OLS model (M2.1), particulate matter (1.70) is statistically significant and positively associated with all-cancer mortality rates. In the random-effects model (M2.2), particulate matter (1.06) is statistically significant and positively associated with all-cancer mortality. Particulate matter is not statistically significant with all-cancer mortality in the fixed-effects (M2.3) models. Neither underground or surface/mtr coal production nor coal mining employment is statistically 
significant in the three models. In model M2.1, the percentage African American (1.08), percentage non-White (-7.95), and rural status (-11.02) are statistically significant and associated with all-cancer mortality. In model M2.1 (1.64) and M2.2 (.61), poverty is statistically significant and positively associated with all-cancer mortality. In models, M2.1 (5.32) and M2.2 (4.38) smoking rate are statistically significant and positively associated with all-cancer mortality. In models M2.1 (-1.28) and M2.3 (-1.32), education is statistically significant and negatively associated with all-cancer mortality. These models suggest that particulate matter can explain differences in all-cancer mortality rates across counties, but have a limited causal association.

\begin{tabular}{|c|c|c|c|c|c|c|c|c|c|}
\hline \multirow[b]{3}{*}{ Air Quality } & \multicolumn{9}{|c|}{ Table 5: All-cancer Mortality \& Particulate Matter Models } \\
\hline & \multicolumn{3}{|c|}{ Model 2.1} & \multicolumn{3}{|c|}{ Model 2.2} & \multicolumn{3}{|c|}{ Model 2.3} \\
\hline & Coefficient & S.E. & Sig. & Coefficient & S.E. & Sig. & Coefficient & S.E. & Sig. \\
\hline PM10 & 1.70 & 0.41 & $* * *$ & 1.06 & 0.44 & $* *$ & 0.27 & 0.46 & \\
\hline \multicolumn{10}{|l|}{ Coal Mining } \\
\hline Underground Production & $-1.27 \mathrm{E}-07$ & $9.89 \mathrm{E}-08$ & & $-4.44 \mathrm{E}-08$ & 7.65E-08 & & $-7.67 \mathrm{E}-08$ & 8.14E-08 & \\
\hline Surface Production & $1.47 \mathrm{E}-07$ & 2.77E-07 & & $-9 \mathrm{E}-09$ & $1.82 \mathrm{E}-07$ & & $-7.36 \mathrm{E}-08$ & $1.55 \mathrm{E}-07$ & \\
\hline Employment & 0.002 & 0.001 & & 0.001 & 0.001 & & -0.001 & 0.001 & \\
\hline \multicolumn{10}{|l|}{ Demographics } \\
\hline African American (\%) & 1.08 & 0.33 & $* * *$ & 0.53 & 0.36 & & -0.09 & 0.67 & \\
\hline Non-white (\%) & -7.95 & 3.55 & $* *$ & -4.29 & 2.84 & & -2.54 & 2.64 & \\
\hline Rural $^{1}$ & -11.02 & 4.02 & $* *$ & & & & & & \\
\hline \multicolumn{10}{|l|}{ Socioeconomics } \\
\hline Poverty (\%) & 1.64 & 0.35 & $* * *$ & 0.61 & 0.27 & $* *$ & -0.11 & 0.26 & \\
\hline$>$ Eight Grade Education (\%) & -1.28 & 0.60 & $* *$ & -0.38 & 0.46 & & -1.32 & 0.47 & $* *$ \\
\hline \multicolumn{10}{|l|}{ Health } \\
\hline Smoking (\%) & 5.32 & 0.60 & $* * *$ & 4.38 & 0.64 & $* * *$ & -0.42 & 1.08 & \\
\hline \multicolumn{10}{|l|}{ Time Period ${ }^{2}$} \\
\hline $1996-2000$ & 2.32 & 4.90 & & 1.84 & 3.74 & & -8.66 & 3.84 & $*$ \\
\hline $2001-2005$ & -12.16 & 9.07 & & -4.26 & 7.09 & & -26.97 & 7.82 & $* *$ \\
\hline $2006-2010$ & 7.46 & 9.91 & & 2.62 & 6.82 & & -25.61 & 8.08 & $* *$ \\
\hline $\begin{array}{c}{ }^{1} \text { reference }=\text { Urban; } \\
{ }^{2} \text { reference }=1990-1995\end{array}$ & \multicolumn{3}{|c|}{$\mathrm{n}=90$} & \multicolumn{3}{|c|}{$\mathrm{n}=90$} & \multicolumn{3}{|c|}{$\mathrm{n}=90$} \\
\hline
\end{tabular}


Table 6 presents the results for the OLS, random-effects and fixed-effects models for lung cancer mortality and particulate matter. In the OLS model (M3.1), particulate matter (1.20) is statistically significant and positively associated with lung cancer mortality. In the random-effects model (M3.2), particulate matter (.67) is statistically significant and positively associated with lung cancer mortality. Particulate matter is not statistically significant in the lung cancer (M3.3) fixed-effects models. In any of the lung cancer mortality models, neither underground or surface/mtr coal production is statistically significant, neither is coal mining employment. In model M3.1 poverty (1.01) and rural status (-7.74) are statically significant and associated with lung cancer mortality. In models, M3.1 (3.56) and M3.2 (2.85) smoking rates are statistically significant and positively associated with lung cancer mortality. Education (-.71) is statistically significant and associated with lung cancer mortality in model M3.3. These findings are similar to those in the all-cause and all-cancer models, suggesting that particulate matter can account for cross-country differences in mortality rates, but have limited power to suggest causal relationships between particulate matter and lung cancer at the population level.

\begin{tabular}{|c|c|c|c|c|c|c|c|c|c|}
\hline \multicolumn{10}{|c|}{ Table 6: Lung Cancer Mortality \& Particulate Matter Models } \\
\hline \multirow{3}{*}{$\begin{array}{c}\text { Air Quality } \\
\text { PM10 }\end{array}$} & \multicolumn{3}{|c|}{ Model 3.1} & \multicolumn{3}{|c|}{ Model 3.2} & \multicolumn{3}{|c|}{ Model 3.3} \\
\hline & Coefficient & S.E. & Sig. & Coefficient & S.E. & Sig. & Coefficient & S.E. & Sig \\
\hline & 1.20 & 0.29 & $* * *$ & 0.67 & 0.27 & $*$ & 0.24 & 0.26 & \\
\hline \multicolumn{10}{|l|}{ Coal Mining } \\
\hline Underground Production & $-5.94 \mathrm{E}-08$ & $6.97 \mathrm{E}-08$ & & $-1.57 \mathrm{E}-08$ & $4.72 \mathrm{E}-08$ & & $-3.28 \mathrm{E}-08$ & 4.7E-08 & \\
\hline Surface Production & $1.92 \mathrm{E}-07$ & $1.95 \mathrm{E}-07$ & & 9.07E-09 & $1.07 \mathrm{E}-07$ & & $-3.24 \mathrm{E}-08$ & $8.96 \mathrm{E}-08$ & \\
\hline Employment & 0.001 & 0.001 & & 0.001 & 0.001 & & -0.0001 & 0.0004 & \\
\hline \multicolumn{10}{|l|}{ Demographics } \\
\hline African American (\%) & 0.44 & 0.23 & & 0.08 & 0.08 & & 0.00 & 0.39 & \\
\hline Non-white (\%) & -2.43 & 2.50 & & -2.09 & 1.72 & & -1.82 & 1.52 & \\
\hline Rural $^{1}$ & -7.74 & 2.83 & $* *$ & & & & & & \\
\hline \multicolumn{10}{|l|}{ Socioeconomics } \\
\hline Poverty (\%) & 1.01 & 0.24 & $* * *$ & 0.24 & 0.17 & & -0.12 & 0.15 & \\
\hline$>$ Eight Grade Education (\%) & -0.29 & 0.42 & & 0.004 & 0.28 & & -0.71 & 0.27 & $*$ \\
\hline
\end{tabular}




\begin{tabular}{|c|c|c|c|c|c|c|c|c|}
\hline $\begin{array}{l}\text { Health } \\
\quad \text { Smoking (\%) }\end{array}$ & 3.56 & 0.42 & $* * *$ & 2.85 & 0.42 & $* * *$ & -0.08 & 0.62 \\
\hline \multicolumn{9}{|l|}{ Time Period $^{2}$} \\
\hline $1996-2000$ & 6.59 & 3.45 & & 4.91 & 2.28 & $*$ & -1.49 & 2.22 \\
\hline 2001-2005 & 5.52 & 6.39 & & 6.27 & 4.36 & & -8.87 & 4.52 \\
\hline $2006-2010$ & 16.54 & 5.58 & $* *$ & 10.29 & 4.26 & $*$ & -7.08 & 4.67 \\
\hline $\begin{array}{c}\text { 1reference=Urban; } \\
\text { 2reference=1990-1995 }\end{array}$ & \multicolumn{3}{|c|}{$\begin{array}{c}\mathrm{n}=90 \\
\mathrm{R}^{2}=73\end{array}$} & \multicolumn{3}{|c|}{$\begin{array}{r}\mathrm{n}=90 \\
\mathrm{R}^{2}=71\end{array}$} & \multicolumn{2}{|c|}{$\begin{aligned} \mathrm{n} & =90 \\
\mathrm{R}^{2} & =.26\end{aligned}$} \\
\hline
\end{tabular}

Table 7 presents OLS, random-effects and fixed-effects models examining the relationship between particulate matter and respiratory disease mortality. In the OLS model (M4.1), particulate matter (.77) is statistically significant and positively associated with respiratory disease mortality. In the random-effects model (M4.2), particulate matter (.68) is statistically significant and positively associated with respiratory disease mortality. Coal production, underground or surface coal production, is not significantly associated with respiratory disease mortality in any of the three models. However, coal mining employment (.001) is statistically significant and positively associated with respiratory disease mortality rates in the OLS (M4.1) model. These findings confirm what prior literature have stated about the relationship between coal mining employment and respiratory diseases (i.e., coal worker pneumoconiosis) in the Appalachian region. Poverty (.89) is statistically significant and positively associated with respiratory disease mortality in model M4.1. Smoking is statistically significant and positively associated with respiratory disease mortality in model M4.1 (2.66) and M4.2 (2.49). These results suggest that for respiratory diseases, like all-cause, all-cancer and lung cancer mortality rates, that particulate matter can account for cross-county mortality rates, but cannot account for a potential causal relationship between particulate matter and respiratory disease mortality rates. 


\begin{tabular}{|c|c|c|c|c|c|c|c|c|c|}
\hline \multicolumn{10}{|c|}{ Table 7: Respiratory Disease Mortality \& Particulate Matter Models } \\
\hline \multirow[b]{2}{*}{ Air Quality } & \multicolumn{3}{|c|}{ Model 4.1} & \multicolumn{3}{|c|}{ Model 4.2} & \multicolumn{3}{|c|}{ Model 4.3} \\
\hline & Coefficient & S.E. & Sig. & Coefficient & S.E. & Sig. & Coefficient & S.E. & Sig. \\
\hline PM10 & 0.77 & 3.72 & ** & 0.68 & 0.30 & * & 0.27 & 0.29 & \\
\hline \multicolumn{10}{|l|}{ Coal Mining } \\
\hline Underground Production & 5.16E-09 & 6.88 & & $4.52 \mathrm{E}-08$ & $5.22 \mathrm{E}-08$ & & 4.85E-10 & $5.28 \mathrm{E}-08$ & \\
\hline Surface Production & 4.62E-09 & 6.00 & & 7.03E-08 & 1.19E-07 & & $4.11 \mathrm{E}-08$ & $1.01 \mathrm{E}-07$ & \\
\hline Employment & 0.001 & 0.001 & $* *$ & 0.001 & 0.0005 & & -0.0003 & 0.0005 & \\
\hline \multicolumn{10}{|l|}{ Demographics } \\
\hline African American (\%) & 0.07 & 0.25 & & -0.09 & 0.27 & & -0.13 & 0.44 & \\
\hline Non-white (\%) & -4.30 & 2.69 & & -1.71 & 1.90 & & -1.39 & 1.71 & \\
\hline Rural $^{1}$ & 4.87 & 3.05 & & & & & & & \\
\hline \multicolumn{10}{|l|}{ Socioeconomics } \\
\hline Poverty (\%) & 0.89 & 0.26 & $* *$ & 0.19 & 0.18 & & -0.19 & 0.17 & \\
\hline$>$ Eight Grade Education (\%) & -0.50 & 0.46 & & 0.19 & 0.31 & & -0.55 & 0.31 & \\
\hline \multicolumn{10}{|l|}{ Health } \\
\hline Smoking (\%) & 2.66 & 0.46 & $* * *$ & 2.49 & 0.46 & $* * *$ & -0.50 & 0.69 & \\
\hline \multicolumn{10}{|l|}{ Time Period $^{2}$} \\
\hline $1996-2000$ & 14.74 & 3.72 & $* * *$ & 14.57 & 2.53 & $* * *$ & 7.70 & 2.49 & $* *$ \\
\hline $2001-2005$ & 15.27 & 6.88 & $* *$ & 22.25 & 4.82 & $* * *$ & 5.97 & 5.07 & \\
\hline $2006-2010$ & 29.83 & 6.00 & $* * *$ & 29.88 & 4.71 & $* * *$ & 11.57 & 5.24 & $*$ \\
\hline $\begin{array}{l}{ }^{1} \text { reference=Urban; } \\
{ }^{2} \text { reference=1990-1995 }\end{array}$ & \multicolumn{3}{|c|}{$\mathrm{n}=90$} & \multicolumn{3}{|c|}{$\mathrm{n}=90$} & \multicolumn{3}{|c|}{$\mathrm{R}^{2}=.07$} \\
\hline
\end{tabular}

Table 8 presents OLS, random-effects and fixed-effects models examining the relationship between particulate matter and neurodegenerative disease mortality. In the OLS model (M5.1), particulate matter (-.81) is statistically significant and negatively associated with neurodegenerative disease mortality. In the random-effects models (M5.2), particulate matter (-.84) is statistically significant and negatively associated with neurodegenerative mortality rates. In the fixed-effects model (M5.2), particulate matter (.74) is statistically significant and negatively associated with neurodegenerative disease mortality. Neither underground or surface/MTR coal production is statistically significant is any of the three models, nor is coal mining employment. Rural status (-14.09) is statistically significant in the OLS (M5.1) model. However, little other covariates are 
significantly associated with neurodegenerative mortality. These models suggest that increases in particulate matter concentrations reduce mortality from neurodegenerative diseases. Currently, scholars exploring causal factors for neurodegenerative disease mortality in biological models. Thus, these models are potentially picking up statistical noise, and factors not measured in these models may, in fact, be a mediating factor. These models are fundamentally exploratory and ecological and cannot account for true causality.

\begin{tabular}{|c|c|c|c|c|c|c|c|c|c|}
\hline \multicolumn{10}{|c|}{ Table 8: Neurodegenerative Disease Mortality \& Particulate Matter Models } \\
\hline \multirow[b]{2}{*}{ Air Quality } & \multicolumn{3}{|c|}{ Model 5.1} & \multicolumn{3}{|c|}{ Model 5.2} & \multicolumn{3}{|c|}{ Model 5.3} \\
\hline & Coefficient & S.E. & Sig. & Coefficient & S.E. & Sig. & Coefficient & S.E. & Sig. \\
\hline PM10 & -0.81 & 0.36 & $* *$ & -0.84 & 0.25 & $* *$ & -0.74 & 0.28 & $* *$ \\
\hline \multicolumn{10}{|l|}{ Coal Mining } \\
\hline Underground Production & $-4.46 \mathrm{E}-08$ & $8.88 \mathrm{E}-08$ & & $-3.25 \mathrm{E}-08$ & 4.39E-08 & & $-3.02 \mathrm{E}-08$ & $5.07 \mathrm{E}-08$ & \\
\hline Surface Production & $2.49 \mathrm{E}-07$ & $2.49 \mathrm{E}-07$ & & $8.73 \mathrm{E}-08$ & $9.26 \mathrm{E}-08$ & & $7.47 \mathrm{E}-08$ & $9.66 \mathrm{E}-09$ & \\
\hline Employment & -0.001 & 0.001 & & -0.001 & 0.0004 & & -0.0005 & 0.0004 & \\
\hline \multicolumn{10}{|l|}{ Demographics } \\
\hline African American (\%) & 0.46 & 0.29 & & 0.19 & 0.27 & & -0.01 & 0.42 & \\
\hline Non-white (\%) & 1.52 & 3.19 & & 2.23 & 1.52 & & 2.41 & 1.64 & \\
\hline Rural $^{1}$ & -14.09 & 3.61 & $* * *$ & & & & & & \\
\hline \multicolumn{10}{|l|}{ Socioeconomics } \\
\hline Poverty (\%) & -0.38 & 0.31 & & 0.02 & 0.15 & & 0.10 & 0.16 & \\
\hline$>$ Eight Grade Education (\%) & 0.21 & 0.54 & & -0.31 & 0.25 & & -0.09 & 0.29 & \\
\hline \multicolumn{10}{|l|}{ Health } \\
\hline Smoking (\%) & -0.19 & 0.54 & & -0.38 & 0.45 & & 0.53 & 0.67 & \\
\hline \multicolumn{10}{|l|}{ Time Period ${ }^{2}$} \\
\hline 1996-2000 & 2.31 & 4.40 & & 3.09 & 2.08 & & 4.74 & 2.39 & $*$ \\
\hline 2001-2005 & 3.06 & 5.15 & & -0.42 & 4.04 & & 3.94 & 4.87 & \\
\hline 2006-2010 & 4.68 & 7.10 & & 2.11 & 4.05 & & 7.00 & 5.03 & \\
\hline $\begin{array}{c}\text { 1reference=Urban; } \\
\text { 2reference=1990-1995 }\end{array}$ & & $\begin{array}{l}\mathrm{n}=90 \\
2=.39\end{array}$ & & & $\begin{array}{l}\mathrm{n}=90 \\
\mathrm{R}^{2}=.32\end{array}$ & & & $\begin{array}{l}n=90 \\
2=.12\end{array}$ & \\
\hline
\end{tabular}

Table 9 presents OLS, random-effects and fixed-effects models examining the relationship between particulate matter and cardiovascular disease mortality. In the OLS model (M6.1), particulate matter (4.73) is statistically significant and positively associated with cardiovascular disease mortality. In the random-effects model (M6.2), particulate 
matter (1.44) is statistically significant and positively associated with cardiovascular disease mortality. In the fixed-effects model (M6.3), particulate matter is not significantly associated with cardiovascular disease mortality. In model M6.1, the percentage African American (2.27) and poverty rate (3.24) are statistically significant and positively associated with cardiovascular disease mortality. In models M6.2 (-11.57) and M6.3 (9.61), the percentage non-Whites are statistically significant and negatively associated with cardiovascular disease mortality. In models M6.1 (8.16) and M6.2(5.07), smoking rates are statistically significant and positively associated with cardiovascular disease mortality. In model M6.3, education (-2.28) is statistically significant and negatively associated with cardiovascular mortality.

\begin{tabular}{|c|c|c|c|c|c|c|c|c|c|}
\hline \multicolumn{10}{|c|}{ Table 9: Cardiovascular Disease Mortality \& Particulate Matter Models } \\
\hline \multirow[b]{2}{*}{ Air Quality } & \multicolumn{3}{|c|}{ Model 6.1} & \multicolumn{3}{|c|}{ Model 6.2} & \multicolumn{3}{|c|}{ Model 6.3} \\
\hline & Coefficient & S.E. & Sig. & Coefficient & S.E. & Sig. & Coefficient & S.E. & Sig. \\
\hline PM10 & 4.73 & 1.17 & $* * *$ & 1.44 & 0.71 & $*$ & 0.59 & 0.68 & \\
\hline \multicolumn{10}{|l|}{ Coal Mining } \\
\hline Underground Production & $-6.99 \mathrm{E}-08$ & $2.84 \mathrm{E}-07$ & & $-2.8 \mathrm{E}-08$ & $1.22 \mathrm{E}-07$ & & $-4.5 \mathrm{E}-08$ & $1.22 \mathrm{E}-07$ & \\
\hline Surface Production & $-4.18 \mathrm{E}-07$ & $7.95 \mathrm{E}-07$ & & $2.01 \mathrm{E}-08$ & $2.57 \mathrm{E}-07$ & & 7.38E-09 & $2.33 \mathrm{E}-07$ & \\
\hline Employment & 0.004 & 0.002 & & 0.001 & 0.001 & & -0.0003 & 0.001 & \\
\hline \multicolumn{10}{|l|}{ Demographics } \\
\hline African American (\%) & 2.27 & 0.95 & $* *$ & 0.73 & 0.76 & & 0.02 & 1.01 & \\
\hline Non-white $(\%)$ & -18.58 & 10.19 & & -11.57 & 4.24 & $* *$ & -9.61 & 3.96 & $*$ \\
\hline Rural $^{1}$ & -7.67 & 11.53 & & & & & & & \\
\hline \multicolumn{10}{|l|}{ Socioeconomics } \\
\hline Poverty (\%) & 3.24 & 0.99 & $* *$ & 0.45 & 0.41 & & -0.21 & 0.39 & \\
\hline$>$ Eight Grade Education (\%) & -2.66 & 1.73 & & -0.97 & 0.71 & & -2.28 & 0.71 & $* *$ \\
\hline \multicolumn{10}{|l|}{ Health } \\
\hline Smoking (\%) & 8.16 & 1.73 & $* * *$ & 5.07 & 1.27 & $* * *$ & -0.02 & 1.62 & \\
\hline \multicolumn{10}{|l|}{ Time Period $^{2}$} \\
\hline $1996-2000$ & 1.24 & 14.07 & & -19.79 & 5.80 & $* * *$ & -32.65 & 5.76 & $* * *$ \\
\hline $2001-2005$ & -65.73 & 26.05 & $* *$ & -75.16 & 11.28 & $* * *$ & -104.31 & 11.74 & $* * *$ \\
\hline $2006-2010$ & -59.17 & 22.72 & $* *$ & -93.15 & 11.33 & $* * *$ & -125.73 & 12.14 & $* * *$ \\
\hline $\begin{array}{l}{ }^{1} \text { reference }=\text { Urban; } \\
{ }^{2} \text { reference }=1990-1995\end{array}$ & & $\begin{array}{l}n=90 \\
2^{2}=.67\end{array}$ & & & $\begin{array}{l}n=90 \\
2=.60\end{array}$ & & & $\begin{array}{l}n=90 \\
2=.22\end{array}$ & \\
\hline
\end{tabular}


Particulate matter in five of the six mortality types (All-cause, all-cancer, lung cancer, respiratory disease, cardiovascular disease), appears to be able to account for variance in mortality rates across counties, but there appears to be limited support for causal links. Given the data limitations (e.g., limited EPA data), it not surprising then that causality has no support in the current models. However, these studies do confirm what has been found in prior literature, but in a new, more rural context. Scholars find that increases in coarse particulate matter (PM10) is associated with increases in all-cause mortality (Dockery et al. 1993; Pope et al. 1995), cardiopulmonary mortality (Pope et al. 1995) and respiratory mortality (Zeka et al. 2005; Analitis et al. 2006; Hales et al. 2010). Increases in fine and ultrafine particulate matter $(\mathrm{PM}<2.5 \mu \mathrm{m} 3)$ is associated with increases in cardiopulmonary mortality (Pope et al. 2002), cardiovascular mortality (Miller et al. 2007), respiratory mortality (Zanobetti et al. 2009; Ostro et al. 2006) and lung cancer mortality (Pope et al. 2002). These results thus confirm prior scholarship.

\section{Air Quality Index \& Mortality Models}

Table 10 presents the OLS, random-effects and fixed-effects models examining the relationship between air quality index (AQI) and all-cause mortality rates. In the OLS model (M1.1), AQI (10.55) is statistically significant and positively associated with allcause mortality. In the random-effects model (M1.2), AQI (6.93) is statistically significant and positively associated with all-cause mortality. AQI is not significantly significant in the fixed-effects (M1.3) model. Neither underground nor surface/mtr coal production is statistically significant in any of the three models. However, in the OLS (M1.1) model, coal mining employment is statistically significant, but this does not continue in the other two models. In the M1.1 the percentage non-White (-24.11) is statistically significant and 
negatively associated with all-cause mortality. The percentage African American is statistically significant and positively associated with all-cause mortality in models M1.1(5.90) and M1.2(3.89). Poverty is statistically significant and positively associated with all-cause mortality in models M1.1(7.00) and M1.2(3.10). Smoking is statistically significant and positively associated with all-cause mortality in models M1.1(19.07) and M1.2(18.18). These models suggest that AQI can explain variance in all-cause mortality across counties, but cannot predict within county variance.

\begin{tabular}{|c|c|c|c|c|c|c|c|c|c|}
\hline \multicolumn{10}{|c|}{ Table 10: All-cause mortality \& AQI models } \\
\hline \multirow[b]{2}{*}{ Air Quality } & \multicolumn{3}{|c|}{ Model 1.1} & \multicolumn{3}{|c|}{ Model 1.2} & \multicolumn{3}{|c|}{ Model 1.3} \\
\hline & Coefficient & S.E. & Sig. & Coefficient & S.E. & Sig. & Coefficient & S.E. & Sig. \\
\hline$A Q I$ & 10.55 & 2.08 & $* * *$ & 6.93 & 2.21 & $* *$ & 2.18 & 2.59 & \\
\hline \multicolumn{10}{|l|}{ Coal Mining } \\
\hline Underground Production & $-1.59 \mathrm{E}-07$ & 4.41E-07 & & $-1.03 \mathrm{E}-08$ & 3.48E-07 & & $-1.74 \mathrm{E}-07$ & $4 \mathrm{E}-07$ & \\
\hline Surface Production & 7.74E-07 & $1.24 \mathrm{E}-06$ & & $6.03 \mathrm{E}-07$ & $8.56 \mathrm{E}-08$ & & $3.81 \mathrm{E}-07$ & 7.63E-07 & \\
\hline Employment & 0.01 & 0.004 & $*$ & 0.005 & 0.003 & & -0.004 & 0.004 & \\
\hline \multicolumn{10}{|l|}{ Demographics } \\
\hline African American (\%) & 5.90 & 1.48 & $* * *$ & 3.89 & 1.50 & $* *$ & -2.41 & 3.30 & \\
\hline Non-white (\%) & -24.11 & 15.83 & $* *$ & -19.77 & 13.10 & & -6.29 & 12.96 & \\
\hline Rural $^{1}$ & -20.41 & & & & & & & & \\
\hline \multicolumn{10}{|l|}{ Socioeconomics } \\
\hline Poverty (\%) & 7.00 & 1.55 & $* * *$ & 3.10 & 1.26 & $* *$ & -0.84 & 1.31 & \\
\hline$>$ Eight Grade Education (\%) & -4.47 & 2.69 & & -0.93 & 2.10 & & -4.88 & 2.34 & $*$ \\
\hline \multicolumn{10}{|l|}{ Health } \\
\hline Smoking (\%) & 19.07 & 2.69 & $* * *$ & 18.18 & 2.74 & $* * *$ & -0.35 & 5.32 & \\
\hline \multicolumn{10}{|l|}{ Time Period ${ }^{2}$} \\
\hline $1996-2000$ & 44.99 & 21.91 & $*$ & 31.87 & 17.18 & & -24.81 & 19.07 & \\
\hline $2001-2005$ & 14.32 & 40.45 & & 37.05 & 32.33 & & -72.52 & 38.57 & \\
\hline $2006-2010$ & 50.44 & 35.63 & & 36.75 & 30.91 & & -95.02 & 40.51 & $* *$ \\
\hline $\begin{array}{c}\text { 'reference=Urban; } \\
{ }^{2} \text { reference=1990-1995 }\end{array}$ & & $\begin{array}{l}\mathrm{C}=90 \\
=0.72\end{array}$ & & & $\begin{aligned} \mathrm{n}=90 \\
\mathrm{R}^{2}=.74\end{aligned}$ & & & $\begin{array}{l}\mathrm{n}=90 \\
\mathrm{R}^{2}=.10\end{array}$ & \\
\hline
\end{tabular}

Table 11 presents the OLS, random-effects and fixed-effects models examining the relationship between air quality index (AQI) and all-cancer mortality rates. In the OLS model (M2.1), AQI (1.97) is statistically significant and positively associated with allcancer mortality. In the random-effects model (M2.2), AQI (1.20) is statistically significant 
and positively associated with all-cancer mortality. AQI is not significantly associated with all-cancer mortality in the fixed-effects (M2.3) models. Neither underground or surface/mtr coal production is statistically significant. Coal mining employment is not statistically significant. The percentage African American (1.10), percentage non-White (-8.05) and rural status (-11.19) are statistically significant and associated with all-cancer mortality in the OLS (M2.1) model. Education is statistically significant and negatively associated with all-cancer mortality in models M2.1 (-1.31) and M3.3 (-1.32). Poverty is statistically significant and associated with all-cancer mortality in models M2.1 (1.65) and M2.2 (.61). Smoking is statistically significant and positively associated with smoking rates in models M2.1 (5.34) and M2.2 (4.38). These models suggest that AQI can account for cross-county variances in all-cancer mortality rates, but cannot explain potential causal links between air quality and all-cancer mortality.

\begin{tabular}{|c|c|c|c|c|c|c|c|c|c|}
\hline \multicolumn{10}{|c|}{ Table 11: All-cancer Mortality \& AQI models } \\
\hline \multirow[b]{2}{*}{ Air Quality } & \multicolumn{3}{|c|}{ Model 2.1} & \multicolumn{3}{|c|}{ Model 2.2} & \multicolumn{3}{|c|}{ Model 2.3} \\
\hline & Coefficient & S.E. & Sig. & Coefficient & S.E. & Sig. & Coefficient & S.E. & Sig. \\
\hline$A Q I$ & 1.97 & 0.46 & $* * *$ & 1.20 & 0.50 & $* *$ & 0.27 & 0.53 & \\
\hline \multicolumn{10}{|l|}{ Coal Mining } \\
\hline Underground Production & $-1.24 \mathrm{E}-06$ & 9.87E-08 & & $-4.41 \mathrm{E}-08$ & 7.65E-08 & & $-7.79 \mathrm{E}-08$ & $8.15 \mathrm{E}-08$ & \\
\hline Surface Production & $1.36 \mathrm{E}-07$ & 2.77E-07 & & $-1.23 \mathrm{E}-08$ & $1.82 \mathrm{E}-07$ & & $-7.36 \mathrm{E}-08$ & $1.55 \mathrm{E}-07$ & \\
\hline Employment & 0.002 & 0.001 & & 0.001 & 0.001 & & -0.0005 & 0.001 & \\
\hline \multicolumn{10}{|l|}{ Demographics } \\
\hline African American (\%) & 1.10 & 0.33 & $* *$ & 0.54 & 0.36 & & -0.10 & 0.67 & \\
\hline Non-white (\%) & -8.05 & 3.54 & $* *$ & -4.29 & 2.84 & & -2.47 & 2.64 & \\
\hline Rural $^{1}$ & -11.19 & 4.01 & $* *$ & & & & & & \\
\hline \multicolumn{10}{|l|}{ Socioeconomics } \\
\hline Poverty (\%) & 1.65 & 0.35 & $* * *$ & 0.61 & 0.61 & $* *$ & -0.11 & 0.27 & \\
\hline$>$ Eight Grade Education (\%) & -1.31 & 0.60 & $* *$ & -0.40 & 0.46 & & -1.32 & 0.48 & $* *$ \\
\hline \multicolumn{10}{|l|}{ Health } \\
\hline Smoking (\%) & 5.34 & 0.60 & $* * *$ & 4.38 & 0.64 & $* * *$ & -0.43 & 1.08 & \\
\hline \multicolumn{10}{|l|}{ Time Period $^{2}$} \\
\hline $1996-2000$ & 2.49 & 4.90 & & 1.86 & 3.75 & & -8.84 & 3.88 & \\
\hline $2001-2005$ & -12.14 & 9.05 & & -4.38 & 7.08 & & -27.23 & 7.85 & $* * *$ \\
\hline $2006-2010$ & 8.19 & 7.97 & & 2.79 & 6.89 & & -25.99 & 8.25 & $* *$ \\
\hline
\end{tabular}


${ }^{1}$ reference=Urban;

${ }^{2}$ reference $=1990-1995$

\begin{tabular}{|c|c|c}
\hline $\mathrm{n}=90$ & $\mathrm{n}=90$ & $\mathrm{n}=90$ \\
$\mathrm{R}^{2}=.75$ & $\mathrm{R}^{2}=.73$ & $\mathrm{R}^{2}=.13$ \\
\hline
\end{tabular}

Table 12 presents the OLS, random-effects and fixed-effects models examining the relationship between air quality index (AQI) and lung cancer mortality rates. In the OLS model (3.1), AQI (1.40) is statistically significant and positively associated with lung cancer mortality rates. In the random-effects model (M3.2), AQI (.78) is statistically significant and positively associated with lung cancer mortality rates. In the fixed-effects model (M3.3), AQI is not statistically significant. Neither underground nor surface/mtr coal production is statistically significant in any of the three models, nor is coal mining employment. The percentage African American (.45), rural status (-7.87) and poverty rates (1.02) are statistically significant and associated with lung cancer models in the OLS model (M3.1). Smoking is statistically significant and positively associated with lung cancer mortality in models M3.1 (2.57) and M3.2 (2.85). These models suggest that AQI can explain the variance between lung cancer mortality rates in counties, but cannot identify a significant causal relationship.

\begin{tabular}{|c|c|c|c|c|c|c|c|c|c|}
\hline \multicolumn{10}{|c|}{ Table 12: Lung Cancer Mortality \& AQI Models } \\
\hline & \multicolumn{3}{|c|}{ Model 3.1} & \multicolumn{3}{|c|}{ Model 3.2} & \multicolumn{3}{|c|}{ Model 3.3} \\
\hline Air Quality & Coefficient & S.E. & Sig. & Coefficient & S.E. & Sig. & Coefficient & S.E. & Sig. \\
\hline$A Q I$ & 1.40 & 0.33 & $* * *$ & 0.78 & 0.31 & * & 0.26 & 0.30 & \\
\hline Coal Mining & & & & & & & & & \\
\hline Underground Production & $-5.68 \mathrm{E}-08$ & $6.95 \mathrm{E}-08$ & & $-1.54 \mathrm{E}-08$ & $-4.7 \mathrm{E}-08$ & & $-3.32 \mathrm{E}-08$ & $4.71 \mathrm{E}-08$ & \\
\hline Surface Production & $1.84 \mathrm{E}-07$ & $1.95 \mathrm{E}-07$ & & $6.6 \mathrm{E}-09$ & $1.07 \mathrm{E}-07$ & & $-3.29 \mathrm{E}-08$ & 8.98E-09 & \\
\hline Employment & 0.001 & 0.001 & & 0.001 & 0.001 & & -0.0001 & 0.0004 & \\
\hline Demographics & & & & & & & & & \\
\hline African American (\%) & 0.45 & 0.23 & $*$ & 0.09 & 0.24 & & -0.01 & 0.39 & \\
\hline Non-white (\%) & -2.51 & 2.49 & & -2.11 & 1.71 & & -1.79 & 1.52 & \\
\hline Rural $^{1}$ & -7.87 & 2.82 & $* *$ & & & & & & \\
\hline Socioeconomics & & & & & & & & & \\
\hline Poverty (\%) & 1.02 & 0.24 & $* * *$ & 0.25 & 0.17 & & -0.16 & 0.15 & \\
\hline$>$ Eight Grade Education (\%) & -0.31 & 0.42 & & -0.008 & 0.28 & & -0.71 & 0.27 & $*$ \\
\hline Health & & & & & & & & & \\
\hline
\end{tabular}




\begin{tabular}{|c|c|c|c|c|c|c|c|c|}
\hline Smoking (\%) & 2.57 & 0.42 & **** & 2.85 & 0.42 & $* * *$ & -0.08 & 0.62 \\
\hline \multicolumn{9}{|l|}{ Time Period ${ }^{2}$} \\
\hline $1996-2000$ & 6.76 & 3.45 & $*$ & 4.99 & 2.29 & & -1.57 & 2.24 \\
\hline $2001-2005$ & 5.58 & 6.37 & & 6.27 & 4.34 & & -8.94 & 4.54 \\
\hline $2006-2010$ & 17.14 & 5.61 & $* * *$ & 10.55 & 4.31 & $*$ & -7.14 & 4.77 \\
\hline $\begin{array}{c}\text { 'reference=Urban; } \\
{ }^{2} \text { reference=1990-1995 }\end{array}$ & \multicolumn{3}{|c|}{$\begin{array}{c}\mathrm{n}=90 \\
\mathrm{R}^{2}=.73\end{array}$} & \multicolumn{3}{|c|}{$\begin{array}{c}\mathrm{n}=90 \\
\mathrm{R}^{2}=.71\end{array}$} & \multicolumn{2}{|c|}{$\begin{array}{c}\mathrm{n}=90 \\
\mathrm{R}^{2}=.26\end{array}$} \\
\hline
\end{tabular}

Table 13 presents the results from the OLS, random-effects and fixed-effects models examining the relationship between air quality index (AQI) and respiratory disease mortality rates. In the OLS model (4.1), AQI (.88) is statistically significant and positively associated with respiratory disease mortality. In the random-effects model (4.2), AQI (.77) is statistically significant and positively associated with respiratory disease mortality. Neither underground or surface/mtr coal production is statistically significant in any of the respiratory disease models. Coal mining employment (.001) is statistically significant and positively associated within the OLS (4.1) respiratory disease model. Poverty (.90) is statistically significant and positively associated with respiratory disease mortality in model M4.1. Smoking is statistically significant and positively associated with respiratory disease in models M4.1 (2.66) and M4.2 (2.50). These models suggest that AQI can explain the variance between respiratory disease mortality rates within counties, but cannot identify the significant causal relationship.

\begin{tabular}{|c|c|c|c|c|c|c|c|c|c|}
\hline \multicolumn{10}{|c|}{ Table 13: Respiratory Disease Mortality \& AQI Models } \\
\hline \multirow[b]{2}{*}{ Air Quality } & \multicolumn{3}{|c|}{ Model 4.1} & \multicolumn{3}{|c|}{ Model 4.2} & \multicolumn{3}{|c|}{ Model 4.3} \\
\hline & Coefficient & S.E. & Sig. & Coefficient & S.E. & Sig. & Coefficient & S.E. & Sig. \\
\hline$A Q I$ & 0.88 & 0.35 & $* *$ & 0.77 & 0.35 & $*$ & 0.27 & 0.34 & \\
\hline \multicolumn{10}{|l|}{ Coal Mining } \\
\hline Underground Production & $5.31 \mathrm{E}-08$ & $5.31 \mathrm{E}-08$ & & $4.54 \mathrm{E}-08$ & $5.23 \mathrm{E}-08$ & & $-6.16 \mathrm{E}-10$ & $5.29 \mathrm{E}-08$ & \\
\hline Surface Production & 4.18E-07 & 2.1E-07 & & $6.84 \mathrm{E}-08$ & 1.19E-07 & & 4.11E-08 & 1.01E-07 & \\
\hline Employment & 0.001 & 0.001 & $* *$ & 0.001 & 0.001 & & -0.0003 & 0.0005 & \\
\hline \multicolumn{10}{|l|}{ Demographics } \\
\hline African American (\%) & 0.08 & 0.25 & & -0.09 & 0.27 & & -0.14 & 0.44 & \\
\hline Non-white (\%) & -4.35 & 2.69 & & -1.70 & 1.91 & & -1.33 & 1.71 & \\
\hline
\end{tabular}




\begin{tabular}{|c|c|c|c|c|c|c|c|c|c|}
\hline Rural $^{1}$ & 4.49 & 3.05 & & & & & & & \\
\hline \multicolumn{10}{|l|}{ Socioeconomics } \\
\hline Poverty (\%) & 0.90 & 0.26 & $* *$ & 0.19 & 0.18 & & -0.19 & 0.17 & \\
\hline$>$ Eight Grade Education (\%) & -0.52 & 0.46 & & 0.19 & 0.31 & & -0.55 & 0.31 & \\
\hline \multicolumn{10}{|l|}{ Health } \\
\hline Smoking (\%) & 2.66 & 0.46 & $* * *$ & 2.50 & 0.46 & $* * *$ & -0.51 & 0.70 & \\
\hline \multicolumn{10}{|l|}{ Time Period ${ }^{2}$} \\
\hline $1996-2000$ & 14.80 & 14.80 & $* * *$ & 14.58 & 2.54 & $* * *$ & 7.53 & 2.52 & $* *$ \\
\hline $2001-2005$ & 15.25 & 15.25 & $* *$ & 22.18 & 4.82 & $* * *$ & 5.72 & 5.10 & \\
\hline $2006-2010$ & 30.11 & 30.11 & $* * *$ & 29.99 & 4.77 & $* * *$ & 11.21 & 5.36 & $*$ \\
\hline $\begin{array}{c}\text { 'reference=Urban; } \\
{ }^{2} \text { reference=1990-1995 }\end{array}$ & \multicolumn{3}{|c|}{$\begin{array}{c}\mathrm{n}=90 \\
\mathrm{R}^{2}=.71\end{array}$} & \multicolumn{3}{|c|}{$\begin{array}{c}\mathrm{n}=90 \\
\mathrm{R}^{2}=.70\end{array}$} & \multicolumn{3}{|c|}{$\begin{array}{c}\mathrm{n}=90 \\
\mathrm{R}^{2}=08\end{array}$} \\
\hline
\end{tabular}

Table 14 presents the results from the OLS, random-effects and fixed-effects models examining the relationship between air quality index (AQI) and neurodegenerative disease mortality rates. In the OLS model (M5.1), AQI (-.98) is statistically significant and negatively associated with neurodegenerative disease mortality. In the random-effects model (M5.2), AQI (-.1.03) is statistically significant and negatively associated with neurodegenerative mortality. In the fixed-effects model (M5.2), AQI (-.91) is statistically significant and negatively associated with neurodegenerative mortality. Rural status is statistically significant and negatively associated with neurodegenerative mortality (13.98) in Model M5.1. A lot remains to be understood about the transmission and development of neurodegenerative disease; recent scholarship continues to understand the role of genetic and environmental factors. Thus, these results should be taken with a grain salt given the ecological nature of the study and the limited sample size.

\begin{tabular}{|c|c|c|c|c|c|c|c|c|c|}
\hline \multirow[b]{3}{*}{ Air Ouality } & \multicolumn{9}{|c|}{ Table 14: Neurodegenerative Disease Mortality \& AQI Models } \\
\hline & \multicolumn{3}{|c|}{ Model 5.1} & \multicolumn{3}{|c|}{ Model 5.2} & \multicolumn{3}{|c|}{ Model 5.3} \\
\hline & Coefficient & S.E. & Sig. & Coefficient & S.E. & Sig. & Coefficient & S.E. & Sig \\
\hline$A Q I$ & -0.98 & 0.42 & $* *$ & -1.03 & 0.29 & $* * *$ & -0.91 & 0.32 & $* *$ \\
\hline Coal Mining & & & & & & & & & \\
\hline Underground Production & $-4.7 \mathrm{E}-08$ & $8.85 \mathrm{E}-07$ & & $-3.38 \mathrm{E}-08$ & 4.34E-08 & & $-3.19 \mathrm{E}-08$ & $5.01 \mathrm{E}-08$ & \\
\hline Surface Production & $2.97 \mathrm{E}-07$ & $2.48 \mathrm{E}-07$ & & $9.12 \mathrm{E}-08$ & $9.14 \mathrm{E}-08$ & & 7.79E-08 & $9.56 \mathrm{E}-08$ & \\
\hline
\end{tabular}




\begin{tabular}{|c|c|c|c|c|c|c|c|}
\hline Employment & -0.001 & 0.001 & & -0.001 & 0.0003 & -0.0005 & 0.0004 \\
\hline \multicolumn{8}{|l|}{ Demographics } \\
\hline African American (\%) & 0.45 & 0.29 & & 0.18 & 0.27 & -0.001 & 0.41 \\
\hline Non-white (\%) & 1.58 & 3.18 & & 2.33 & 2.33 & 2.47 & 1.62 \\
\hline Rural ${ }^{1}$ & -13.98 & 3.59 & $* * *$ & & & & \\
\hline \multicolumn{8}{|l|}{ Socioeconomics } \\
\hline Poverty (\%) & -0.38 & 0.31 & & 0.004 & 0.15 & 0.08 & 0.16 \\
\hline$>$ Eight Grade Education (\%) & 0.22 & 0.54 & & -0.29 & 0.25 & -0.08 & 0.29 \\
\hline \multicolumn{8}{|l|}{ Health } \\
\hline Smoking (\%) & -0.21 & 0.54 & & -0.39 & 0.45 & 0.48 & 0.47 \\
\hline \multicolumn{8}{|l|}{ Time Period $^{2}$} \\
\hline $1996-2000$ & 2.05 & 4.39 & & 2.74 & 2.07 & 4.37 & 2.39 \\
\hline $2001-2005$ & 2.84 & 8.12 & & -0.74 & 3.99 & 3.49 & 4.83 \\
\hline $2006-2010$ & 3.99 & 7.15 & & 1.21 & 4.06 & 6.02 & 5.07 \\
\hline $\begin{array}{c}{ }^{1} \text { reference=Urban; } \\
{ }^{2} \text { reference=1990-1995 }\end{array}$ & \multicolumn{3}{|c|}{$\begin{aligned} \mathrm{n} & =90 \\
\mathrm{R}^{2} & =.40\end{aligned}$} & \multicolumn{2}{|c|}{$\begin{aligned} \mathrm{n} & =90 \\
\mathrm{R}^{2} & =.32\end{aligned}$} & \multicolumn{2}{|c|}{$\begin{array}{c}\mathrm{n}=90 \\
\mathrm{R}^{2}=.14\end{array}$} \\
\hline
\end{tabular}

Table 15 presents the results from the OLS, random-effects and fixed-effects models examining the relationship between air quality index (AQI) and neurodegenerative disease mortality rates. In the OLS model (M6.1), AQI (5.53) is statistically significant and positively associated with cardiovascular disease mortality. In the random-effects model (M6.2), AQI (1.64) is statistically significant and positively associated with cardiovascular disease mortality. In the fixed-effects model, AQI is not statistically significant. Neither underground or surface/mtr coal production is statistically significant, nor is coal mining employment statistically significant in any of the models. In model M6.1, the percentage African American (2.31) and poverty (3.25) are statistically significant and positively associated with cardiovascular disease mortality. In model M6.2 (-11.55) and M6.3 (-9.48), the percentage non-White is statistically significant and negatively associated with cardiovascular disease mortality. In models M6.1 (8.22) and M6.2 (5.11), smoking is statistically significant and positively associated with cardiovascular disease mortality. These models suggest that AQI can explain some of the variances between counties' 
cardiovascular disease mortality rates. However, there is little evidence of a causal relationship.

\begin{tabular}{|c|c|c|c|c|c|c|c|c|c|}
\hline \multicolumn{10}{|c|}{ Table 15: Cardiovascular Disease Mortality \& AQI Models } \\
\hline \multirow[b]{2}{*}{ Air Quality } & \multicolumn{3}{|c|}{ Model 6.1} & \multicolumn{3}{|c|}{ Model 6.2} & \multicolumn{3}{|c|}{ Model 6.3} \\
\hline & Coefficient & S.E. & Sig. & Coefficient & S.E. & Sig. & Coefficient & S.E. & Sig \\
\hline$A Q I$ & 5.53 & 1.33 & $* * *$ & 1.64 & 0.82 & * & 0.60 & 0.79 & \\
\hline \multicolumn{10}{|l|}{ Coal Mining } \\
\hline Underground Production & $-5.87 \mathrm{E}-08$ & $2.83 \mathrm{E}-07$ & & $-2.82 \mathrm{E}-08$ & $1.23 \mathrm{E}-07$ & & $-4.73 E-08$ & $1.22 \mathrm{E}-07$ & \\
\hline Surface Production & $-4.5 \mathrm{E}-07$ & $7.92 \mathrm{E}-07$ & & $1.61 \mathrm{E}-08$ & $2.58 \mathrm{E}-07$ & & $7.15 \mathrm{E}-09$ & $2.34 \mathrm{E}-07$ & \\
\hline Employment & 0.004 & 0.002 & & 0.001 & 0.001 & & -0.0003 & 0.001 & \\
\hline \multicolumn{10}{|l|}{ Demographics } \\
\hline African American (\%) & 2.31 & 0.95 & $* *$ & 0.73 & 0.76 & & 0.006 & 1.01 & \\
\hline Non-white $(\%)$ & -18.89 & 10.14 & & -11.55 & 4.25 & $* *$ & -9.48 & 3.97 & $*$ \\
\hline Rural $^{1}$ & -8.19 & 11.49 & & & & & & & \\
\hline \multicolumn{10}{|l|}{ Socioeconomics } \\
\hline Poverty (\%) & 3.25 & 0.99 & $* *$ & 0.46 & 0.42 & & -0.22 & 0.40 & \\
\hline >Eight Grade Education (\%) & -2.74 & 1.72 & & -0.98 & 0.71 & & -2.28 & 0.71 & $* *$ \\
\hline \multicolumn{10}{|l|}{ Health } \\
\hline Smoking (\%) & 8.22 & 1.72 & $* * *$ & 5.11 & 1.27 & $* * *$ & -0.03 & 1.63 & \\
\hline \multicolumn{10}{|l|}{ Time Period ${ }^{2}$} \\
\hline $1996-2000$ & 2.7 & 14.03 & & -19.70 & 5.85 & $* * *$ & -33.01 & 5.83 & $* * *$ \\
\hline $2001-2005$ & -65.28 & 25.91 & $* *$ & -75.15 & 11.30 & $* * *$ & -104.82 & 11.80 & $* * *$ \\
\hline $2006-2010$ & -56.48 & 22.82 & $* *$ & -92.74 & 11.51 & $* * *$ & -126.45 & 12.39 & $* * *$ \\
\hline $\begin{array}{c}{ }^{1} \text { reference=Urban; } \\
{ }^{2} \text { reference=1990-1995 }\end{array}$ & & $\begin{array}{l}\mathrm{n}=90 \\
\mathrm{R}^{2}=.67\end{array}$ & & & $\begin{array}{l}n=90 \\
2^{2}=.61\end{array}$ & & & $\begin{array}{l}n=90 \\
R^{2}=.22\end{array}$ & \\
\hline
\end{tabular}

\section{Discussion}

The body of literature linking air pollution to higher all-cause and disease-specific mortality rates has grown exponentially over the last three decades. We have ample evidence from multiple geographic locations, using multiple methods, that particulate matter is associated with increases in all-cause mortality rates (Dockery et al. 1993; Pope III, et al. 1995; Katsouyanni et al. 1997; Burnett et al. 1998; Samet et al. 2000; Stieb et al. 2002; Omori et al. 2003; Pope III et al. 2002; Zeka et al. 2004; Eftim et al. 2008; Samoli et al. 2008; Wong et al. 2008; Zanobetti et al. 2009; Hales et al. 2010), cancer mortality rates (Pope III, et al. 1995; Pope III et al. 2002; Laden et al. 2006), respiratory disease 
(Samet et al. 2000; Ballester et al. 2002; Zeka et al. 2004; Analitis et al. 2006; Wong et al. 2008; Zanobetti et al. 2009), cardiovascular disease mortality (Pope III, et al. 1995; Samet et al. 2000; Hoek et al. 2002; Ballester et al. 2002; Pope III et al. 2002; Pope III et al. 2004; Zeka et al. 2004; Analitis et al. 2006; Laden et al. 2006; Wong et al. 2008; Zanobetti et al. 2009) and growing evidence suggests neurodegenerative disease mortality as well (Kettunen et al. 2007; Lisabeth et al. 2008; Levesque et al. 2011).

Hypothesis $\mathrm{H}_{2}$ is confirmed in this study, higher concentrations of particulate matter and AQI are associated with higher mortality for all-cause, all-cancer, lung cancer, respiratory disease, and cardiovascular disease (However, the neurodegenerative disease results had counter findings). The findings suggest that even in an area with less air pollution than other areas, there is a significant relationship between air quality and mortality. The AQI annual average concentration in the study counties in Central Appalachia are on average 15 points lower than the United States average. Figure 7 presents the average AQI measure between 1990 and 2010. The Central Appalachia counties start with an AQI of 26 in 1990-95 period and fall to below 20 AQI in the 200610 period. The United States had a higher AQI on average, and it increased over the twodecade period, from a 35 AQI in 1990-95 to an average AQI of 39 in 2006-10 period. Surface/MTR and underground coal mining counties had AQI's similar to that of Central Appalachian counties as well, with AQI of 26 in 1990-95 and an AQI of 19 in 2006-10. 


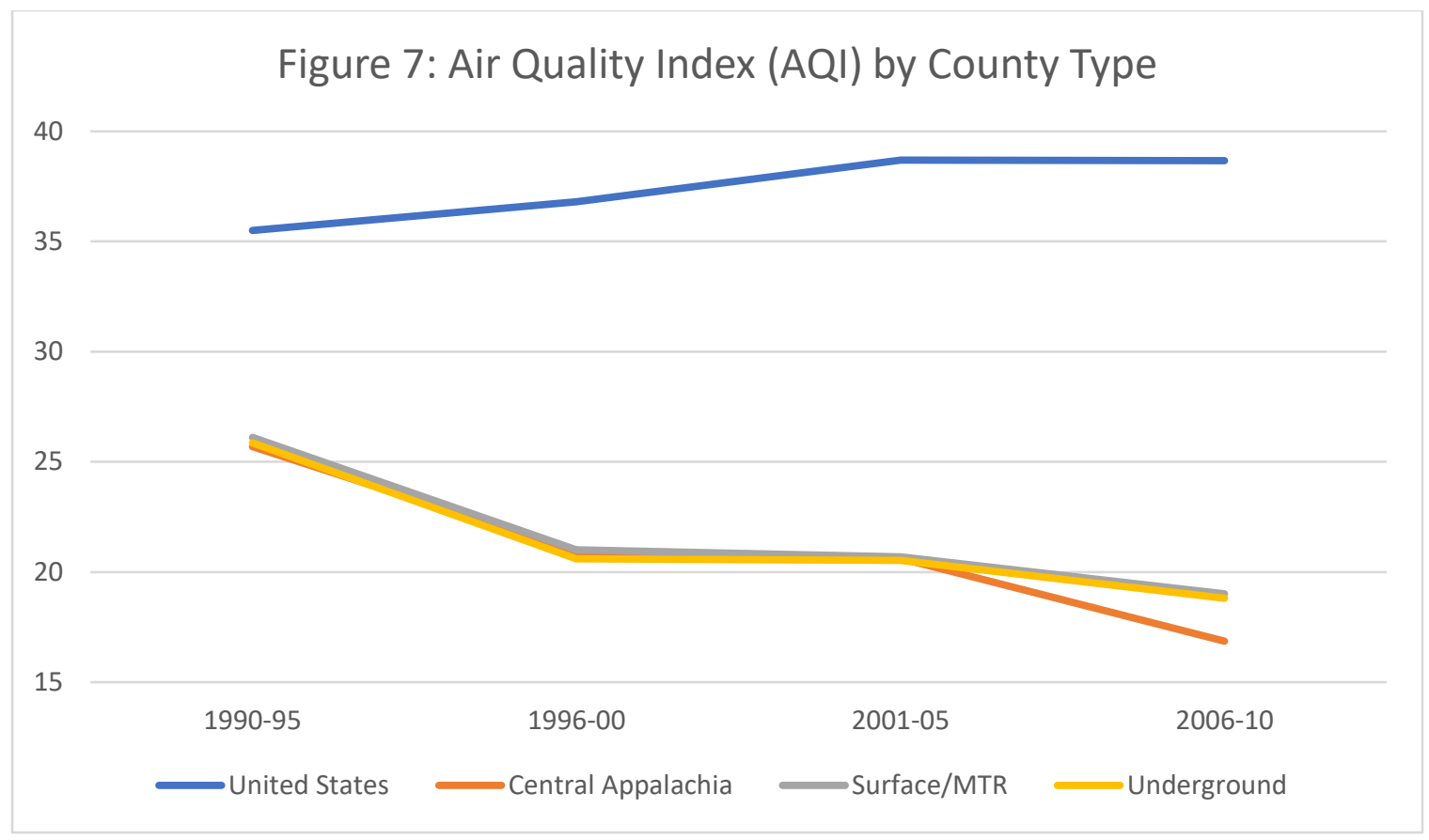

In Figure 8 particulate matter (PM10) concentrations are lower in Central Appalachia and surface/mtr and underground coal mining counties than the average across the United States in the 1990-95 to 1996-00 time periods. However, after the 1996-00 period, the roles reverse, and the Central Appalachia and coal mining counties lag the national rates of decline. These results suggest that overall air quality is remarkably better in the Central Appalachian region than in the average county in the United States. However, particulate matter concentrations appear to lag the United States average, particularly after the 1996-00 time period. It is not surprising then that particulate matter pollution is a concern in the Appalachian region. 


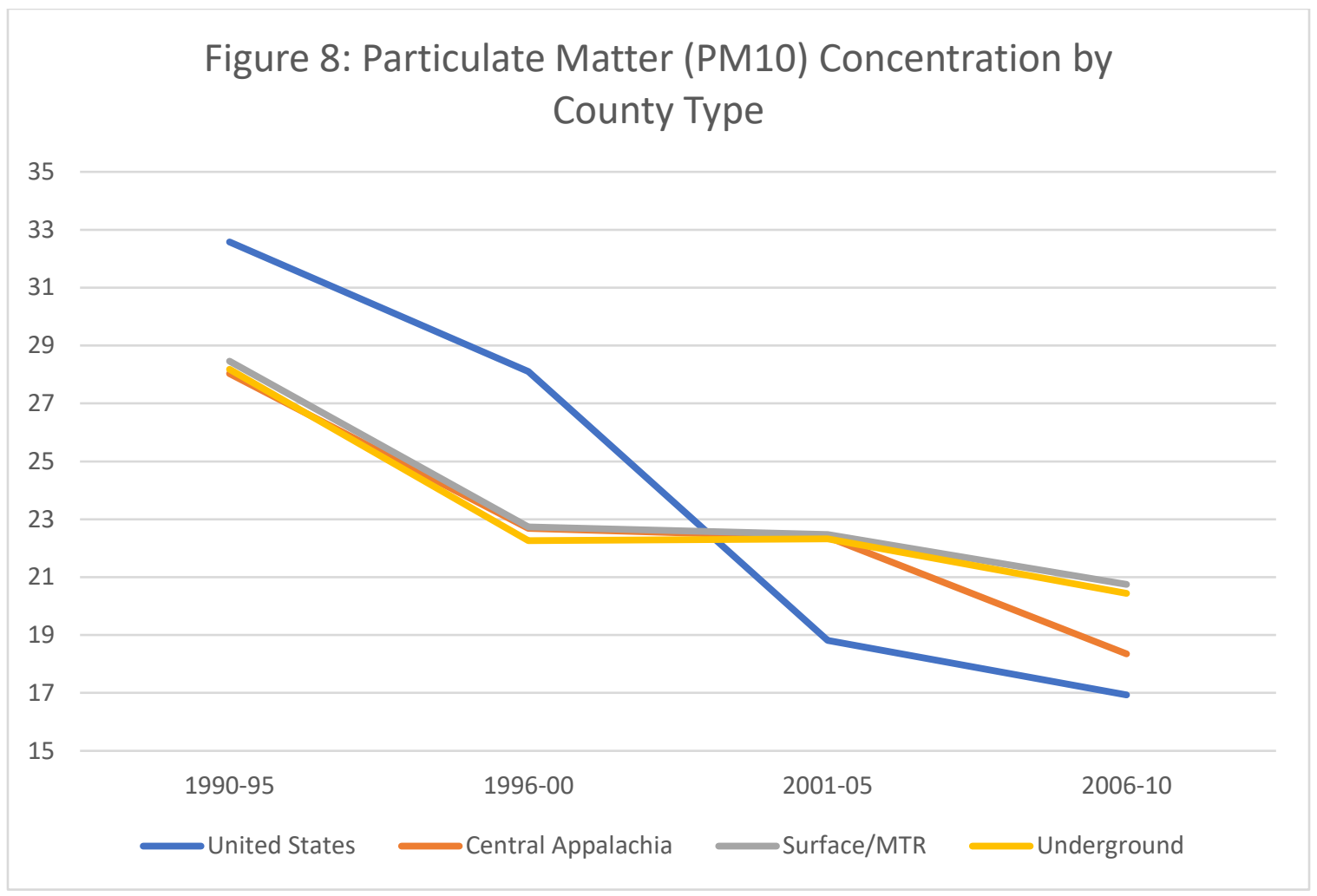

Particulate matter pollution is a significant concern for surface and mountaintop removal coal mining sites. Research from West Virginia (Kurth et al. 2012; Kruth et al. 2012[1]), India (Ghose \& Majee 2000), United Kingdom (Reynolds et al. 2013), China (Liu et al. 2012), Columbia (Huertas et al 2012) and Australia (Higginbotham et al. 2010) find significant increases in particulate matter pollution near surface and mountaintop removal coal mining sites. The results of this study found that air pollution, particulate matter specific, but AQI measures of air pollution, in general, are significantly associated with all-cause, all-cancer, lung cancer, respiratory disease, and cardiovascular disease mortality. It should be noted, that little to no studies have examining air pollution and mortality in largely rural areas. In this study, $77 \%$ of the sample counties are classified by the USDA as rural communities. Much of the prior work has looked exclusively at large or medium-sized cities (e.g. Dockery et al. 1993; Pope III, et al. 1995; Katsouyanni et al. 
1997; Samet et al. 2000; Pope III et al. 2004; Zeka et al. 2004; Analitis et al. 2006; Zanobetti et al. 2009). This study confirms that even in a largely rural setting (Central Appalachia), the relationship between air quality, particulate matter, and mortality, particularly for all-cause, lung cancer, and cardiovascular disease, is confirmed. However, these results should be taken with some grain of salt.

In all but the neurodegenerative disease mortality models (I will discuss at length later in this section), air quality index (AQI) or particulate matter was not statistically significant in the fixed-effects models. These findings suggest that air quality is not a significant causal factor for mortality. Thus, air quality can explain differences between counties, but cannot explain the change over time within county mortality rates. Fixed effects models attempt to account for non-measure factors that might impact the change in mortality rates over time. However, there are potential factors that do change over time that were considered in these models. Random-effects models measure both change over time in counties, but also differences between counties. Thus, these models try to predict causality. However, in this case there appears to be other factors that I did not include in the models that mediates the relationship over time between air quality and mortality rates.

Air quality data is notoriously sparse and intermittent, particularly in rural communities (Mintz 2009). However, the fact that the relationship is statistically significant after the data limitations is an important finding of this study.

Rural communities have traditionally been thought to be immune from air pollution issues, with the exception being communities near power plants, industrial facilities, and those with a history of wildfires. The results of this study counter this narrative by showing that, even in largely rural regions ( $77 \%$ of counties classified as rural in the study area), air 
quality is statistically significant and positively associated with mortality rates. However, one of the key questions in this study was the relationship between coal mining and air quality; these results prove inconclusive.

Coal mining in the study sample counties is not statistically significant and thus not associated with air quality. Thus, Hypothesis $\mathrm{H}_{1}$ is not confirmed by these results. The analysis of air quality and coal production is hampered by the limited amount of data, only $17 \%$ of the county- years in the region during the time period have air quality data measured by the U.S. EPA. Thus, the study reduces the number of county-years available for the models from $n=530$ to $n=90$, a reduction of $83 \%$ of the county-years in the study area. Nearly half of all coal-producing county-years are removed from the sample, potentially downwardly biasing the results. Thus, both in the models predicting air quality and in the mortality models, coal production is not statistically significant. This factor is countered by the fact that in many of the same models in the coal-exposure model (Discussed further in the next chapter) produce statistically significant associations between coal production and mortality. Despite the flaws in the data, the results do confirm a relationship between air quality and mortality rates for all-cause, all-cancer, lung cancer, respiratory disease, and cardiovascular disease.

Air pollution has been a public health concern for urban areas around the world. No studies are examining the relationship between air pollution and rural community mortality. This study fills this gap and finds that, even in a prominently rural sample (77\% vs. 33\% Rural-Urban), air quality, measured using a composite index (AQI) or concentration of particular measure (Particulate matter PM10) is significantly associated 
with increased mortality rates. Thus, it will be important to explore the relationship between rural air quality and mortality further in depth in future research. 


\section{COAL-EXPOSURE STUDY}

\section{Univariate Results}

On average, nearly a fourth of the counties' populations live within two miles of a surface/mtr coal mining site. However, this is concentrated largely in a few counties, with a maximum of $100 \%$ of the county population living within two miles of a surface/mtr coal mining facility. Table 16 presents the descriptive statistics for the coal-exposure model. On average the percentage of county's population living within .25 miles of a surface $/ \mathrm{mtr}$ coal mining site is $7.93 \%$. However, the highest coal-exposure rates are largely concentrated in a few counties having a maximum percentage of $84.11 \%$ living within the .25 range. On average $10.65 \%$ of counties population lives within half a mile of a surface/mtr coal mining site, with this concentrated in a few with a maximum $91.15 \%$ of the counties population living with a half mile from surface/mtr coal mining site. An average of $15.77 \%$ of counties population lives within one mile of surface/mtr coal mining sites, with it a few counties with nearly $99 \%$ of the population living within one mile of a surface/mtr coal mining site.

The average surface/mtr coal production across the counties was 3,234,000 tons, with some counties having a maximum of $86,100,000$ tons coal mined. Underground coal mining has an average coal production double that of surface coal production across the study counties. An average of nearly 6,000,000 tons of underground coal is mined, with a maximum production of 102,000,000 tons of coal mined. In the study counties, coal mining employment averaged 1,253 with a maximum of 21,927 employed in coal mines. Similar to coal production, employment in coal mines are concentrated in a few coalfield counties in Central Appalachia. 
Overall, across all six categories of mortality used the study, there is a wide range of mortality rates. The average age-adjusted all-cause mortality rate across the counties in the study is 1086 deaths per 100,000 population, which ranges from 794 to 1407 deaths per 100,000 population. The age-adjusted all-cancer mortality rate is 247 per 100,000 population with a range between 167 to 316 per 100,000 population. The lung cancer mortality rate for the study counties is 88 per 100,000, with a range between 43 and 143 per 100,000 population. Respiratory disease mortality average for the study counties is 79 , in a range between 42 and 148 per 100,000 population. Neurodegenerative mortality average across the study counties is 86, in a range between 42 and 142 per 100,000 population. Cardiovascular disease mortality averages 389 per 100,000 population, with a range between 42 and 570 per 100,000 population.

The study counties are largely white and rural. However, there are pockets of nonwhite populations and urban communities as well. Across the study counties, $2.78 \%$ of the population is African American, with a range between 0 and $44.95 \%$. Other racial groups make up on average $.53 \%$ of study counties population, with a range between $0 \%$ and $5.63 \%$. More than three-fourths of the counties in the study area are rural $(77.3 \%)$, while more than a fifth are urban $(22.7 \%)$ according to the USDA codes.

The study counties are largely poorly educated, with high rates of poverty and smoking rates. An average of nearly one-tenth (9.8\%) of people living in the study counties has less than an eighth-grade education, with a range between $.47 \%$ to $32.49 \%$. One in five residents in the study counties live below the poverty line $(21.2 \%)$, some counties having a poverty rate of over $50 \%$. An average of a third of study county residents is currently a 
daily smoker, with counties that range between less than one fifth (18.09\%) and nearly $40 \%$ of the county's population being a current smoker.

\begin{tabular}{|l|cccc|}
\hline \multicolumn{5}{|c|}{ Table 16: Descriptive Statistics for Coal-Exposure Model } \\
\hline & Mean & S.D. & Min. & Max. \\
\hline Coal-exposure measure (\% pop lives within) & & & & \\
.25 miles & 7.93 & 14.52 & 0 & 84.11 \\
.50 miles & 10.65 & 18.21 & 0 & 91.14 \\
1 mile & 15.77 & 23.73 & 0 & 98.09 \\
2 miles & 24.92 & 32.36 & 0 & 100 \\
Coal Production & & & & \\
Surface (000 tons) & 3234 & 9153 & 0 & 86100 \\
Underground (000 tons) & 5993 & 15100 & 0 & 102000 \\
Employment (\# employed in coal mines) & 1253 & 2964 & 0 & 21927 \\
Mortality Rates (per 100,000 pop) & & & & \\
All-cause mortality & 1086 & 116 & 794 & 1407 \\
All-cancer mortality & 247 & 28 & 167 & 316 \\
Lung-cancer mortality & 88 & 18 & 43 & 143 \\
Respiratory disease mortality & 79 & 21 & 42 & 148 \\
Neurodegenerative mortality & 86 & 18 & 42 & 142 \\
Cardiovascular disease mortality & 389 & 66 & 42 & 570 \\
Demographics & & & & \\
African American (\%) & 2.78 & 4.57 & 0 & 44.95 \\
Other Races (\%) & 0.53 & 0.57 & 0 & 5.63 \\
Rural (1=rural; 0=urban) & 0.77 & 0.42 & 0 & 1 \\
Socioeconomics & & & & \\
Education (\% <Eight Grade Education) & 9.80 & 6.65 & 0.47 & 32.49 \\
Poverty (\% currently living in poverty) & 21.20 & 7.61 & 5.11 & 51.03 \\
Smoking (\% currently a daily smoker) & 31.01 & 3.56 & 18.09 & 38.47 \\
\hline
\end{tabular}

\section{Geographic Distribution of Coal-exposure measure}

Figure 9a is a map of the quarter-mile coal-exposure measure in the 1990-95 time period. The highest concentration clusters in the tri-state border between southern West Virginia, southwest Virginia, and southeastern Kentucky. No county has more than $60 \%$ of the county's population living within a quarter mile of a surface/mtr coal mining site. However, by the 1996-00 period, several counties in southeastern Kentucky have more 
than $60 \%$ of the county population living within a quarter mile of a surface/mtr coal mining site. In Figure 9b, three counties in southeastern Kentucky (Pike, Knott, and Letcher counties) have more than $60 \%$ of the county population living within a quarter mile of a surface/mtr coal mining site. In the 2001-05 period in Figure 9c, this grows to five counties clustered in southeastern Kentucky. It by the 2001-05 time period that percentage of county populations outside of the core counties in southeastern Kentucky and southern West Virginia begins to expand to neighboring counties. By the 2006-10 time period, a total of 13 counties in Kentucky, two counties in West Virginia and one county in Virginia have between $26 \%$ to $90 \%$ of their population living within a quarter mile of a surface $/ \mathrm{mtr}$ coal mining site. The quarter-mile coal-exposure measure is heavily concentrated in southeastern Kentucky, southwest Virginia, and southern West Virginia. 

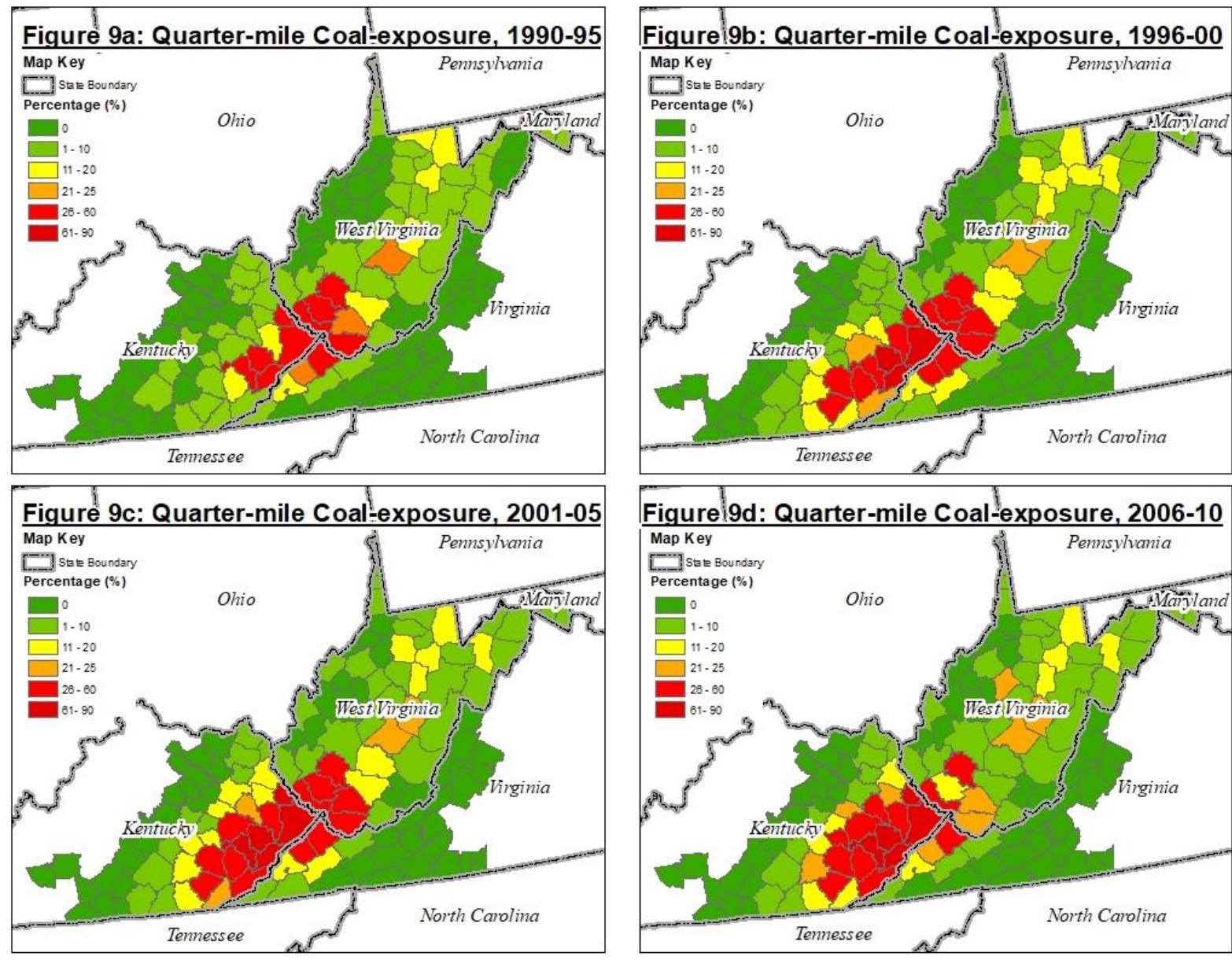

Figure 10a is a map of the half-mile coal exposure measure in the 1990-95 time period. The highest concentration of the measure concentrates in the southern West Virginia, eastern Kentucky, and southwest Virginia border regions. Only Pike County, KY has more than $60 \%$ of the population living within a half-mile of surface/mtr coal mining sites. In Figure 10b is the half-mile coal-exposure measure in the 1996-00 time period. The highest concentrations are in southeastern Kentucky, southern West Virginia, and southwest Virginia. The highest concentrations (county populations with $>60 \%$ living within a half-mile) are in five counties in eastern Kentucky and one county in southern West Virginia. The half-mile coal-exposure measure in the 2000-05 time period is presented in Figure 10c. Concentrations are the highest in southeastern Kentucky and 
southern West Virginia and southwest Virginia. However, by this time period, the measure has spread beyond its core in the central coalfield counties to neighboring counties. This trend continues into the 2006-10 time period in Figure 10d. The majority of counties with greater than $60 \%$ of their population living within half-mile of a surface/mtr site is concentrated in southeastern Kentucky.
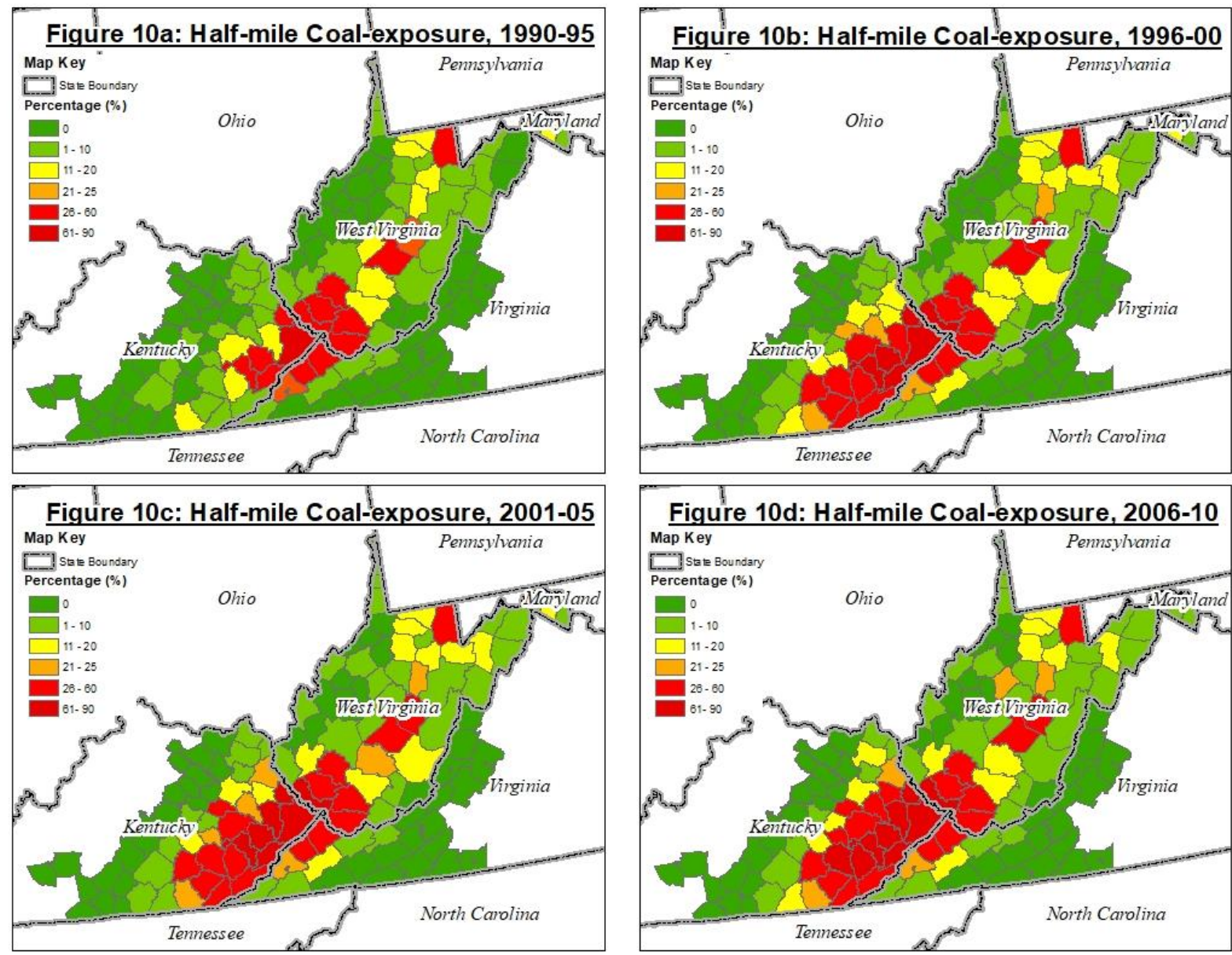

Figure 11a is a map of the one-mile coal exposure measure in the 1990-95 time period. The highest concentration of counties with more than $60 \%$ of the population living within one mile of a surface/mtr coal mining site is in three counties (two in Kentucky, one in West Virginia). In the 1996-00 time period (Figure 11b) the percentage of people living within one mile of a surface/mtr coal mining site increases across the 
region, but particularly in southern West Virginia and southeastern Kentucky. This increase continues, and by the 2001-05 time period (Figure 11c), 14 counties have more than $60 \%$ of their population living within one mile of a surface/mtr coal mining site.

However, this trend levels off by the 2006-10 time period (Figure 11c) and the concentrations slowly increase in marginal counties. The one-mile coal-exposure measure is heavily concentrated in southeastern Kentucky, southern West Virginia, north-central West Virginia, and southwest Virginia.
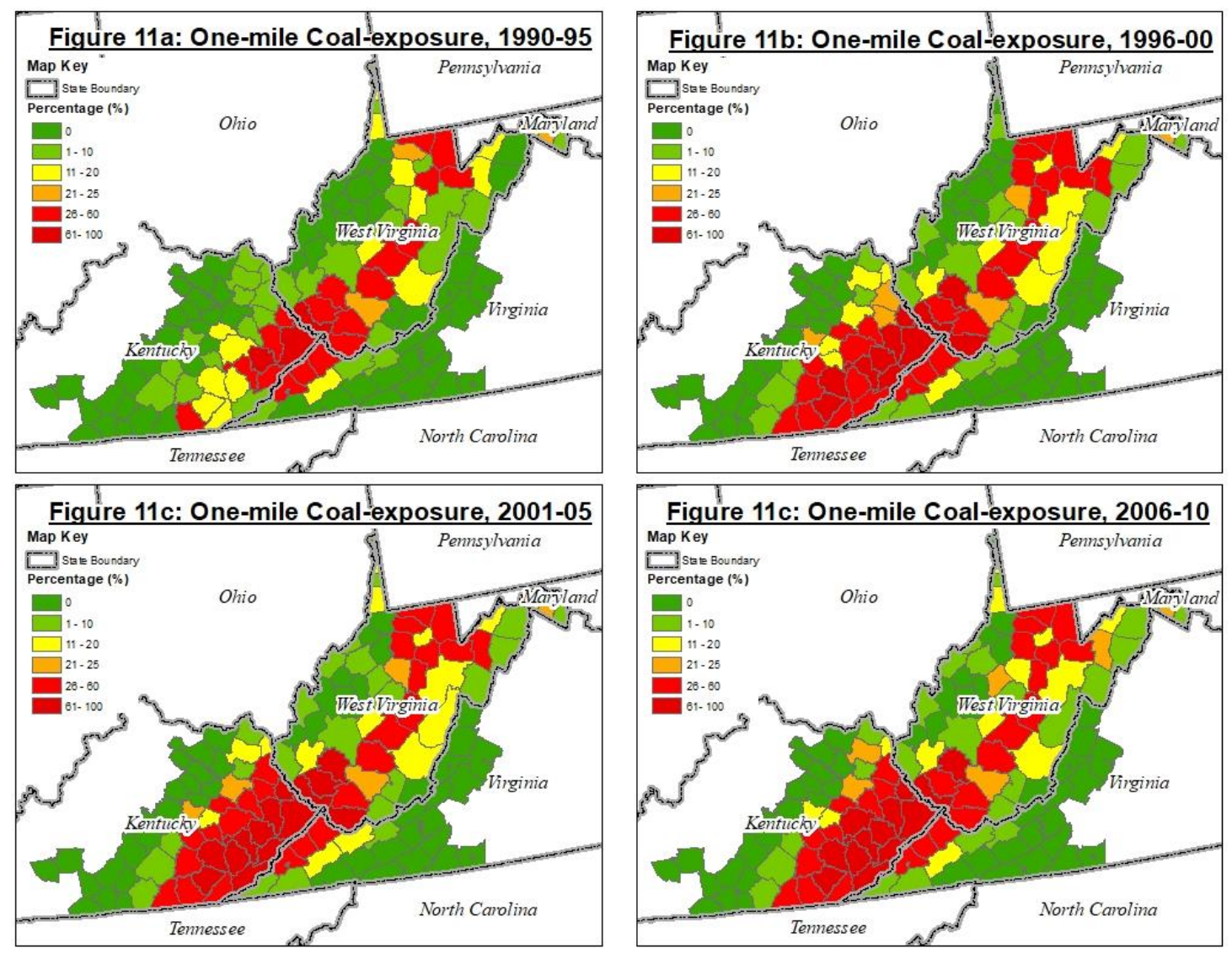

In Figure 12a is a map of the two-mile coal exposure measure in the 1990-95 time period. There are 15 counties with between $60-100 \%$ of the county's population lives within two miles of a surface/mtr coal mining site. The two-mile coal exposure measure 
increases between the 1990-95 and 1995-00 time period (Figure 12b). A continue link of counties from north-central West Virginia through southern West Virginia and into southeastern Kentucky and southwest Virginia have between $60-100 \%$ of their population living within two miles of surface/mtr coal mining sites. The geographic concentration of the two-mile coal-exposure measure remains relatively stable through the 2001-05 (Figure 12c) and 2006-10 (Figure 12d) period, with modest growth in surrounding counties in West Virginia and southeastern Kentucky.
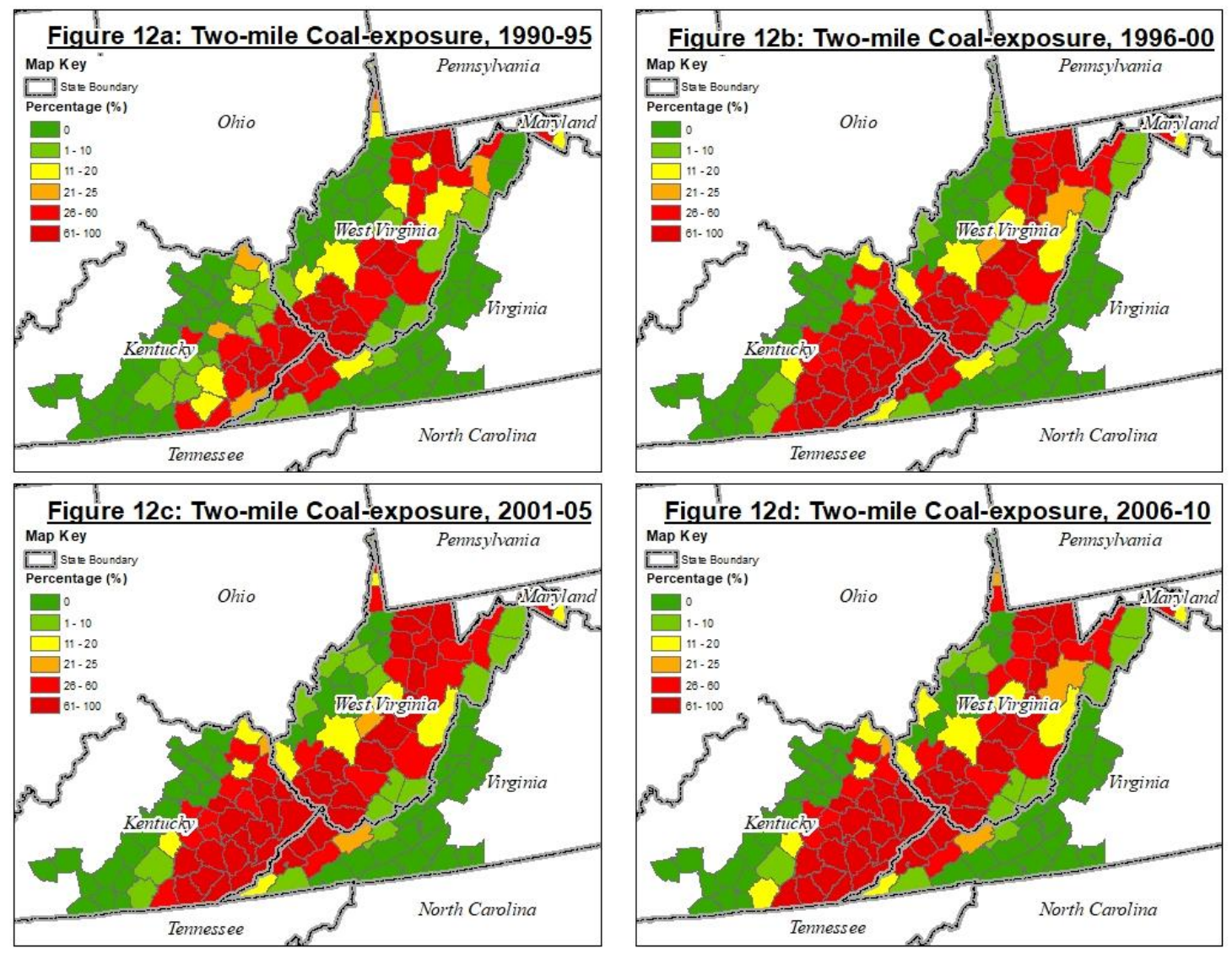

\section{All-cause mortality models}

Table 17 present the regression coefficients for the all-cause mortality OLS, random-effects and fixed-effect models. In Model 1.1 we see the quarter mile exposure measure is a significant predictor of all-cause mortality, increasing .88 deaths per one 
percent increase in .25 coal-exposure measure. Surface coal production (1.42E-06), percentage African American (2.89), poverty (3.53) and smoking (17.05) are all statistically significant, and this confirms what prior literature suggests. Model 1.2 shows the half-mile (.50) exposure measure to be statistically significant, with a slightly lower effect size compared to the quarter mile model (.88 vs. .84). Surface coal production (1.34E-06), percentage African American (2.92), poverty (3.43), smoking and 2006-2010 time period (-62.77) are statistically significant and confirms what prior literature suggests. Model 1.3 shows the mile coal exposure measure is statistically significant. However, the regression coefficient decreased from the half-mile coal exposure measure (.84 vs .67). Surface coal production (1.33E-06), percentage African American (2.99), poverty (3.37), smoking rate (17.09) and the 2006-2010 time period (-63.39) are statistically significant and confirm what prior literature suggests. Model 1.4 shows that two-mile coal exposure measure is statistically significant (.46). However, the coefficient decreases from the onemile exposure model (.67 vs .46). Surface coal production (1.43E-06), percentage African American (3.06), poverty (3.39), smoking (17.01) and 2006-2010 time period (-63.46) are all statistically significant and confirm what prior literature suggests. The coal-exposure measure reduces in effect size in a stair-step manner as the distance measure widens. The significance of the coal-exposure measure and surface coal production suggest an environmental population health risk associated with coal production.

The random-effects models are presented in Table 17 show similar results compared to the OLS models. The coal-exposure model is significant at all levels, and the coefficient decreases in a stair-step manner similar to the OLS models. Across all of the random-effects models, the distances measured for coal exposure are all statistically significant, with the effect size decreasing slightly from the quarter mile $(0.78)$, half mile $(0.70)$, one mile 
(0.54), to the two-mile radius $(0.38)$. For every model, smoking also remains the only non-time period factor statistically significant. The statistical significance of the coal-exposure measure in the random-effects suggests an environmental population health risk. However, surface coal production becomes non-significant between the OLS and random-effects modeling, bringing more uncertainty into the potential causal relationship between coal production and all-cause mortality. I will discuss this further in the next chapter. However, these results suggest that either the current measures are not picking up any association between coal production over time or coal production is a better predictor of mortality disparities across counties, but not within counties over time.

Table 17 presents the findings for the fixed-effects models for all-cause mortality. The coal-exposure measure at all distance lengths is non-significant. However, the socioeconomic factors become significant negative predictors of all-cause mortality, counter to the prior literature has found. Education is statistically significant and negative associated with all-cause mortality (-2.49 across all four models). Poverty is statistically significant and negatively associated with all-cause mortality across all four models (-.79 across all four models). Smoking is statistically significant and negatively associated allcause mortality (-3.78 in Models $3.1 \& 3.2 ;-3.76$ in Models 3.3 \& 3.4). While these results are surprising, they can account for less than two percent of the variance in all-cause mortality rates over time. These findings suggest that the factors in the fixed-effects models are poor predictors of all-cause mortality change over time. Rather, the coal exposure measure, coal production, demographics, and socioeconomics are significant predictors of all-cause mortality differences across counties and not within counties. 


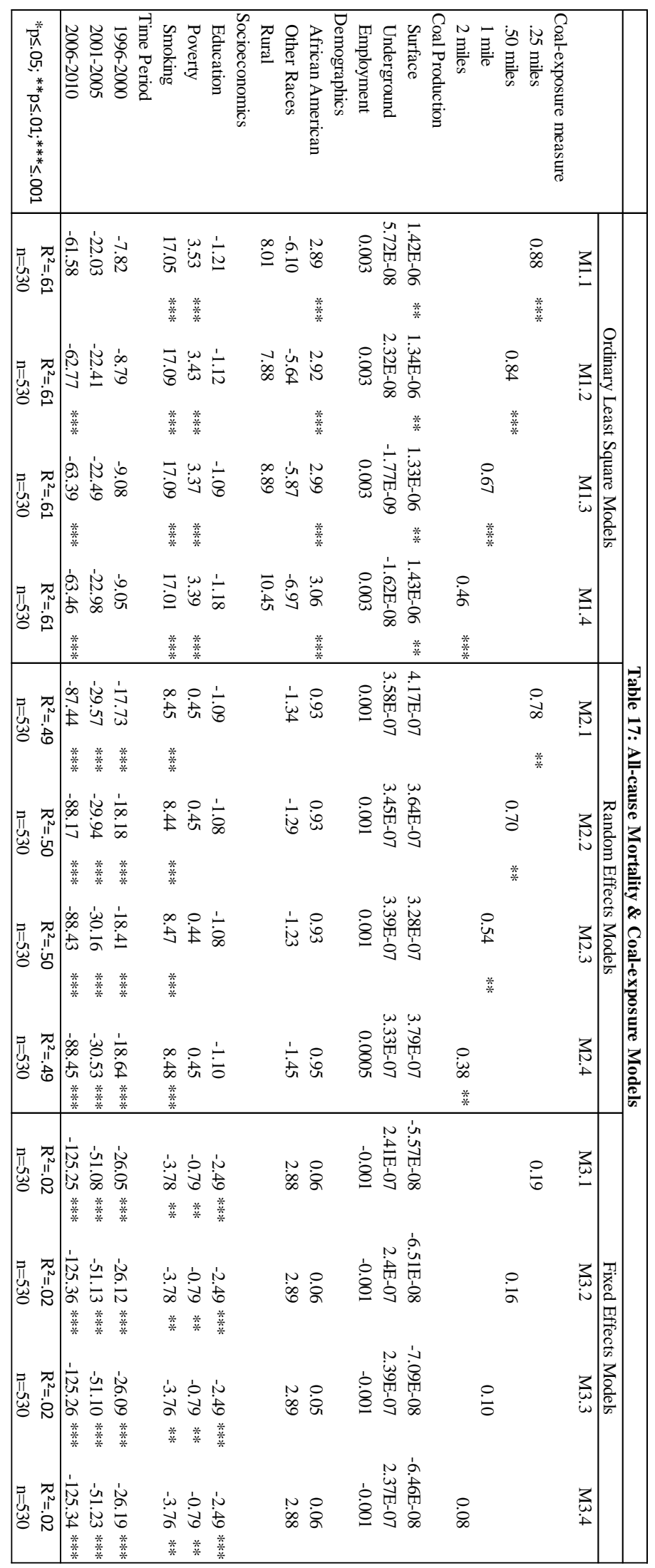




\section{All-cancer mortality models}

Table 18 shows the results from the all-cancer OLS, random-effects and fixedeffects models. In the OLS models, we see that only the half-mile (.11) and one-mile (.08) distance measures are statistically significant predictors of all-cancer mortality. In model M1.1 (4.02E-07), M1.2 (3.91E-07), M1.3 (3.91E-07) and M1.4 (4.08E-07) are surface coal production is a statistically significant predictor of all-cancer mortality. These findings suggest a significant association between surface coal production and all-cancer mortality. However, a smaller effect size compared to the relationship between surface coal production and all-cause mortality. Race also appears to be a statistically significant predictor of all-cancer mortality. In models M1.1 (.59), M1.2 (.59), M1.3 (.61), and M1.4 (.61) the percentage African American in a county is a significant positive predictor of allcancer mortality. Increases in the percentage of people living in poverty are a statistically significant positive predictor of all-cancer mortality in models M1.1 (1.04), M1.2 (1.03), M1.3 (1.03), and M1.4 (1.04). The smoking rate is a statistically significant and positive predictor of all-cancer mortality in models M1.1 (5.22), M1.2 (5.23), M1.3 (5.23) and M1.4 (5.21). Counter to prior literature, there is a negative relationship between the education level (percentage with less than an eighth-grade education) and all-cancer mortality, suggesting that increases in low levels of education reduce all-cancer mortality in the OLS

models. Further investigated yield no major flaw in the models, including tests for multicollinearity and heteroskedasticity.

Table 18 presents the results for the random-effects models for coal-exposure and all-cancer mortality. In only two of three coal-exposure models, for the half-mile (.10) and one mile (.07), are statistically significant. In the OLS model, surface coal production is 
statistically significant and associated with all-cancer mortality; this is not the case in the random effects models. Smoking and education are the only non-time period covariates that are statistically significant. Smoking prevalence in statistically significant in models M2.1 (1.85), M2.2 (1.84), M2.3 (1.85) and M2.4 (1.86). Education, similar to the OLS model presented results that run counter to the literature, suggesting increases in the levels of individuals with less than an eighth-grade education reduces all-cancer mortality rates. Additional tests find these results persist.

In the final all-cancer models, the fixed-effects results show no statistical significance for the coal-exposure measure or coal production covariates. Only education and poverty remain statistically significant predictors, and the direction of the results change for poverty. In models M3.1 (-.51), M3.2 (-.51), M3.3 (-.51) and M3.4 (-.52) education is negatively associated with all-cause cancer. In models M3.1 (-.18), M3.2 ($.18)$, M3.3 (-.18) and M3.4 (-.18) poverty is negatively associated with all-cancer mortality, suggesting increases in county poverty rates reduces all-cancer mortality over time. These results are contradictory to much of the prior literature. It should be noted the fixed-effects models can only account for between three and four percent of the variance in all-cancer mortality rates over time. Thus, the results presented here may be "statistical noise." 


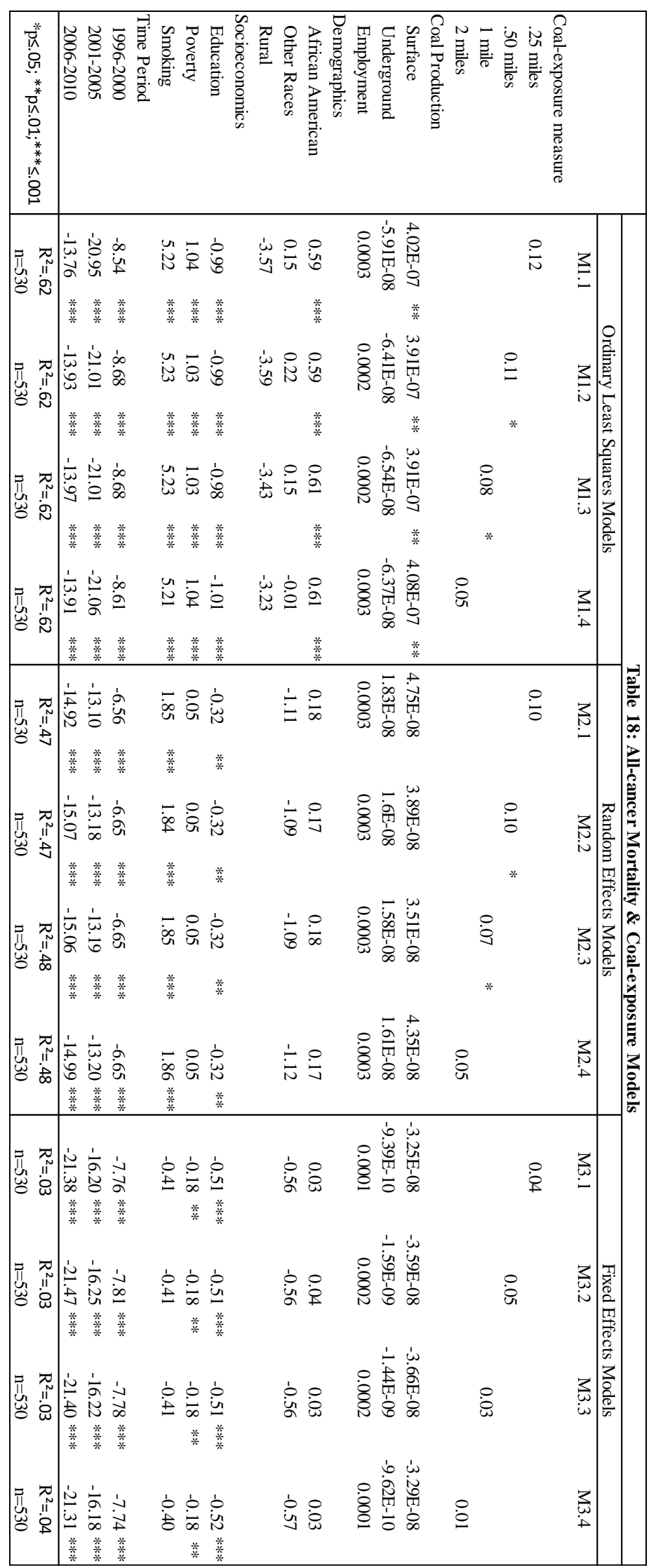




\section{Lung Cancer mortality models}

Table 19 presents the results from the lung cancer mortality models. In the OLS models, coal-exposure is significantly associated with lung cancer mortality rates. In Models, M1.2 (.07), M1.3 (.06) and M1.4 (.05) the coal exposure measure is statistically significant. The quarter-mile measure is not significantly associated with lung cancer mortality, suggesting the measure is suffering from some form of specification error. Surface coal production is also significantly associated with lung cancer mortality in models M1.1 (2.54E-07), M1.2 (2.46E-07), M1.3 (2.42E-07) and M1.4 (2.51E-07). Surface coal production and the coal-exposure measure suggest an environmental pollution risk associated with lung cancer.

In the random-effects lung cancer mortality models only one of the coal-exposure measure models is statistically significant. The half-mile measure (.06) is statistically significantly associated with lung cancer mortality. Coal mining employment is statistically positively associated with lung cancer mortality in models M2.1 (.0003), M2.2 (.0003) and M2.3 (.0003). These suggest a very limited association with coal production and environmental pollution, but a potential occupational health hazard. Education and smoking are the other covariates that statistically significant. In the models, M2.1 (.99), M2.2 (.99), M2.3 (1) and M2.4 (1.01) increases in the smoking rate are associated with increases in lung cancer mortality rates. Education is statistically significant in models M2.1 (-.25), M2.2 (-.25), M2.3 (-.25), and M2.4 (-.25). These models suggest a more complex picture of the association between coal mining and lung cancer compared to the OLS model. 
In the fixed-effects model, there is no significant association between coalexposure measure and coal production; this is counter to the results in the random-effects and OLS regression models. In the fixed-effects model, only education, poverty and smoking are the non-time period covariates statistically significant. Education is statistically significantly associated with lung cancer mortality in models M3.1(-.37), M3.2(-.37), M3.3(-.37) and M3.4(-.37). Smoking is statistically significantly associated with lung cancer mortality in models M3.1(-.29), M3.2(-.30), M3.3(-.29) and M3.4(-.29). The poverty rate is statistically significantly associated with lung cancer mortality in models in M3.1(-.11), M3.2(-.30), M3.3(-.29) and M3.4(-.29).

The relationship between coal-exposure measure, coal production and lung cancer mortality are more complicated than the initial OLS models suggest. Random-effects and fixed-effects results suggest a more complicated causality model. However, the OLS results do suggest that coal-exposure and coal production can account for between county variation in lung cancer mortality. 


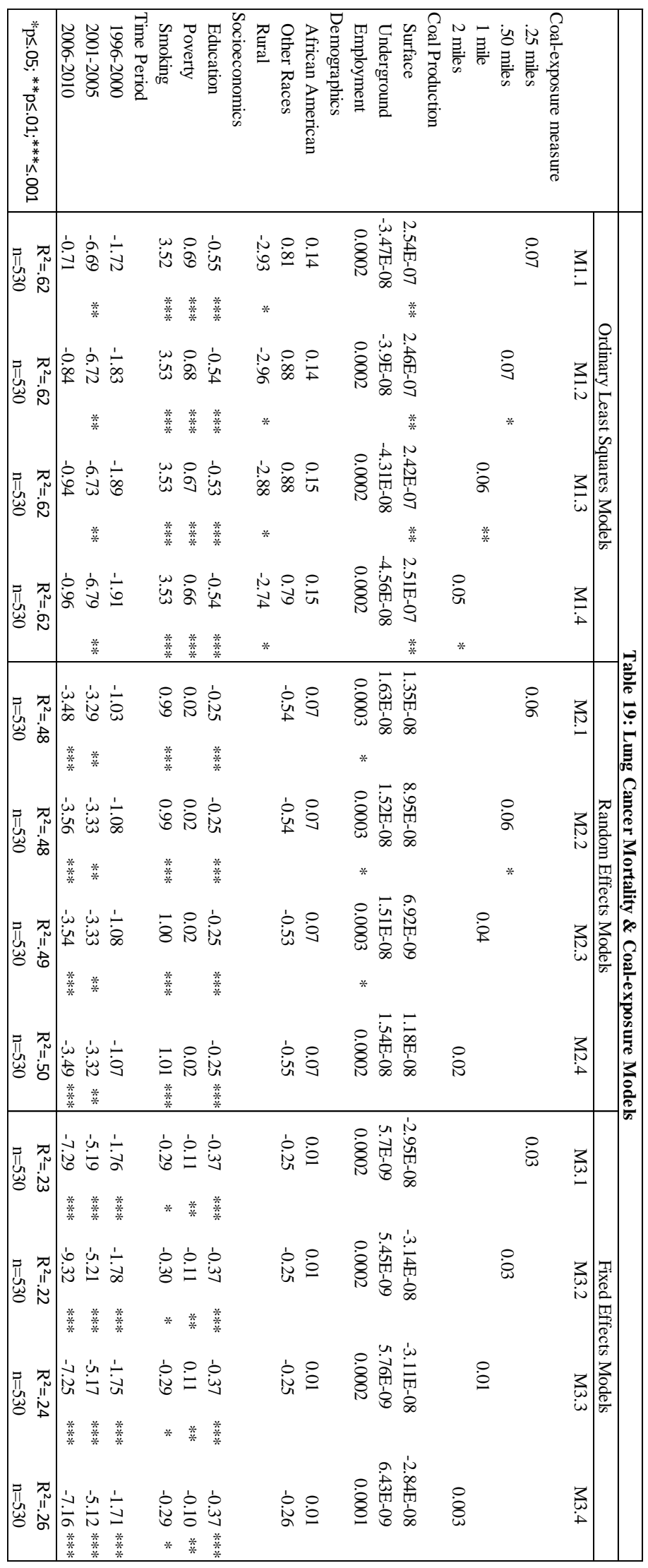




\section{Respiratory Disease Model}

Table 20 presents the results for the OLS, random-effects and fixed-effects models for respiratory disease mortality and coal-exposure model. The results suggest a complex causal relationship between respiratory disease and coal-exposure mortality. However, there does appear to be some cross-county association between respiratory disease mortality and coal-exposure measure. In the OLD models all levels of the coal exposure measure, quarter-mile (.35), half-mile (.30), one mile (.25) and two-mile (.18) are statistically significant and associated with respiratory disease mortality. However, coal mining employment (.001) is statistically significant as well.

Rural status is statistically significant and associated with increases in respiratory disease mortality in models M1.1(4.22), M1.2(4.28), M1.3(4.63), and M1.4(5.19). Poverty is statistically significant and associated with respiratory disease mortality in models M1.1(.56), M1.2(.54), M1.3(.52), and M1.4(.51). Smoking is statistically significant in models M1.1(2.04), M1.2(2.04), M1.3(2.05), and M1.4(2.03). These findings are consistent with prior literature has found about the predictors of respiratory disease.

Table 20 presents the results from the random effects models. In the random effects models, all levels of the coal-exposure measure are statistically significant and associated with respiratory disease mortality. All levels of the coal-exposure measure, quarter-mile (.16), half-mile (.14), one mile (.11) and two-mile (.08). Surface or underground coal production nor coal mining employment is statistically significant in all four models. The only non-time period covariate significant is smoking in models M2.1(.72), M2.2(.73), M2.3(.73), and M2.4(.73). These are consistent with prior scholarship linking smoking and respiratory disease. 
In the fixed effects models presented in Table 20, I find no statistically significant associations between any level of coal-exposure measure or coal production or employment. However, education in models M3.1(-.15), M3.2(-.15), M3.3(-.15) and M3.4(-.15) is statistically significant and associated with respiratory disease mortality. Poverty is statistically significant and associated with respiratory disease mortality in models M3.1(-.17), M3.2(-.17), M3.3(-.17), and M3.4(-.16). These results contradict findings in the prior literature regarding associations between poverty and education with respiratory disease mortality. Additionally, smoking rates are non-significant in all four fixed-effects models, counter to what prior scholarship has suggested. It should be noted that the fixed effects model all account for less than one percent of variance within counties $\left(\mathrm{R}^{2}=.004-.005\right)$. Thus, these much of the findings in these models suggest statistical noise and the little causal relationship between the factors and respiratory disease mortality.

These results suggest a link between coal mining occupation and respiratory disease mortality. This not surprising consider the long history of coal workers' pneumococcus in the coal mining regions. However, the potential environmental pollution risk from coal mining is not clear in these models. It is possible that the coal-exposure measure is picking up a higher concentration of coal miners living near coal mining sites. Thus, it is unclear if these results show an environmental health risk or just merely an occupational health risk. 


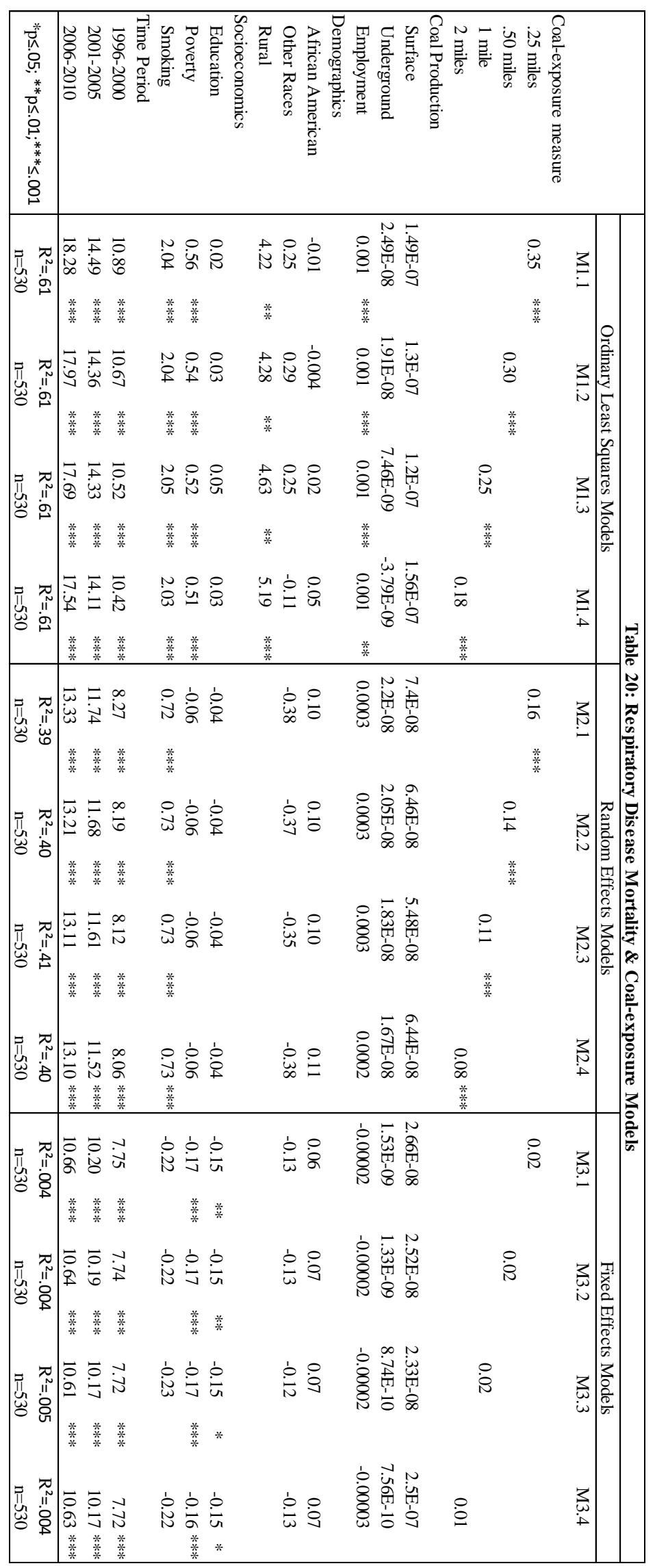




\section{Neurodegenerative Disease Mortality Models}

While links between all-cause, all-cancer, lung cancer and respiratory disease have support in the literature, there has been no scholarly working examining the relationship between neurodegenerative disease mortality and coal production. In Table 21 I examine the relationship between the coal-exposure measure, coal production and coal employment in an OLS, random effects and fixed effects models. In the OLS models, the coal-exposure measure at the quarter-mile (-.18), half-mile (-.16), one mile (-.14) and two-mile (-.12) are statistically significant. However, unlike the prior relationship with other mortality categories, these results suggest that increases in populations living near coal production significantly reduces mortality from the neurogenerative disease. The coal-exposure results are counter to the results for the surface coal production. In models M1.1(3.36E-07), M1.2(3.47E-07), M1.3(3.57E-07) and M1.4(3.43E-07) surface coal production are statistically significant and a positive association with neurodegenerative disease mortality, suggesting that coal production is a significant predictor of increased neurodegenerative disease mortality. Coal mining employment is statistically significant and negatively associated with neurodegenerative disease mortality in models M1.1(-.001), M1.2(-.001), M1.3(-.001) and M1.4(-.001). These results suggest that increases in coal mining employment decrease neurodegenerative disease mortality rates. Race is statistically significant in two of the four models, models M1.1(.35) and M1.2(.35). Rural status is the only non-time period covariate that is statistically significant and associated with neurodegenerative mortality rates in models M1.1(-10.55), M1.2(-10.57), M1.3(-10.72) and M1.4(-11.04). The OLS models suggest there is potentially a negative, statistically 
significant association between coal-exposure measure and neurodegenerative mortality rates. However, this relationship does not persist in other models.

Table 21 presents the results for the random-effects models. No level of the coalexposure measure is statistically significantly associated with neurodegenerative mortality rates. However, coal mining employment is statistically significant and associated with neurodegenerative disease mortality in models M2.1(-.04), M2.2(-.001), M2.3(-.001) and M2.4(-.001). These results suggest that increases coal mining employment potentially reduces neurodegenerative disease mortality rates. No other covariates other than time period measures are statistically significant. However, it should be noted that randomeffects models can account for $13 \%$ of between and within county variance. Similar results are found in the fixed-effects models.

The fixed-effects are presented in Table 21. All-levels of the coal-exposure measure is statistically non-significant. Neither surface or underground coal production is statistically significant and associated with neurodegenerative disease mortality. Coal mining employment, however, is statistically significant and negatively associated with neurodegenerative mortality. These results suggest that increases in coal mining employment reduce mortality from neurodegenerative mortality rates. All three models (OLS, random-effects, fixed-effects) suggest there is a limited connection between coal production, either in the coal-exposure measure or production. There is perhaps some connection between coal mining employment and reduction in neurodegenerative diseases. These results should be taken with a grain of salt, given much of the research surrounding neurodegenerative disease mortality is still growing, and there are limited environmental health studies examining links between neurodegenerative disease mortality. This study is 
fundamentally an ecological study, and thus many factors such as individual-level factors, such as genetics, family history, etc. cannot be accounted. 


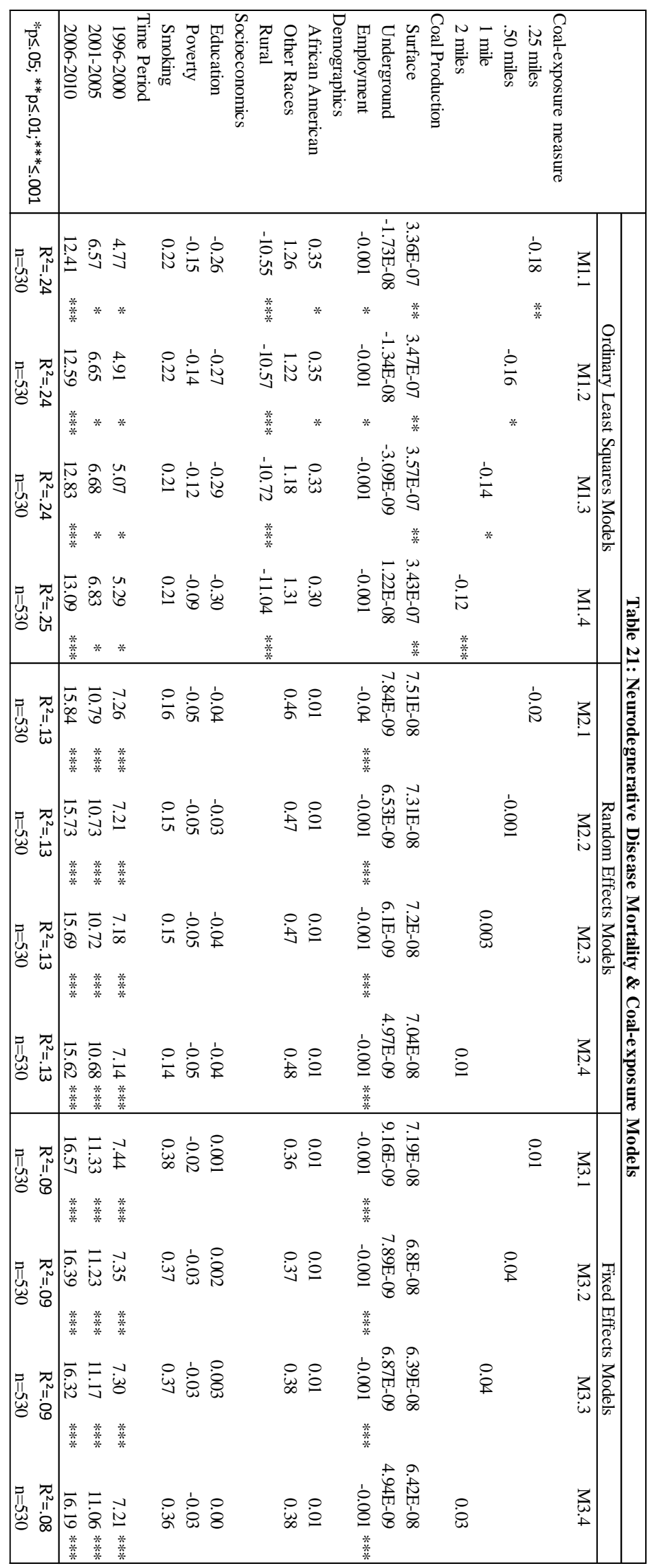




\section{Cardiovascular Disease Mortality Models}

Table 22 presents the OLS, random-effects and fixed-effects models. There is mixed support the models for a statistically significant association between coal-exposure measure and cardiovascular mortality rates. In the OLS model, only three of the coalexposure measures are statistically significant and associated with cardiovascular mortality rates (M1.2(.27), M1.3(.25), M1.4(.19). Coal production, underground or surface, and coal mining employment are not statistically significant in the OLS models. Rural status is statistically significant and associated with cardiovascular disease mortality in models M1.1(9.34), M1.2(9.16), M1.3(9.40) and M1.4(9.95). Poverty is statistically significant and associated with cardiovascular disease mortality in models M1.1(1.25), M1.2(1.19), M1.3(1.15), and M1.4(1.13). Smoking is statistically significant and associated with cardiovascular disease mortality in models M1.1(6.24), M1.2(6.27), M1.3(6.29) and M1.4(6.27). These results are similar to those found in prior literature.

In the random-effects model, there is no statistically significant association between cardiovascular disease mortality and any of the coal-exposure measure. Coal mining employment, however, is statistically significant and associated with cardiovascular disease mortality in models M2.1(.001), M2.2(.001), M2.3(.001) and M2.4(.001). Education is statistically significant and negatively associated with cardiovascular disease mortality in models M2.1(-.48), M2.2(-.48), M2.3(-.48) and M2.4(-.48). Increases in the population with less than eighth-grade education reduce cardiovascular disease mortality; this is counter to prior literature on the topic. Smoking is statistically significant and associated with cardiovascular disease in models M2.1(2.19), M2.2(2.18), M2.3(2.19), and M2.4(2.19). These results are consistent with prior literature. The random-effects models 
suggest no significant association between cardiovascular disease mortality and coal mining production or exposure, fixed-effects models have similar results.

In Table 22, presents the fixed-effect results for the cardiovascular mortality models. The same as the findings in the random-effects models, no level of the coalexposure measure is statistically significant. Neither surface nor underground coal production is associated with cardiovascular disease mortality rates. Coal mining employment is statistically significant and associated with cardiovascular disease mortality in models M3.1(.001), M3.2(.001), M3.3(.001) and M3.4(.001). The random-effects and fixed-effects models suggest a relationship between coal mining employment and cardiovascular disease mortality. Education is the only other non-time period that statistically significant and associated with cardiovascular disease mortality in models M3.1(-.81), M3.2(-.81), M3.3(-.81), and M3.4(-.81). These models suggest a complex relationship between coal mining and cardiovascular disease mortality. It is possible that the coal-exposure measure is best at explaining variation in cardiovascular disease mortality between counties, while coal mining employment can explain within-county variation. 


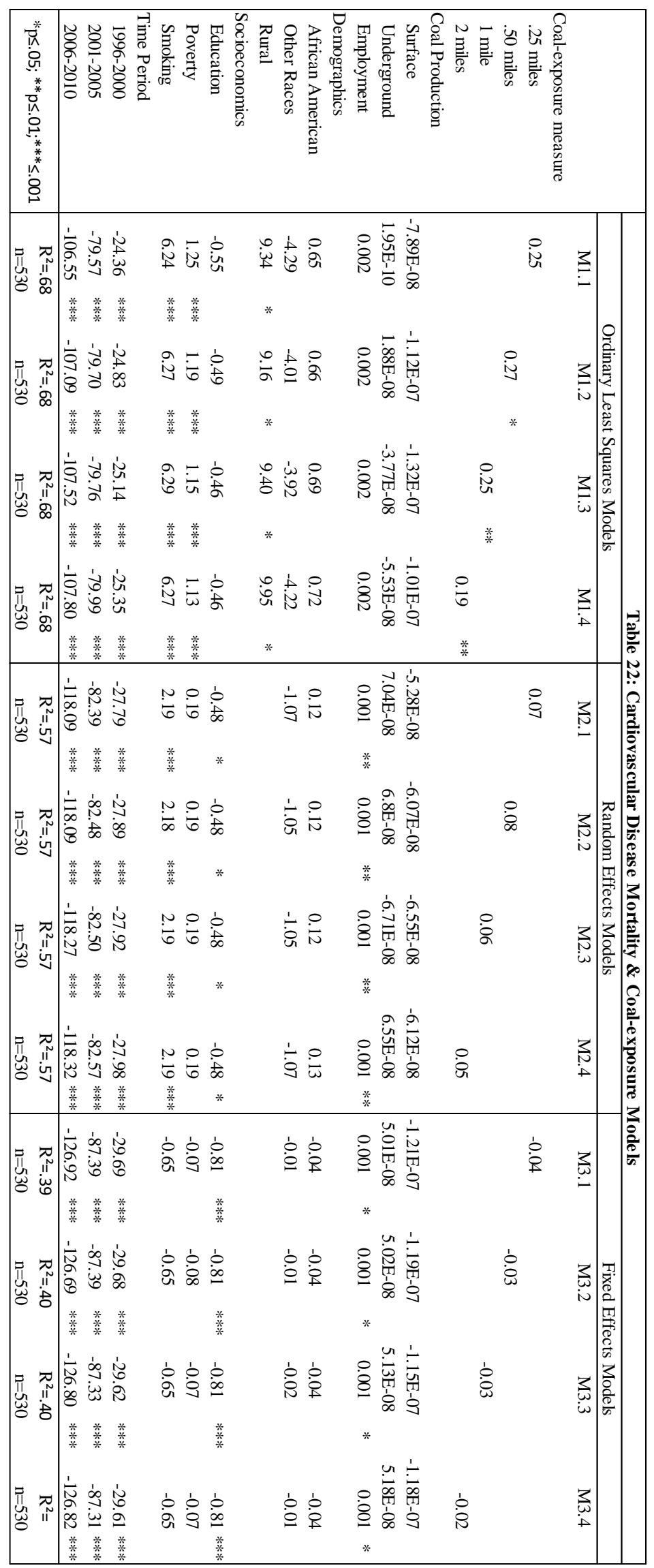




\section{Discussion}

The relationship between coal mining and mortality is complex. This study provides evidence that surface/mtr coal mining exposure is a potentially serious environmental health exposure issue. Five of the six models show that increases in the population exposed to surface/mtr coal mining increases mortality rates for all-cause, allcancer, lung cancer, respiratory disease, and cardiovascular disease mortality rates, thus confirming hypothesizes $\mathrm{H}_{3}$ and $\mathrm{H}_{4}$. However, this study fails to find a causal link between surface/mtr coal mining exposure and mortality rates over time thus hypothesis $\mathrm{H}_{5}$ is not confirmed. While these results point to serious environmental health risks associated with surface/mtr coal mining, there needs to be considerable caution taken in interpreting the findings.

There is a debate in the scholarly literature as to whether coal mining is associated with increased mortality rates. In a replication study of the work of Hendryx and Ahern (2009), Borak et al. (2012) find limited support for an independent relationship between coal mining and all-cause mortality rates in Appalachian counties. Boark et al. (2012)'s model was replicated by Hendryx \& Ahern (2012), and several inconsistencies were found, including instances of multicollinearity, unstable elements, and modeling issues. Buchanich et al. (2014) also find that all-cause mortality rates are not significantly associated with coal production. My study adds to this scholarly debate by incorporating environmental and geographic data into the modeling relationship. While the results in the air pollution models did not find a connection between coal mining and air pollution, they do point to the problems associated with air pollution even in a rural setting, suggesting that surface/MTR coal mining could be a major factor impacting mortality via air pollution 
if more robust data are available. In all coal-exposure models, except the neurogenerative disease models, mortality from all-cause, all-cancer, lung cancer, respiratory disease, and cardiovascular disease the measures of coal-exposure was statistically significant. These results suggest there is a strong association between coal-exposure and disease mortality rates in the Central Appalachian region. Thus, it is important to view these results within the larger body of literature.

The first scholarly work to examine county-level, all-cause mortality rates found highly productive coal mining counties have higher mortality rates than non-coal mining counties (Hendryx 2008). Building on this work, scholars have found that the all-cause mortality trends in coal mining counties are consistently higher than non-coal mining counties (Hendryx and Ahern 2009). While this work has been important in addressing if there is a relationship, there has been only a few scholarly attempts to move beyond and directly correlate environmental measures that are directly connected to pollution from mountaintop removal coal mining sites to mortality outcomes.

There has been little scholarly work attempting to incorporate environmental health measures of potential risk. Hitt and Hendryx (2010) examined stream pollution levels and respiratory, digestive, urinary and breast cancer rates. Hendryx, Fedorko \& AnesettiRothermel (2010) used an inverse-distance measure to coal mining sites as a proxy for environmental exposure and found statistically significant results with lung cancer. This study fills the gaps by creating a population-based coal mining exposure model. Thus, in many ways, this is a novel technique for attempting to understand the relationship between coal mining and mortality risks. 
Coal mining in the Appalachian region is environmentally destructive and has created serious ecological harms to local environment including hydrological impacts (Vengosh et al. 2013; Evans et al. 2015), polluting of surrounding streams and groundwater (McAuley \& Kazor 2006; Lindberg et al. 2011), reduced air quality (Aneja, Isherwood \& Morgan 2012; Kruth et al. 2014) and drastic changes in the topography of the land (Wickham et al. 2013; Ross, McGlynn \& Bernhardt 2016). These environmental harms have serious implications for human health in the Appalachian region. This study finds that counties with a higher population living near mountaintop and surface coal mining sites have higher mortality rates for all-cause, all-cancer, lung cancer, respiratory and cardiovascular mortality rates. This study confirms what other scholars have found in regards to the association between coal mining and mortality from respiratory disease (Hendryx 2009; Hendryx \& Holland 2016), lung cancer (Hendryx, O’Donnell \& Horn 2008; Hendryx, Fedorko \& Anesetti-Rothermel 2010; Hendryx \& Holland 2016), and cardiovascular disease (Esch \& Hendryx 2011). However, while this study confirms much of the literature regarding the relationship between coal production and coal mining, it provides some contradictory and conflicting findings regarding neurodegenerative disease mortality.

There is evidence that air pollution, particularly particulate matter, is associated with neurodegenerative-related diseases and mortality (Kettunen et al. 2007; Block \& Calderon-Garciduenas 2009; Levesque et al. 2011). However, the results from this study suggest there is little predictive power in coal mining and neurodegenerative mortality rates at the county level. Additionally, given the limited understanding of how different types of neurodegenerative diseases are transmitted, including by genetics, environmental, socio- 
cultural, and behavioral factors, these results should be taken with caution. The current evidence of environmental factors impacting neurodegenerative diseases is inconclusive at best (Brown, Lockwood \& Sonawane 2005). Additional, this study is fundamentally limited by being an ecological study, measuring factors at the population-level. In order to get a clear picture of the relationship between environmental factors and neurodegenerative disease mortality, it would be best to conduct an individual-level analysis with more direct measures of exposure to coal mining pollution, for example, air quality samples in or around their homes. Ecological studies can only tell you about factors which we have to measure at the county-level. Thus, this limits our understanding of if there is a causal relationship between environmental factors and neurodegenerative disease mortality. Future research could use mixed-level modeling techniques to incorporate both community (county/state) level factors with individual-level data. Thus, in this study, while there are statistically significant results, they should be considered with a considerable grain of salt.

\section{Study Limitations}

This study is ecological in its nature and design, which limits the ability for the study to provide causal explanations for environmental health processsses. Thus, while the results do suggest coal mining exposure can explain cross-county differences, there are limitations in the ability of the fixed-effects models to provide causal explanations. The biological causes of many diseases, such as neurodegenerative diseases, cannot all be explained by environmental factors. Thus, it is difficult to account for every potential causal pathway. Thus, there are missing controls in the model to isolate purely environmental factors. The current study is a population-level analysis, examining mortality rates at the county-level versus measuring at the individual level. In this case, 
there are potential limitations regarding unmeasured factors in, within and between the counties that may not be measured by any dataset. This study is limited by the availability of data over a long period of time.

There is currently in adequate data to measure the length of potential population exposure to environmental risks. As with many regions in the United States, the population in Appalachia is mobile and people move in and out of the region frequently. Thus, it can be difficult to assess potential exposure to environmental harms associated with coal mining. Future research will need to attempt to address this selection issue.

There are multiple data sources that are not available before the 1990 period or are inaccessible to the public and thus unavailable for this study. Publicly available coal mining data are not available before 1989 in the three states in the study area (Kentucky Coal Facts, 2017). The National Land Cover Database (NLCD) is only available from 1992 to 2011, thus limiting the ability to estimate the mining area extent before 1992 (U.S. Geological Survey 2012). It also should be noted that compared to underground coal mining, surface/mtr coal mining is rather a recent phenomenon, starting in the late 1970's, but hitting its pick in the late 1990's and early 2000's (Hendryx \& Holland 2010). These factors may limit the fixed-effects models' ability to pick up long-term impacts associated with the increased surface/mtr coal mining in many of these communities.

This study uses population data and, as such, the data is subject to different interpretation than working using samples. Given p-values are typically used for sample data, in these two-study p-values are used as a supportive measure. P-values are testing a certain measure is statistically significant from the null hypothesis which is that if I were to take random samples from the entire population what is the probability that I would not 
find a similar pattern. Thus, when the sample is instead the entire population, as in the air quality and coal-exposure study, the p-value losses it's meaning significantly. These results should be taken with a grain of salt. 


\section{IMPLICATIONS \& CONCLUSION}

In the 2016 U.S. presidential elections, the fate of the coal industry, particularly in the Appalachian regions of West Virginia, Pennsylvania, Ohio, Virginia, and Kentucky, became a political issue, with multiple politicians, including future President Trump, offering to bring back the downtrodden industry (Krauss \& Corkery 2016). The election of President Trump has led to the rollback of many Obama-era regulations regulating the coal industry, including the stream protection rule (Henry 2017) and the Clean Power Plan (DiChristopher 2017). Despite these changes in regulations, preliminary data suggest that coal production has increased little and employment has continued to decline, and longterm projections suggest coal production and employment will continue to decline (Kentucky Energy and Environment Cabinet 2017). The political debate surrounding the coal industry focused almost exclusively on the economic impact of coal mining while leaving little room for discussion regarding environmental health impacts of coal mining.

Popular discussion of the coal industry has focused on the fact that the coal industry historically has employed a larger number of people in a very poor and rural region of the United States, specifically Appalachia. However, little consideration is given in the popular press about the significant health impacts of coal production. This study confirms what prior research suggests regarding the relationship between coal production, in particular, living near or around surface/mtr coal mining facilities, increases the risk of mortality, particularly from causes such as cancer. The relatively little attention given to the potential health hazards of coal production is perhaps the result of the limited, and sometimes, conflicting nature of the current literature on coal production's impact on health and 
mortality. Less than twenty-five peer-reviewed studies exist examining health outcomes (hospitalization, mortality rates, self-rated health, etc.) and coal production in the Appalachian region. Many of these studies are limited by the availability of data only at population levels such as county or state. Most recently the Trump administration defunded a study being conducted by the National Academy of Sciences examining the health risks for residents near surface coal mining sites in Appalachia (Fears 2017). Studies like the National Academy of Sciences study are attempts to provide some clarity in the scholarly community about the exact nature of the relationship between coal mining and population health.

This project is an attempt to fill the gaps left in the literature regarding the nature of the relationship between surface/mtr coal mining and mortality in the Appalachian region. Given the relatively lengthy limitations in doing this type of work, I employ innovative and previously unused data and techniques to uncover the relationships between living near surface/mtr coal mining sites and mortality rates. My results suggest that crosscounty differences in mortality rates within the Appalachian region can in part be explained by differences in the relative risk associated with surface/mtr coal mining. However, the long-term effects, at this point, cannot be properly assessed with the given data. Despite the limitations, the results of this study point to a larger pattern that other scholars have noticed about resource-rich regions like Appalachia.

\section{Appalachian Coal Mining in Context}

Coal production in the Appalachian region has fueled the American and global economy for well over a century (Eller 2008). However, social, and environmental consequences have been left in the wake. Higher rates of all-cause mortality and disease- 
specific mortality are an externality of the natural resource-based economy, thus provides more supporting evidence of an Appalachian-specific natural resource curse. Famous Appalachian scholar Helen Lewis coined the idea that Appalachia was an internal colony of the United States in her seminal work "Colonialism in Modern America: The Appalachian Case" (1978). For Helen and other Marxian Appalachian scholars, the natural resource economic model, with foreign ownership of the means of production and natural resource industries (In the Appalachian context, coal mines and railroads owned by companies based in Eastern coastal and Midwestern states.), was the model they saw in Appalachian history with the introduction of the coal industry in the late 1800's into the region (Lewis 1978). This colonial model closely mirrors the model laid out by scholars examining the natural resource curse (Antry 1993). Appalachia is and remains a region whose fate is intimately tied to the coal industry. Thus, it should be no surprise that the dominant industry impacts the health and well-being of the region.

Allan Schnaiberg (1980) argues that capitalist societies seek to increase their rate of growth at the expense of the natural and social world. Capitalist societies seek to expand the production of goods and services, monopolize production processes within society and increase the capital intensity of production (Schnaiberg 1980). Appalachia in many ways serves as a textbook example of Schnaiberg's thesis. In the case of Appalachia, the region has served as a place for the extraction of natural resources to fuel expanded production of industrial output, first in the form of steel production, electricity production, and other industrial uses, but later migrating to mainly the production of electricity in the late twentieth century (Eller 2008). 
Schnaiberg (1980) argues that the "Treadmill of Production" is created by the constant need for capitalists to continually increase production and reduce labor production in the industrial process. Thus, capitalists invest heavily in capital-intensive technologies to replace workers, and these technologies involve the depletion of natural resources and have ecological and social harms. In the Appalachian context, mountaintop removal coal mining is a golden example of such process. MTR coal mining requires significant investment in heavy machinery, explosives, and land acquisition; it also reduces labor employment compared to traditional underground coal mining. They then seek to increase the mining of coal dramatically and reduces the costs, such as labor and environmental remediation.

This process began in earnest in the 1970's, exceptions in the Clean Air Act allowed grandfathering in new coal-fired power plants, which increased demand for Appalachian low-sulfur coal, which produces less dirty air emissions than high sulfur coal found in other regions (Hendryx \& Holland 2016). This boom in the already exhausted coal fields of the Appalachian region, new techniques (mountaintop removal coal mining) was needed to retrieve the less desirable seams of coal (Hendryx \& Holland 2016). Thus, mountaintop removal coal mining is the results of the constant "Treadmill of Production" in the Appalachian and United States context, which has sought to increase production at the expense of labor and the environment.

Mountaintop removal coal mining has left ecological scars on the landscape of the Appalachian region, from hydrological impacts (Vengosh et al. 2013; Evans et al. 2015), polluting of streams and groundwater (McAuley \& Kazor 2006; Lindberg et al. 2011), reduced air quality (Aneja, Isherwood \& Morgan 2012; Kruth et al. 2014) to drastic 
changes in the topography of the land (Wickham et al. 2013; Ross, McGlynn \&

Bernhardt 2016). The environmental consequences have extended beyond the natural environment and into the sphere of human health. My study, along with those conducted by others, find that coal mining has a deleterious impact on mortality, with increases in all-cause (Hendryx 2008; Hendryx \& Ahern 2009), lung cancer (Hendryx, O’Donnell \& Horn 2008; Hendryx, Fedorko \& Anesetti-Rothermel 2010; Hendryx \& Holland 2016) and respiratory mortality (Hendryx \& Holland 2016) in Appalachian coal mining counties.

\section{Future Directions}

This research study is fundamentally hampered by two major factors, the level of analysis and the limitations of the data. Most publicly available health data are only available at the county-level. Individual-level death records require approval and use by the National Center for Health Statistics, which can take up to three years or more. Thus, they were not considered for use in this project. However, future research should examine individual-level data to construct far more robust analyses. The National Center for Health Statistics has worked to link the NDI records with several other national surveys of health. Thus it will be important to explore these new data sources (National Center for Health Statistics 2016). Another important route is the use of administrative data.

Scholars are increasingly utilizing federal government administrative records, largely from the Social Security Administration and the Centers for Medicaid and Medicare to analyze health and mortality better. For example, using Medicare records matched to Social Security death records, Sarah Taylor (2013) found higher rates of mortality for those over the age of 65 in steel production towns than those in the same age group in non-steel 
production towns in Pennsylvania. Projects like this are opening up the possibility of finding causal pathways for environmental factors and mortality beyond population-level data.

While much work has been done using dichotomous and ordinal level measures, future research should also examine linear measures of coal production as I have done in the paper. A potential way to modify the measure would be to subtract the mean coal production and thus measuring the standard deviations of coal production. This would be used specifically in the random and fixed effects models so that you could parse out the between county effects.

While individual-level analysis is important, it is appropriate to include multi-level and mixed models into future research. While my studies assume of a linear relationship between mortality rates and coal production, exposure to coal mines impacts mortality rates through environmental exposure. However, considering there is evidence of a "Natural Resource Curse" and Treadmill of Production in the Appalachia, perhaps it is the social factors (poverty, education, etc.) (Black, McKinnish \& Sanders 2005; Hendryx 2010; Deaton \& Niman 2011) that are the mediating factor between coal production and mortality. Another possibility is that the level of social disadvantage is connected to health that the additional burden of environmental health risk has diminished returns. These are topics for serious consideration for future research.

\section{Policy Implications of the Study}

My research confirms the work of other scholars, in finding a strong systematic relationship between coal mining production and mortality rates in the Appalachian region. While far from exhaustive, the body of literature as it currently stands, with the addition of 
this project, warrants serious policy considerations. While the coal industry continues to decline in many parts of the United States, in part due to the competition from natural gas, the environmental impacts will have long-lasting impacts on the environment and health of the Appalachian region. Thus, serious policy solutions should be considered to remedy the negative externalities that coal production has produced. However, the political climate may pose a serious challenge to the enactment of such policies.

In the Obama Administration, serious efforts were taken to attempt to address the problems associated with coal production and the burning of fossil fuels, including the enactment of the Stream Protection Rule, the Clean Power Plan, and the signing of the Paris Climate Accords (Eilperin \& Dennis 2017). However, the Trump Administration in early 2017 started the rollback of many of the Obama administration environmental policies, including the Clean Power Plan, that was. Given the uncertain political climate and growing hostility in the U.S. government to environmental policies and the increased role of energy industries in the policymaking process, more regulations to remediate and eliminate the impacts of the coal industry should not be expected.

While the current political environment may not be hospitable towards changing environmental policies, my research suggests that changing environmental policies could change can health outcomes. The coalfields of the Appalachian region are one of the most unequal places in the United States, with high rates of poverty, unemployment and low levels of education, poor health in almost every way you can measure, and environmental destruction has ravaged the region. A recent report conducted by the Population Reference Bureau finds that the Appalachian region, in particular, the Central Appalachian sub region, which consists of eastern Kentucky, West Virginia, and southwest Virginia have not 
recovered at the same rate as the nation from the 2008 recession (Pollard \& Jacobson 2017). Using data from the 2011-15 American Community Survey, Pollard and Jacobson found that the Appalachian region remains behind the nation in unemployment, poverty rates and disability status (Pollard \& Jacobson 2017). While the unemployment rate in the whole Appalachian region is the same as the national rate in the $2011-15$ time period $(6.9 \%)$, the Central Appalachian sub region was more than two points above the national rate $(8.6 \%)$. Median household income in the Appalachian region is $\$ 60,525$, nearly $\$ 6,000$ less than the United States rate, the rate in Central Appalachia is more than $\$ 28,000(\$ 47,535)$ less than the United States rate (Pollard \& Jacobson 2017).

The higher unemployment and lower household income levels make it unsurprising that the Central Appalachian region lags the national in a reduction in poverty. The Appalachian poverty rate in $2011-15(17.1 \%)$ is slightly higher than the national rate (15.5\%). However, in the Central Appalachian subregion, almost one in four people live below the poverty line (24.4\%). One in three children (33.4\%) in the Central Appalachian sub region lives in poverty compared to one in four (24.4\%) for the whole Appalachian region and one in five for the United States $(21.7 \%)$. Poverty rates remain high the in the Central Appalachian region; this is also a region where high rates of disability exist as well. The Appalachian regions disability rate $(15.9 \%)$ is slightly higher than the United States (12.4\%). However, in the Central Appalachian sub region more than one in five are disabled (23.4\%). Disability rate is nearly double the rate of the United States (Pollard \& Jacobson 2017). Appalachia has been and remains a region of deep social, economic and health inequality in the United States. 
The high price of inequality continues to perplex policymakers both at the state and federal level. While programs such as the Appalachian Region Commission (Eller 2008) have promised to fight a war on the high poverty and inequality in the region, there has been little progress in bringing the region within striking distance of the nation. Adding to the complexities is the environmental inequality and destruction that will be left behind long after the last ton of coal has been mined. Coal mining has long been the dominant industry in Central Appalachia for nearly 100 years. However, over the last decade, coalfired electricity generation has declined. In 2008 coal represented $48 \%$ of total electricity generated in the United States, by 2016 less than $30 \%$ of electricity generated was from coal (Energy Information Administration, 2017). Coal mining employment has continued to decline. Currently national coal mining employment is at the lowest level since the government began collecting statistics began on coal mining employment (Karlstad 2017). As coal continues to decline, the repercussion will continue to be felt throughout the region and the nation. The decline in the coal industry will impact the ability of state and local governments to address crucial health and quality of life issues in the region.

As the coal industry has declined, so have the revenues generated by the taxes on coal mining (coal severance taxes), local income and property taxes (Bailey 2013). Coal severance taxes have been used to fund local emergency medical services, community centers, libraries, ambulances and fire trucks, water and sewer projects, medical school scholarships, parks among many others (Baiey 2013). Many communities have regularly used these taxes to plug budget holes and provide important community social and health services. As these taxes decline with a continued decline in coal production and employment, communities will find it difficult to continue to survive (Estep 2017). The 
ability for these communities to deal with the serious long-term implications of coal mining, long after the coal has all been mined, is seriously harmed by the decline in the industry.

Coal mining will have a long-lasting scar on the Appalachian region. This study project has exposed some of the scars on the region. All of the evidence points to the fact that coal mining will have a long-lasting impact on the Appalachian region far beyond the moment the last coal train rolls out of the mountains. Coal mining will have a long arm into the future of the Appalachian region. 


\section{REFERENCES:}

“About NHGIS.” 2016. National Historic Geographic Information System. Retrieved on November 21, 2016. (https://www.nhgis.org/user-resources/project-description).

“About Skytruth.” 2016. SkyTruth. Retrieved on November 21, 2016. (http://skytruth.org/about/).

Ahern, Melissa and Michael Hendryx. 2012. "Cancer mortality rates in Appalachian mountaintop coal mining areas." Journal of Environmental Occupational Science. $1(2): 63-70$.

Allison, Paul D. 2009. Fixed Effects Regression Models. SAGE Publications, Thousand Oaks, CA.

Amandus, H.E., M.R. Petersen and T.B. Richards. 1989. "Health Status of Anthracite Surface Coal Miners." Archives of Environmental Health. 44(2):75-81.

Analitis, Antonia, Klea Katsouyanni, Konstantina Dimakopoulou, Evangelia Samoli, Aristidis K. Nikolulopoulos, Yannis Petasakis, Giota Touloumi, Joel Schwartz, Hugh Ross Anderson, Koldo Cambra, Francesco Forastiere, Denis Zmirou, Judith M. Vonk, Luke Clancy, Bohumir Kriz, Janos Bobvos and Juha Pekkanen. 2006. "Short-term Effects of Ambient Particles on Cardiovascular and Respirtory Mortality.” Epidemiology. 17(2):230-233. 
Anderson, Jonathan O., Josef G. Thundiyil and Andrew Stolbach. 2012. "Clearing the Air: A Review of the Effects of Particulate Matter Air Pollution on Human Health.” Journal of Medical Toxicology. 8:166-175.

Anderson, Roger T., Tse-Chang Yang, Stephen A. Matthews, Fabian Camacho, Teresa Kern, Heath B. Mackley, Gretchen Kimmick, Christopher Louis, Eugene Lengerich, and Nengliang Yao. 2014. "Breast Cancer Screening, Area Deprivation, and Later-Stage Breast Cancer in Appalachia: Does Geography Matter?" Health Services Research. 49(2):1475-6773.

Aneja, Viney P., Aaron Isherwood and Peter Morgan. 2012. "Characterization of Particulate Matter (PM10) related to surface coal mining operations in Appalachia." Atmospheric Environment. 54:496-501.

“Annual Coal Report.” 2015. U.S. Energy Information Administration, U.S. Department of Energy, Washington, D.C. (https://www.eia.gov/coal/annual/pdf/acr.pdf).

“Counties in Appalachia.” 2016. Appalachian Regional Commission: Washington, D.C. (https://www.arc.gov/counties).

Autry, Richard M. 1993. "Sustainable Development in Mineral Economies: The Resource Curse Thesis.” Routledge, New York, NY.

Bailey, Jason. 2013. "Investing in a Future for Appalachian Kentucky: The Coal Severance Tax.” Kentucky Center for Economic Policy: Berea, KY. Retrieved on November 11, 2017.

(http://www.kypolicy.us/sites/kcep/files/Coal\%20Severance\%20Presentation.pdf) 
Barnett, Elizabeth, Joel A. Halverson, Gregory A. Elmes and Valerie E. Braham. 2000. "Metropolitan and Non-Metropolitan Trends in Coronary Heart Disease Mortality within Appalachia, 1980-1997." Annals of Epidemiology. 10:370-379.

Behringer, Bruce and Gilbert H. Friedell. 2006. "Appalachia: Where Place Matters in Health." Preventing Chronic Disease. 3(4).

Bernhardt, Emily S., Brian D. Lutz, Ryan S. King, John P. Fay, Catherine E. Carter, Ashley M. Helton, David Campagna and John Amos. 2012. "How Many Mountains Can We Mine? Assessing the Regional Degradation of Central Appalachian Rivers by Surface Coal Mining.” Environmental Science \& Technology. 46:8115-8122.

Betz, Mike, Mark D. Partridge, Michael Farren, and Linda Labao. 2015. "Coal Mining, Economic Development and the Natural Resource Curse.” Energy Economics. 50:105-116.

Bhatnagar, Aruni. 2006. "Environmental Cardiology: Studying Mechanistic Links Between Pollution and Heart Disease." Circulation Research. 99:693-705.

Black, Michelle L., and Lilian Calderon-Garciduenas. 2009. "Air pollution: mechanisms of neuroinflammation and CNS disease." Trends in Neurosciences. 32(9);506516.

Black, Dan A., Terra G. McKinnish and Seth G. Sanders. 2005. "Tights Labor Markets and the Demand for Education: Evidence from the Coal Boom and Bust." Industrial and Labor Relations Review. 59(1):3-16. 
Blackley, David, Bruce Behringer and Shimin Zheng. 2012. "Cancer Mortality Rates in Appalachia: Descriptive Epidemiology and an Approach to Explaining Differences in Outcomes." Journal of Community Health. 37:804-813.

Block, Michelle L, and Lilian Calderon-Garciduenas. 2009. “Air pollution: mechanisms of neuroinflammation and CNS disease." Trends in Neurosciences. 32(9): 506516.

Borak, Jonathan, Catherine Saltpante-Zatdel, Martin D. Slade and Cheryl A. Fields. 2012. “Mortality Disparities in Appalachia.” Journal of Occupational and Environmental Medicine. 54(2):146-156.

Brabin, Bernard, Mary Smith, Paul Milligan, Christopher Benjamin, Eithne Dunne and Michael Pearson. 1994. "Respiratory morbidity in Merseyside schoolchildren exposed to coal dust and air pollution." Archives of Disease in Childhood. 70:305312.

Brink, LuAnn L., Evelyn O. Talbott, Shaina Stacy, Lynne P. Marshall, Ravi K. Sharma and Jeanine Buchanich. 2014. "The Association of Respiratory Hospitalizations Rates in WV Counties, Total, Underground, and Surface Coal Production and Sociodemographic Covariates." Journal of Occupational and Environmental Medicine. 56(11):1179-1188.

Brown, Rebecca C., Alan H. Lockwood, and Babasaheb R. Sonawane. 2005. "Neurodegenerative Diseases: An Overview of Environmental Risk Factors." Environmental Health Perspectives. 113:1250-1256. 
Bruggers, James. 2016. "Appalachian coal mining to continue free fall.” The Louisville Courier-Journal, July 8, online. Retreieved November 2, 2017. (http://www.courierjournal.com/story/tech/science/environment/2016/07/08/appalachian-coal-miningcontinue-free-fall/86849370/).

Buchanich, Jeanine, Lauren C. Balmert, Ada O. Youk, Shannon M.Woolley and Evelyn O. Talbott. 2014. "General Mortality Patterns in Appalachian Coal-Mining and Non-Coal-Mining Counties." Journal of Occupational \& Environmental Medicine. 56(11):1169-1178.

Castranova, Vincent and Val Vallyathan. 2000. "Silicosis and Coal Workers' Pneumoniosis." Environmental Health Perspectives. 108(4):675-684.

“CDC WONDER.” 2017. Center for Surveillance, Epidemiology , and Laboratory Services. Centers for Disease Control and Prevention: Atlanta, GA. Retrieved on November 2, 2017. (https://wonder.cdc.gov/wonder/help/about-cdc-wonder508.pdf).

Centers for Disease Control and Prevention. 2000. "Measuring Health Days." U.S. Department of Health and Human Services, Centers for Disease Control: Atlanta, GA. Retrieved on November 11, 2016. (http://www.cdc.gov/hrqol/pdfs/mhd.pdf). Center for Regional Economic Competitiveness. 2014. "Statistical Portrait of Economic Diversity in Appalachia.” Appalachian Regional Commission: Washington, D.C.. (http://www.arc.gov/assets/research_reports/EconomicDiversityinAppalachiaStatisticalPortraitofEconomicDiversityinAppalachia.pdf). 
Chaulya, S.K. 2004. "Assessment and management of air quality for an opencast coal mining area." Journal of Environmental Management. 70:1-14.

Chapman, Robert S., William P. Watkinson, Kevin L. Dreher and Daniel L. Costa. 1997. "Ambient particulate matter and respiratory and cardiovascular illness in adults: particulate-borne transition metals and the heart-lung axis." Environmental Toxicology and Pharmacology. 4: 331-338.

Christian, W. Jay, Bin Huang, John Rinehart and Claudia Hoppenhayn. 2011. "Exploring Geographic Variation in Lung Cancer Incidence in Kentucky Using a Spatial Scan Statistic: Elevated Risk in the Appalachian Coal-Mining Region." Public Health Reports. 126: 789-796.

Crosby, L, C. Tatu, and K. Charles. 2016. "Lung and Bronchus Cancer Deaths in Boone County, WV Before and After Mountaintop Removal Mining." Journal of Rare Disorders: Diagnosis \& Therapy. 2(1):35.

Coggon, David and Anthony Newman Taylor. 1998. "Coal mining and chronic obstructive pulmonary disease: a review of the evidence." Thorax. 53:398-407.

Copeland, Claudia. 2015. "Mountaintop Mining: Background on Current Controversies." Congressional Research Service: Washington, D.C.

Cossman, Jeralynn Sittig, Ronald E. Cossman, Wesley L. James, Carol R. Campbell, Troy C. Blanchard and Arthur G. Cosby. 2007. "Persistent Clusters of Mortality in the United States.” American Journal of Public Health. 97(12):2148-2150. 
Cutlip, Kimbra. 2016. "Impact Story: SkyTruth Measures Advance of Mountaintop Destruction in Appalachia.” SkyTruth. Retrieved on November 21, 2016. (http://skytruth.org/2016/06/skytruth-mountain-top-removal-analysis/).

Deaton, B. James and Ekaterina Niman. 2012. “An empirical examination of the relationship between mining employment and poverty in the Appalachian region." Applied Economics. 44:303-312.

DeStefano, Frank, Robert F. Anda, Henry S. Kahn, David F. Williamson and Carl M. Russell. 1993. "Dental disease and risk of coronary heart disease and mortality." BMJ. 306:688-91.

DiChristopher, Tom. 2017. “Trump signs executive order to roll back Obama-era climate actions, power plant emissions rule." CNBC.com, March 27. Retrieved on November 5, 2017. (https://www.cnbc.com/2017/03/27/trump-to-roll-backobama-climate-actions-power-plant-emissions-rule.html)

Dockery, Douglas W., C. Arden Pope III, Xiping Xu, John D. Spengler, James H. Ware, Martha E. Fay, Benjamin G. Ferris and Frank E. Speizer. 1993. “An Association Between Air Pollution and Mortality in Six U.S. Cities.” The New England Journal of Medicine. 24(239): 1753-1759.

Dominici, Francesca, Roger D. Peng, Michelle L. Bell, Luu Pham, Aidan McDermott, Scott L. Zeger and Jonathan M. Samet. 2006. "Fine Particulate Air Pollution and Hospital Admission for Cardiovascular and Respiratory Diseases." Journal of American Medical Association. 295(10):1127-1134. 
Donaldson, Ken, David Brown, Anna Clouter, Rodger Duffin, William MacNee, Louise Renwick, Lang Tran, and Vicki Stone. 2002. "The Pulmonary Toxicology of Ultrafine Particles.” Journal of Aerosol Medicine. 15:213-220.

Dos S Antao, V.C., E.L. Petsonk, L.Z. Sokolow, A.L. Wolfe, G.A. Pinheiro, J.M. Hale and M.D. Attfield. 2005. "Rapidly progressive coal workers' pneumoconiosis in the United States: geographic clustering and other factors." Occupational Environmental Medicine. 62:670-674.

Douglas, Stratford and Anne Walker. 2016. "Coal Mining and the Resource Curse in the Eastern United States.” Journal of Regional Science. Online First.

Dwyer-Lingren, Laura, Ali H. Mokdad, Tanja Srebotnjak, Abraham D. Flaxman, Gillian M. Hanson and Christopher JL Murray. 2014. "Cigarette smoking prevalence in US counties: 1996-2012.” Population Health Metrics. 12(5).

Dwyer-Lindgren, Laura, Amelia Bertozzi-Villa, Rebecca W. Stubbs, Chloe Morozoff, Michael J. Kutz, Chantal Huynh, Ryan M. Barber, Katya A. Shackelford, Johan P. Mackenbach, Frank J. van Lenthe, Abraham D. Flaxman, Mohsen Haghavi, Ali H. Mokdad and Christopher J.L. Murray. 2016. "US County-Level Trends in Mortality Rates for Major Causes of Death, 1980-2014.” Journal of American Medical Association. 316(22):2385-2401.

Eftim, Sorina E., Jonathan M. Samet, Holly James, Aidan McDermott and Francesca Dominici. 2008. "Fine Particulate Matter and Mortality: A Comparison of the Six Cities and American Cancer Society Cohorts With a Medicare Cohort.” Epidemiology. 19(2):209-216. 
Eilperin, Juliet and Brady Dennis. 2017. "Trump moves decisively to wipe out Obama's climate change record." The Washington Post, March 28. Retrieved online November 5, 2017. (https://www.washingtonpost.com/national/healthscience/trump-moves-decisively-to-wipe-out-obamas-climate-changerecord/2017/03/27/411043d4-132c-11e7-9e4f-09aa75d3ec57_story.html)

Eller, Ronald D. 2008. “Uneven Ground: Appalachia since 1945.” The University Press of Kentucky: Lexington, KY.

Esch, Laura and Michael Hendryx. 2011. "Chronic Cardiovascular Disease Mortality in Mountaintop Mining Areas of Central Appalachian States.” The Journal of Rural Health. 42:350-357.

Estep, Bill. 2017. "Historic coal towns are fighting to survive. Could three of them merge into one?." The Lexington Herald-Leader, October 26. Retrieved on 11/7/2017. (http://www.kentucky.com/news/state/article181032761.html).

Evans, Daniel M., Carl E. Zipper, Erich T. Hester, and Stephan H. Schoenholtz. 2015. "Hydrologic Effects of Surface Coal Mining in Appalachia." Journal of the American Water Resources Association. 51(5):1436-1452.

Fears, Darryl. 2017. “Trump administration halted a study of mountaintop coal mining's health effects." The Washington Post, August 21. Retrieved on November 5, 2017. (https://www.washingtonpost.com/news/energyenvironment/wp/2017/08/21/trump-administration-halted-a-study-ofmountaintop-coal-minings-health-effects/) 
Fisher, James L., Holly L. Engelhardt, Julie Stephens, Bette R. Smith, Georgette G. Haydu, Robert W. Indian and Electra D. Paskett. 2008. “Cancer-related Disparities among Residents of Appalachian Ohio.” Journal of Health Disparities Research and Practice. 2(2):61-74.

Fry, Joyce A., George Xian, Suming Jin, Jon A. Dewitz, Collin G. Homer, Limin Yang, Christopher A. Barnes, Nathaniel D. Herold and James D. Wickham. 2011. "National Land Cover Database for the Conterminous United States." Photogrammetric Engineering \& Remote Sensing. 77(9):858-866.

Ghose, M.K. and S.R. Majee. 2000. "Assessment of the impact on the air environment due to opencast coal mining - an Indian case study." Atmospheric Environment. 2791-2796.

Graber, Judith M., Leslie T. Stayner, Robert A. Cohen, Lorraine M. Conroy, and Michael D.Attfield. 2014. "Respiratory disease mortality among US coal miners; results after 37 years of follow-up.” Occupational Environmental Medicine. 71:30-39.

Gorsuch, Marina Mileo, Seth G. Saunders and Bei Wu. 2014. “Tooth Loss in Appalachia and the Mississippi Delta Relative to Other Regions in the United States, 19992010." American Journal of Public Health. 104(5):e85-e91.

Goodell, Jeff. 2006. “Big Coal: The Dirty Secret Behind America's Energy Future.” Houghton Mifflin Company, New York, NY.

Griswold, Eliza. 2017. "The Future of Coal Country." The New Yorker, July 3. Retrieved on November 5. (https://www.newyorker.com/magazine/2017/07/03/the-futureof-coal-country). 
Hamra, Ghassan B., Neela Guha, Aaron Cohen, Francine Laden, OleRaaschou-Nielsen, Jonathan M. Samet, Paolo Vineis, Francesco Forastiere, Paulo Saldiva, Takashi Yorifuji, and Dana Loomis. 2014. “Outdoor Particulate Matter Exposure and Lung Cancer: A Systematic Review and Meta-Analysis.” Environmental Health Perspectives. 122:906-911.

Hales, Simon, Tony Blakely and Alistair Woodward. 2010. “Air pollution and mortality in New Zealand: cohort study.” Journal of Epidemiology \& Community Health. Online First.

Hall, H. Irene, Joseph D. Rogers, Hannah K. Weir, Daniel S. Miller and Robert J. Uhler. 2000. "Breast and Cervical Carcinoma Mortality among Women in the Appalachian Region of the U.S., 1976-1996.” Cancer. 89(7): 1593-1602.

Halverson, Joel A. and Greg Bischak. 2008. "Underlying Socioeconomic Factors Influencing Health Disparities in the Appalachian Region.” Appalachian Regional Commission: Washington, D.C.

Halverson, Joel A., Elizabeth Barnett and Michele Casper. 2002. "Geographic Disparities in Heart Disease and Stroke Mortality Among Black and White Populations in the Appalachian Region.” Ethnicity \& Disease. 12:S3-82-S3-91.

Halzman, David C. 2011. "Mountaintop Removal Mining: Digging Into Community Health Concerns.” Environmental Health Perspectives. 119(11):a476-a483.

Hassing, Carlijne, Marcel Twickler, Bert Brunekreef, Flemming Cassee, Pieter Doevendans, John Kastelein, and Maarten Jan Cramer. 2009. "Particulate air pollution, coronary heart disease and individual risk assessment: a general 
overview." European Journal of Cardiovascular Prevention and Rehabilitation. $16: 10-15$.

Hendryx, Michael. 2008. "Mortality Rates in Appalachian Coal Mining Counties: 24 Years Behind the Nation.” Environmental Justice. 1(1):5-11.

Hendryx, Michael. 2009. "Mortality from heart, respiratory, and kidney disease in coal mining areas of Appalachia." International Archives of Occupational \& Environmental Health. 82:243-249.

Hendryx, Michael. 2011. "Poverty and Mortality Disparities in Central Appalachia: Mountaintop Mining and Environmental Justice." Journal of Health Disparities Research and Practice. 4(3):44-53.

Hendryx, Michael. 2013. "Personal and Family Health in Rural Areas of Kentucky With and Without Mountaintop Coal Mining." The Journal of Rural Health. 29: s79s88.

Hendryx, Michael and Melissa M. Ahern. 2008. "Relations Between Health Indicators and Residential Proximity to Coal Mining in West Virginia." American Journal of Public Health. 98(4):669-671.

Hendryx, Michael and Melissa M. Ahern. 2009. "Mortality in Appalachian Coal Mining Regions: The Value of Statistical Life Lost." Public Health Reports. 124:541-550.

Hendryx, Michael and Melissa Ahern. 2012. "Reply to Borak et al 'Mortality Disparities in Appalachia: Reassessment of Major Risk Factors." Journal of Occupational and Environmental Medicine. 54(7):768-769 
Hendryx, Michael, Melissa M. Ahern and Timothy R. Nurkiewicz. 2007.

"Hospitalization Patterns Associated with Appalachian Coal Mining." Journal of Toxicology and Environmental Health. 70(24):2064-2070.

Hendryx, Michael, Evan Fedorko, and Andrew-Anesetti-Rothermel. 2010. “A geographical information system-based analysis of cancer mortality and population exposure to coal mining activities in West Virginia, United States of America." Geospatial Health. 4(2):243-256.

Hendryx, Michale, Florence Fulk, and Andrea McGinley. 2012. "Public Drinking Water Violations in Mountaintop Coal Mining Areas of West Virginia, USA.” Water Quality, Exposure and Health. 4(3): 169-175.

Hendryx, Michael, Kathryn O’Donnell and Kimberly Horn. 2008. 'Lung cancer mortality is elevated in coal-mining areas of Appalachia.” Lung Cancer. 62:1-7.

Hendryx, Michael and Benjamin Holland. 2016. "Unintended consequences of the Clean Air Act: Mortality rates in Appalachian coal mining communities." Environmental Science \& Policy. 63:1-6.

Higginbotham, Nick, Sonia Freeman, Linda Connor and Glenn Albrecht. 2010. "Environmental injustice and air pollution in coal affected communities, Hunter Valley, Australia.” Health \& Place. 16(2): 259-266.

Hitt, Nathaniel P. and Michael Hendryx. 2010. "Ecological Integrity of Streams Related to Human Cancer Mortality Rates.” EcoHealth. 7(1):91-104. 
Homer, Collin and Joyce Fry. 2012. "The National Land Cover Database.” U.S.

Geological Survey, U.S. Department of the Interior: Washington, D.C. (https://pubs.usgs.gov/fs/2012/3020/).

Huertas, Jose I., Maria E. Huertas, Sebastian Izquierdo and Enrique D. Gonzalez. 2012.

"Air quality impact assessment of multiple open pit coal mines in northern

Colombia." Journal of Environmental Management. 93: 121-129.

Idler, Ellen L. and Yael Benyamini. 1997. "Self-rated Health and Mortality: A Review of Twenty-Seven Community Studies." Journal of Health and Social Behavior. 38:21-37.

Jemal, Ahmedin, Michael J.Thun, Lynn A.G. Ries, Holly L. Howe, Hannah K. Weir, Melissa M. Center, Elizabeth Ward, Xiao-Cheng Wu, Christie Eheman, Robert Anderson, Umed A. Ajani, Betsy Kohler and Brenda K. Edwards. 2008. “Annual Report to the Nation on the Status of Cancer, 1975-2005, Featuring Trends in Lung Cancer, Tobacco Use, and Tobacco Control.” Journal of National Cancer Institute. 100:1672-1694.

Jylha, Marja. 2009. "What is self-rated health and why does it predict mortality? Towards a unified conceptual model." Social Science \& Medicine. 69:307-316.

“Kentucky Coal Facts." 2016. Department of Energy Development and Independence, Energy and Environment Cabinet: Frankfort, KY. Retrieved November 21, 2016. (http://energy.ky.gov/Pages/CoalFacts.aspx?Paged=TRUE\&p_SortBehavior=0\&p _Revised=19931201\%2005\%3a00\%3a00\&p_ID=26\&PageFirstRow=31\&\&View $=\% 7 \mathrm{~b} 30 \mathrm{C} 57 \mathrm{EBA}-7527-4 \mathrm{E} 4 \mathrm{D}-9970-9205 \mathrm{D} 0 \mathrm{~A} 9 \mathrm{C} 032 \% 7 \mathrm{~d})$. 
“Kentucky Quarterly Coal Report (Q1-2017).”2017. Kentucky Energy and Environment Cabinet: Frankfort, KY. Retrieved November 5, 2017. Retrieved on November 5, 2017.

(http://energy.ky.gov/Coal\%20Facts\%20Library/Kentucky\%20Quarterly\%20Coal \%20Report\%20(Q1-2017).pdf).

Kettunen, Jaana, Timo Lanki, Pekka Tiittanen, Pasi P. Aalto, Tarja Koskentalo, Markku Kulmala, Veikko Salomaa and Juha Pekkanen. 2007. “Associations of Fine and Ultrafine Particulate Air Pollution With Stroke Mortality in an Area of Low Air Pollution Levels." Stroke. 38:918-922.

King, Brian A., Shanta R. Dube and Michael A. Tynan. 2012. "Current Tobacco Use Among Adults in the United States: Findings from the National Adult Tobacco Survey." American Journal of Public Health. 102(11):e93-e100.

Knuckles, Travis L., Phoebe A. Stapleton, Valerie C. Minarchick, Laura Esch, Michael McCawley, Michael Hendryx, and Timothy R. Nurkiewicz. 2012. “Air Pollution Particulate Matter Collected from an Appalachian Mountaintop Mining Site Induces Microvascular Dysfunction.” Microcirculation. 20:158-169.

Kodavanti, Urmila P., Mette C. Schladweiler, Allen D. Ledbetter, William P. Watkinson, Matthew J. Campen, Darrell W. Winsett, Judy R. Richards, Kay M. Crissman, Gary E.Hatch and Daniel L. Costa. 2000. "The Spontaneously Hypertensive Rat as a Model of Human Cardiovascular Disease: Evidence of Exacerbated Cardiopulmonary Injury and Oxidative Stress from Inhaled Emission Particulate Matter." Toxicology and Applied Pharmacology. 164:250-263. 
Kolstad, Charles. 2017. “What Is Killing the U.S. Coal Industry?” Institute for Economic Policy Research at Stanford University: Palo Alto, CA. Retrieved on November 11, 2017. (https://siepr.stanford.edu/research/publications/what-killing-us-coalindustry).

Krause, Denise D., Warren L. May, Nancy M. Lane, Jeralynn Cossman and Thomas R. Cossman. 2011. "An Analysis of Oral Health Disparities and Access in Appalachia.” Appalachian Regional Commission: Washington, D.C.

Krauss, Clifford and Michael Corkery. 2016. “A Bleak Outlook for Trump's Promises to Coal Miners." The New York Times, Nov 19. Retrieved on November 2, 2017. (https://www.nytimes.com/2016/11/20/business/energy-environment/a-bleakoutlook-for-trumps-promises-to-coal-miners.html).

Kurth, Laura, Allan Kolker, Mark Engle, Nicholas Geboy, Michael Hendryx, William Orem, Michael McCawley, Lynn Crosby, Calin Tatu, Matthew Varonka and Christina DeVera. 2014. "Atmospheric particulate matter in proximity to mountaintop coal mines: sources and potential environmental and human health impacts." Environmental Geochemical Health. 37(3):529-44.

Kruth, Laura, Michael McCawley, Michael Hendryx and Stephanie Lusk[1]. 2014. "Atmospheric particulate matter size distribution and concentration in West Virginia coal mining and non-mining areas." Journal of Exposure Science and Environmental Epidemiology. 24:405-411.

Laden, Francine, Lucas M. Neas, Douglas W. Dockery and Joel Swartz. 2000. “Association of Fine Particulate Matter from Different Sources with Daily 
Mortality in Six U.S. Cities.” Environmental Health Perspectives. 108(10):941947.

Lane, Nancy M., Andrew Y. Lutz, Kimberley Baker, Thomas R. Konrad, Thomas R. Ricketts, Randy Randolph, Charles Tran and Christopher A. Beadles. 2012. "Health Care Costs and Access Disparities in Appalachia." Appalachian Regional Commission: Washington, D.C.

Laney, A. Scott, Anita L. Wolfe, Edward L. Petsonk and Cara N. Halldin. 2012. "Pneumoconiosis and Advanced Occupational Lung Disease Among Surface Coal Miners - 16 States, 2010-2011." Morbidity and Mortality Weekly Reports. 61(23):431-434.

Laney, A. Scott and Michael D. Attfield. 2010. "Coal workers' pneumoconiosis and progressive massive fibrosis are increasingly more prevalent among workers in small underground coal mines in the United States." Occupational and Environmental Medicine. 67(6):428-431.

Laney, A. Scott, Edward L. Petsonk and Michael D. Attfield. 2009. "Pneumoconiosis among underground bituminous coal miners in the United States: is silicosis becoming more frequent?" Occupational and Environmental Medicine. 67:652656.

Lindberg, T. Ty., Emily S. Bernhardt, Raven Bier, A.M. Helton, R.Brittany Merola, Avner Vengosh and Richard T. Di. Giulio. 2011. "Cumulative impacts of mountaintop mining on an Appalachian watershed." Proceedings of the National Academy of Sciences of the USA. 108(52):20929-20934. 
Lengerich, Eugene J., Thomas C. Tucker, Raymond K. Powell, Pat Colsher, Erik Lehman, Ann J. Ward, Jennifer C.Siedlecki and Stephen W. Wyatt. 2005. "Cancer Incidence in Kentucky, Pennsylvania, and West Virginia: Disparities in Appalachia." Journal of Rural Health. 21(1):39-47.

Levesque, Shannon, Michael J. Surace, Jacob McDonald and Michelle L Block. 2011. "Air pollution \& the brain: Subchronic diesel exhaust exposure causes neuroinflammation and elevates early markers of neurodegenerative disease." Journal of Neuroinflammation. 8:105-115.

Lewis, Helen M. and Edward E. Knipe. 1978. “The Colonialism Model: The Appalachian Case.” Pp.9-32 in Colonialism in Modern America: The Appalachian Case, edited by Helen M. Lewis, Linda Johnson and Donald Askins. Boone, NC: The Appalachian Consortium Press.

Lewtas, Joellen. 2007. “Air pollution combustion emissions: Characterization of causative agents and mechanisms associated with cancer, reproductive, and cardiovascular disease effects." Mutation Research. 636:95-133.

Lisabeth, Lynda D., James D. Escobar, J. Timothy Dvonch, Brisa N. Sanchez, Jennifer J. Majersik, Devin L. Brown, Melinda A. Smith, and Lewis B. Morgenstern. 2008. "Ambient Air Pollution and Risk for Ischemic Stroke and Transient Ischemic Attack.” Annals of Neurology. 64:53-59.

Liu, Jingjing, Guijian Liu, Jiamei Zhang, Hao Yin and Ruwei. 2012. "Occurrence and risk assessment of polycyclic aromatic hydrocarbons in soil from the Tiefa coal mine district, Liaoning, China." Journal of Environmental Monitoring. 14: 2634. 
Lutz, Brian D., Emily S. Bernhardt and William H. Schlesinger. 2013. "The Environmental Price Tag on a Ton of Mountaintop Removal Coal.” PLoS One. 8(9):e73203.

Marmot, Michael. 2005. "Social determinants of health inequalities." The Lancet. 365:1099-1104.

Mastin, J. Patrick. 2006. "The Contribution of Air Pollution to the Burden of Cardiovascular Disease." Sustain: a journal of environmental and sustainability issues. 13:3-5.

Mattila, Kimmo J., Markku S. Nieminen, Ville V. Valtonen, Vesa P Rasi, Y Antero Kesaniemi, Satu L. Syrjala, Peter S. Jungell, Martti Isoluoma, Katariina Hietaniemi, Matti J. Jokinen and Jussi K Uttunen. 1989. “Association between dental health and acute myocardial infarction." Br Med J. 298:779-82.

McAuley, Steven D. and Mark D. Kozar. 2006. “Ground-Water Quality in Unmined Areas and Near Reclaimed Surface Coal Mines in the Northern and Central Appalachian Coal Regions, Pennsylvania and West Virginia.” U.S. Geological Survey, U.S. Department of the Interior: Washington, D.C.

McGarvey, Elizabeth L., MaGuadalupe Leon-Verdin, Lydia F. Kilos, Thomas Guterbock and Wendy F. Cohn. 2011. "Health Disparities Between Appalachian and NonAppalachian Counties in Virginia, USA.” Journal of Community Health. 36:348356. 
Mensah, George A., Ali H. Hokdad, Earl S. Ford, Kurt J. Greenlund and James B. Croft. 2005. "State of Disparities in Cardiovascular Health in the United States." Circulation. 111:1233-1241.

Michimi, Akihiko. 2010. "Modeling coronary heart disease prevalence in regional and sociodemographic contexts." Health and Place. 16:147-155.

Miilunpalo, Seppo, Ikka Vuori, Pekka Oja, Matti Pasanen and Helka Urponen. 1997. "Self-rated health status as a health measure: The predictive value of self-reported health status on the use of physician services and on mortality in the working-age population.” Journal of Clinical Epidemiology. 50(5):517-528.

Milici, Robert C. and Kristin O. Dennen. 2009. "Production and Depletion of Appalachian and Illinois Basin Coal Reserves.” The National Coal Resource Assessment Overview. U.S. Geological Survey, U.S. Department of the Interior: Washington, D.C.

Miller, Kristin A., David S. Siscovick, Lianne Sheppard, Kristen Shepherd, Jeffrey Sullivan, Garnet L. Anderson and Joel D. Kaufman. 2007. "Long-Term Exposure to Air Pollution and Incidence of Cardiovascular Events in Women." The New England Journal of Medicine. 356(5): 447-458.

Mintz, David. 2009. “Technical Assistance Document for the Reporting of Daily Air Quality - the Air Quality Index (AQI).” U.S. Environmental Protection Agency, Research Triangle Park, North Carolina.

Morrice, Emily and Ruth Colagiuri. 2012. "Coal mining, social injustice and health: A universal conflict of power and priorities." Health \& Place. 19:74-79. 
Mossey, J.M. and E. Shaprio. 1982. "Self-rated health: a predictor of mortality among the elderly." American Journal of Public Health. 72:800-808.

“NCHS Data Linkage.” 2016. National Center for Health Statistiscs. Retreived on November 2, 2017. (https://www.cdc.gov/nchs/data-linkage/mortality.htm).

Neas, Lucas M. 2000. "Fine particulate matter and cardiovascular disease.” Fuel Processing Technology. 55-67.

Neuberger, Manfred, Michael G. Schimek, Friedrich Horak Jr., Hanns Moshammer, Michael Kundi, Thomas Frischer, Bostjan Gomiscek, Hans Puxbaum and Helger Hauck. 2004. "Acute effects of particulate matter on respiratory diseases, symptoms and functions: epidemiological results of the Austrian Project on Health Effects of Particulate Matter (AUPHEP).” Atmosphereic Environment. 38:3971-3981.

Ostro, Bart, Rachel Broadwin, Shelley Green, Wen-Ying Feng and Michael Lipsett. 2006. "Fine Particulate Air Pollution and Mortality in Nine California Counties: Results from CALFINE.” Environmental Health Perspectives. 114(1):29-33.

Palmer, M.A., E.S. Bernhardt, W.H. Schlesinger, K.N. Eshleman,E. Foufoula-Georgiou, M.S. Hendryx, A.D. Lemly, G.E. Likens, O.L. Loucks, M.E. Powers, P.S. White and P.R. Wilcock. 2010. “Mountaintop Mining Consequences.” Science. 327:148149.

Park, Madison. "6 Obama climate policies that Trump orders change.” CNN.com, March 28, 2017. Retrieved on November 2, 2017. 
(http://www.cnn.com/2017/03/28/politics/climate-change-obama-rulestrump/index.html).

"Particulate Matter (PM) Basics.” 2016. U.S. Environmental Protection Agency. Retrieved on November, 11, 2016. (https://www.epa.gov/pmpollution/particulate-matter-pm-basics\#PM).

Partridge, Mark D., Michael E. Betz and Linda Lobao. 2012. "Natural Resource Curse and Poverty in Appalachia America." American Journal of Agricultural Economics. 95(2):449-456.

Paskett, Eletra D., James L. Fisher, Eugene J. Lengerich, Nancy E. Schoenberg, Stephenie K. Kennedy, Mary Ellen Conn, Karen A. Roberto, Sharon K. Dwyer, Darla Fickle and Mark Dignan. 2011. "Disparities in Underserved White Populations: The Case of Cancer-Related Disparities in Appalachia." The Oncologist. 16:1072-1081.

Pastor, JR, Manuel, Jim Sadd and John Hipp. 2002. "Which came first? Toxic Facilities, Minority Move-In, and Environmental Justice." Journal of Urban Affairs. 23(1):1-21.

Peng, Roger D., Howard H. Chang, Michelle L. Bell, Aidan McDermott, Scott L. Zeger, Jonathan M. Samet and Fancesca Dominici. 2008. "Coarse Particulate Matter Air Pollution and Hospital Admissions for Cardiovascular and Respiratory Diseases Among Medicare Patients." Journal of the American Medical Association. 299(18):2172-2179. 
Peters, Annette. 2005. "Particulate matter and heart disease: Evidence from epidemiological studies.” Toxicology and Applied Pharmacology. 207:S477S482.

Plumer, Brad. 2013. "Here's why Central Appalachia's coal industry is dying.” The Washington Post, November 4, online. (https://www.washingtonpost.com/news/wonk/wp/2013/11/04/heres-why-centralappalachias-coal-industry-is-dying/).

Pollard, Kelvin and Linda A. Jacobsen. 2015. “The Appalachian Region: A Data Overview from the 2009-2013 American Community Survey." Appalachian Regional Commission: Washington, D.C.

Pope III, C. Arden, Douglas W. Dockery, John D. Spengler and Mark E. Raizenne. 1991. "Respiratory health and PM10 Pollution." American Review of Respiratory Disease. 144(3):668-674.

Pope II, C. Arden. 2000. "Epidemiology of Fine Particulate Air Pollution and Human Health: Biologic Mechanisms and Who's at Risk?" Environmental Health Perspectives. 108(4):713-723.

Pope III, C. Arden, Richard T. Burnett, Michael J. Thun, Eugenia E. Calle, Daniel Krewski, Kazuhiko Ito and George D. Thurston. 2002. "Lung Cancer, Cardiopulmonary Mortality, and Long-term Exposure to Fine Particulate Air Pollution.” Journal of the American Medical Association. 287(9):1132-1141. 
Reynolds, L., T. P. Jones, K.A. BeruBe, H. Wie and R. Richards. 2003. "Toxicity of airborne dust generated by opencast coal mining." Mineralogical Magazine. 67(2): 141-152.

Rosenbaum, Paul R. and Donald B. Rubin. 1983. "The Central Role of Propensity Score in Observational Studies for Causal Effects.” Biometrika. 70(1):41-55.

Ross, Matthew R.V., Brian L. McGlynn and Emily S. Bernhardt. 2016. "Deep Impact: Effects of Mountaintop Mining on Surface Topography, Bedrock Structure and Downstream Waters.” Environmental Science \& Technology. 50:2064-2074.

Scott, Douglas F., R. Larry Grayson and Edward A. Metz. 2004. "Disease and Illness in U.S. Mining, 1983-2001.” Journal of Environmental Medicine. 46(12):12721277.

Samet, Jonathan M., Scott L. Zeger, Francesca Dominici, Frank Durriero, Ivan Coursac, Douglas W. Dockery, Joel Swartz, and Antonella Zanobetti. 2000. "The National Morbidity, Mortality, and Air Pollution Study Part II: Morbidity and Mortality from Air Pollution in the United States." Health Effects Institute: Cambridge, MA.

Schnaiberg, Allan. 1980. “The Environment: From surplus to scarcity.” Oxford University Press, Oxford, UK.

Shandera-Ochsner, Anne L., Dong Y Han, Danny Rose, Sushanth R. Aroor, Federick Schmitt, Lisa M. Bellamy and Michael R. Dobbs. 2014. "Comparing the Trends of Elevated Blood Pressure in Appalachia and Non-Appalachian Regions." The Journal of Clinical Hypertension. 16(10):713-715. 
Sherry, B, H.M. Blanck, D.A. Galuska, L. Pan, W.H. Dietz and L. Balluz. 2010. "Vital Signs: State-Specific Obesity Prevalence Among Adults - United States, 2009.” Morbidity and Mortality Weekly Report. 59:1-5.

Shiber, John G. 2004. "Arsenic in Domestic Well Water and Health in Central Appalachia, USA.” Water, Air and Soil Pollution. 160:327-341.

Strager, Michael P., Jacquelyn M. Strager, Jeffrey S. Evans, Judy K. Dunscomb, Brad J. Kreps and Aaron E. Maxwell. 2015. "Combining a Spatial Model and Demand Forecasts to Map Future Surface Coal Mining in Appalachia." PLoS One. 10(6):e0128813.

Smith, Laureen H. and Christopher H. Holloman. 2011. "Health Status and Access to Health Care Services: A Comparison Between Ohio’s Rural Non-Appalachian and Appalachian Families.” Family Community Health. 34(2):102-110.

Suarthana, Eva, A. Scott Laney, Eileen Storey, Janet M. Hale and Michael A. Attfield. 2011. “Coal workers' pneumoconiosis in the United States: regional differences 40 years after implementation of the 1969 Federal Coal Mine Health and Safety Act.” Occupational Environmental Medicine. 68:908-913.

Talbott, Evelyn O., Ravi K. Sharma, Jeanine Buchanich and Shatna L. Stacy. 2015. "Is There an Association of Circulatory Hospitalizations Independent of Mining Employment in Coal-Mining and Non-Coal-Mining Counties in West Virginia?" Journal of Occupational \& Environmental Medicine. 57(4):e30-e36.

Taylor, Sarah. 2013. "Growing up in a steel town: Early childhood exposure to pollution and later-life mortality." Conference paper presented at Population Association of 
America annual meetings April 11-13, 2013.

(http://paa2013.princeton.edu/papers/130965).

Tecer, Lokman Hakan, Omar Alagha, Ferhat Karaca, Gurdal Tuncel and Nilufer Eldes. 2008. "Particulate Matter and Children's Hospital Admissions for Asthma and Respiratory Diseases: A Bidirectional Case-Crossover Study.” Journal of Toxicology and Environmental Health. 72:512-520.

Thurston, G. and M. Lippmann. 2015. “Ambient particulate matter air pollution and cardiopulmonary diseases.” Semin Respir Crit Care Med. 36(3):422-432.

U.S. Energy Information Administration. 2016. “Annual Coal Report.” U.S. Department of Energy: Washington, D.C. d on November 21, 2016. (http://www.eia.gov/coal/annual/).

U.S. Department of Health and Human Services. 2014. "The Health Consequences of Smoking - 50 Years of Progress: A Report of the Surgeon General. Centers for Disease Control and Prevention: Atlanta, GA.

Valavanidis, Athanasios, Konstatinos Fiotakis and Thomais Vlachogianni. 2008. “Airborne Particulate Matter and Human Health: Toxicological Assessment and Importance of Size and Composition of Particles for Oxidative Damage and Carcinogenic Mechanisms.” Journal of Environmental Science and Health, Part C. 26:339-362.

Vengosh, Avner, T. Ty. Lindberg, Brittany R. Merola, Laura Ruhl, Nathaniel R. Warner, Alissa White, Gary S. Dwyer and Richard T. Di Giulio. 2013. "Isotopic Imprints 
of Mountaintop Mining Contaminants." Environmental Science \& Technology. 47:10041-10048.

Virginia Center for Coal and Energy Research. 2013. Virginia Polytechnic \& State University: Blacksburg, VA. Retrieved on November 21, 2016 (https://www.energy.vt.edu/).

"Virginia Energy Patterns and Trends.” 2016. Virginia Department of Mines, Minerals and Energy. Retrieved November 21, 2016. (https://www.energy.vt.edu/vept/coal/prodtables.asp).

Walker, Annie. 2013. "An Empirical Analysis of Resource Curse Channels in the Appalachian Region.” Department of Economics, West Virginia University: Morgantown, WV.

“West Virginia Mining Statistics 1996-2012.” 2016. West Virginia Office of Miners' Health Safety and Training: Charleston, WV. Retrieved November 21, 2016. (http://www.wvminesafety.org/STATS.HTM).

Wickham, James, Petra Bohall Wood, Matthew C. Nicholson, William Jenkins, Daniel Druckenbrod, Glenn W. Suter, Michael P. Strager, Christine Mazzarella, Walter Galloway and John Amos. 2013. "The Overlooked Terrestrial Impacts of Mountaintop Mining.” BioScience. 63(5):335-348.

Williams, John Alexander. 2002. “Appalachia: A History.” The University of North Carolina Press, Chapel Hill, NC. 
Wilson, Reda J., A. Blythe Ryerson, Simple D. Singh and Jessica B. King. 2016. "Cancer Incidence in Appalachia." Cancer Epidemiology, Biomarkers \& Prevention. 25(2):250-258.

Wingo, Phyllis, Thomas C. Tucker, Patricia M. Jamison, Howard Martin, Colleen McLaughlin, Rana Bayakly, Susan Bolick-Aldrich, Pat Colsher, Robert Indian, Karen Knight, Stacey Neloms, Reda Wilson and Thomas B. Richards. 2007. “Cancer in Appalachia, 2001-2003.” Cancer. 112(1):181-192.

Woolley, Shannon M., Ada O. Youk, Todd M. Bear, Lauren C. Blamert, Evelyn O. Talbott and Jeanine M. Buchanich. 2015. "Impact of Coal Mining on Self-Rated Health among Appalachian Residents." Journal of Environmental and Public Health. Online.

Yao, Nengliang, Hector E. Alcala, Roger Anderson and Rajesh Balkrishnan. 2016. "Cancer Disparities in Rural Appalachia: Incidence, Early Detection and Survivorship." The Journal of Rural Health. 1-8.

Yao, Nengliang, Eugene J. Lengerich and Marianne M. Hillemeier. 2012. "Breast Cancer Mortality in Appalachia: Reversing Patterns of Disparity over Time." Journal of Health Care for the Poor and Underserved. 23(2):715-725.

Yao, Nengliang, Stephen A. Matthews and Marianne M. Hillemeier. 2012. "White Infant Mortality in Appalachian States, 1976-1980 and 1996-2000: Changing Patterns and Persistent Disparities." The Journal of Rural Health. 28:174-182. 
Young Jr., Roscoe C., Raylinda E. Rachal, Peggy G. Carr and Harry C. Press. 1992.

“Patterns of Coal Workers' Pneumoconiosis in Appalachian Former Coal Miners." Journal of the National Medical Association. 84(1): 41-48.

Zanobetti, Antonella and Joel Schwartz. 2009. "The Effect of Fine and Coarse Particulate Air Pollution on Mortality: A National Analysis.” Environmental Health Perspectives. 117(6): 898-903.

Zeka, A, Z. Zanobetti and J. Schwartz. 2005. "Short term effects of particulate matter on cause specific mortality: effects of lags and modification by city characteristics." Occupational \& Environmental Medicine. 62:718-725.

Zhang, Zhiwei, Alycia Infante, Michael Meit, Ned English, Michael Dunn and Kristine Harper Bowers. 2008. “An Analysis of Mental Health and Substance Abuse Disparities and Access to Treatment Services in the Appalachian Region.” Appalachian Regional Commission: Washington, D.C.

Zullig, Keith J. and Michael Hendryx. 2010. “A Comparative Analysis of Health-Related Quality of Life for Residents of U.S. Counties with and without Coal Mining.” Public Health Reports. 125:548-555.

Zullig, Keith J. and Michael Hendryx. 2011. "Health-Related Quality of Life Among Central Appalachian Residents in Mountaintop Mining Counties.” American Journal of Public Health. 101(5):848-853 
CIRRICULUM VITA

James Kent Pugh

Department of Sociology

115 Lutz Hall

University of Louisville

Louisville, KY 40292

Work: (502) 852-6836

Cell: (606) 484-0043

Jkpugh01@louisville.edu

\section{EDUCATION}

Ph.D. Applied Sociology

University of Louisville, 2017, Expected

Major: Demography; Minor: Environmental Sociology

Dissertation Title: Moving Mountains: An examination of long-term impacts of mountaintop

removal coal mining on mortality in the Appalachian region using GIS techniques.

Chair: Latrica Best, $\mathrm{PhD}$

M.A. Sociology

University of Louisville, 2014

Thesis title: Down Comes the Mountain: Coal Mining and Health in Central Appalachia, 2000 to 2010.

Chair: Robin Högnäs, $\mathrm{PhD}$.

B.A. Sociology

Berea College, 2012

Senior Thesis title: Who to Blame? Explanations of Poverty among Berea College Students. Advisor: Jill Bouma, PhD.

\section{ADDITIONAL TRAINING}

Formal Demography Workshop $\quad$ University of California, Berkeley, August 2016

\section{RESEARCH INTERESTS}

Medical Sociology; Public Health; Environmental Health; Human \& Population Geography, Demography, Human Life-Course \& Older Age Mortality, Rural Demography, Public Policy, Environmental Policy, Poverty Studies, Social Policy, Geographic Information Science (GIS) analyses

\section{EMPLOYMENT}


Graduate Teaching Assistant

Graduate Research Assistant

$\underline{\text { Student Office Coordinator }}$

TEACHING
Department of Sociology

University of Louisville, August 1, 2012 to May 30, 2014; August 1, 2016 - current

- Taught small group sections of larger 120 section courses.

- Responsible for grading all homework, exams, and other assignments.

- Responsible for correspondence with students about assignments, grades, and other information regarding the class.

- $\quad$ Tutored and mentored students as needed.

Center for Environmental Policy and Management PI: Lauren Heberle, PhD.

University of Louisville, June, 302014 to June 302016

- I worked with research team to write, draft and edit reports for various grants from community and government organizations.

- Worked on EPA-funded grant to create communitybased indictors.

○ Worked with a team to develop a system of community indicators.

- Assigned tasks related to data collection, collection of literature review.

- Worked with principal investigator to develop plans of how to organize, collect and report community indictors from the project.

- Responsible for compiling, editing, and creating visualizations (maps, tables, and graphs) for research reports.

- Including processing geographic housing data from Louisville Housing Authority.

- Fixing address discrepancies.

- Editing address formats.

- Aligning multiple housing datasets into combined file for mapping purposes.

- Responsible for downloading, editing, and reporting U.S. Census data, including American Community Survey, American Housing Survey, Decennial Census data for reports.

Department of Sociology

Berea College, Fall 2010 to Spring 2012

- Operated front desk of Sociology Department office.

- General office duties as assigned. 


\section{As Instructor:}

- SOC 202: Social Problems

○ Fall 2017

- Summer II 2017

- SOC 201: Introduction to Sociology

○ Spring 2017

As Teaching Assistant:

- SOC 201: Introduction to Sociology

- Fall 2017

- SOC 301: Introduction to Social Statistics

○ Fall 2013

- Spring 2014

- $\quad$ SOC 210: Race in the United States

○ Fall 2012

○ Spring 2013

\section{PUBLICATIONS}

\section{MANUSCRIPTS/PAPERS}

\section{To Be Submitted}

Pugh, James K., and David Roelfs. "Life expectancy disparities in coal producing U.S. counties, 2010." (Submitted by September $1^{\text {st }}$ to International Journal of Occupational \& Environmental Health)

\section{Being Revised}

Pugh, James K. and Robin Högnäs "Down Comes the Mountain - Mountaintop coal removal mining and health in Appalachia from 2000 to 2010."

Pugh, James K., Latrica E. Best and Allison S. Smith. "Up in Smoke: Assessing the Impacts of Coal-Fired Power Plants on Respiratory, Cardiovascular and Lung Cancer Mortality Using a Power Plant Population Risk Measure."

\section{In Preparation}

Pugh, James K. and Latrica E. Best. "It Takes a Village - The Impact of Province-level Development Characteristics on Chronic Disease Management in Ghana."

\section{REPORTS}

\section{Listed as co-author}

Carol Norton, Lauren Heberle, Allison Smith, Ryan Fenwick, Daniel Weinstein, [James] Kent Pugh and Adam Sizemore. (2014). State of Metropolitan Housing Report 2014. Center for Environmental Policy and Management at University of Louisville. Prepared for the Metropolitan Housing Coalition, Louisville, KY. (http://www.metropolitanhousing.org/wpcontent/uploads/member_docs/CORRECTED\%20WITH\%20ALL\%20DONORS\%202014\%20S MHR\%2012-10-14.pdf) 


\section{Listed as contributor}

Heberle, Lauren, Catherine Fosi and Telesphore Kagaba. 2015. Searching for Safe, Fair, and Affordable Housing: Learning from Experiences - an analysis of housing challenges in Louisville Metro. Center for Environmental Policy and Management, Anne Braden Institute at University of Louisville \& Metropolitan Housing Coalition, Louisville, KY. Prepared for Louisville Metro Human Relations Commission. (http://www.metropolitanhousing.org/wpcontent/uploads/member_docs/Searching\%20for\%20Safe\%20Fair\%20and\%20Affordable\%20Ho using\%20-\%20Learning\%20from\%20Experiences.pdf).

Heberle, Lauren and Cathy Hinko. 2015. 2015 State of Metropolitan Housing Report. Center for Environmental Policy and Management at University of Louisville. Prepared for the Metropolitan Housing Coalition, Louisville, KY. (http://www.metropolitanhousing.org/wp-

content/uploads/member docs/2015\%20State\%20of\%20Metropolitan\%20Housing\%20Report.pd f).

\section{PRESENTATIONS}

\section{CONFERENCE PRESENTATIONS}

Pugh, James K. "Coal Tattoo: an aerial interpolation model of surface and mountaintop removal coal mining and mortality in Appalachia, 1990-2010." Presented at the Rural Sociology Society Annual Meetings, July $29^{\text {th }}, 2017$.

Pugh, James K. "Moving Mountains - An GIS Analysis of Mortality Rates and MTR Coal Mining in Appalachia." Presented at Southern Sociology Society Annual Conference, April 1, 2017.

Pugh, James K. and Brandon McReynolds. "A Coal Miner's Education: An analysis of coal mining's impact on educational attainment in the Appalachian region." Presented at Southern Sociological Society Annual Conference, April 15, 2016.

Pugh, James K., Latrica Best., and Allison S. Smith. "Up in Smoke: Assessing the Impacts of Coal-Fired Power Plants on Respiratory, Cardiovascular and Lung Cancer Mortality Using a Power Plant Population Risk Measure.” Presented as a poster at Population Association of America annual meetings, April 1, 2016.

Pugh, James K. "Mountains and Molehills: A GIS analysis of Mountaintop Coal Mining and Health in Appalachia." Presented at Southern Demographic Association Meeting, Memphis, TN, October 17, 2014.

Pugh, James K. "Down Comes the Mountain: Coal Mining and Health in Central Appalachia from 2000 to 2010." Presented as a poster at the Population Association of America annual meetings, Boston, MA, May 1, 2014.

Pugh, James K. "Economics of Mountain Top Coal Removal in Central Appalachia." Presented as a poster at the Appalachian Studies Association annual meetings, Marshall University, Huntington, WV, March 28, 2014. 
Pugh, James K. "Mountains of Health: Mountaintop Coal Removal and Health in Appalachia, 2000-2010." Presented at $5^{\text {th }}$ Annual Appalachian Research Community Symposium, University of Kentucky, Lexington, KY. March 8, 2014.

Pugh, James K. "Who to Blame? Explanations of Poverty among Berea College Students." Session Leader, presented at Anthropologists and Sociologists of Kentucky Conference, Bellarmine University, Louisville, KY, April 6, 2013.

\section{OTHER PRESENTATIONS}

Pugh, James K. "Mountains and Molehills: A GIS analysis of Mountaintop Coal Mining and Health in Appalachia." Presented as poster at 2014 Graduate Student Council Research Symposium, University of Louisville, Louisville, KY. November 14, 2014.

Pugh, James K. "Mountains and Molehills: A GIS analysis of Mountaintop Coal Mining and Health in Appalachia." Presented at Brown Bag series, Department of Sociology, University of Louisville, Louisville, KY. October 9, 2014.

Pugh, James K. "Down Comes the Mountain: Coal Mining and Health in Central Appalachia from 2000 to 2010." Presented at Brown Bag series, Department of Sociology, University of Louisville, Louisville, KY. April 28, 2014.

\section{INVITED LECTURES}

Pugh, James K. “Mountaintop Coal Removal: What is it? Why is it important?" Invited to speak to Biology 102: Intro to Biological Systems class at the University of Louisville, November 12, 2014.

\section{AWARDS/HONORS}

\section{University of Louisville}

Outstanding Teaching Award, Department of Sociology - Spring 2017

Outstanding Research Award, Department of Sociology - Spring 2014

Alice Eaves Barns Award - Spring 2014

Dean's Citation - Spring 2014

\section{Berea College}

Dallas and Betty Johnson Sociology Scholarship - 2012

John B. Stephenson Scholarship for Non-Western Travel - 2011

New Horizons Grant - 2009

\section{ADDITIONAL TRAINING}

Graduate Grant Writing Academy - Spring 2014

Graduate Teaching Academy - Fall/Spring 2012/13

\section{SERVICE}

SIGS Ambassador - member since August 2014

Sociology Graduate Student Association UofL - member since August 2012 


\section{PROFESSIONAL MEMBERSHIPS}

Anthropologists and Sociologists of Kentucky - 2013-present

Appalachian Studies Association - 2013-present

Population Association of America - 2013-present

Rural Sociology Society - 2016-present

Southern Demographic Association - 2014-present

Southern Sociological Society - 2016-present

\section{SOFTWARE SKILLS}

Stata, SPSS, ArcGIS, SAS, R, Microsoft Office products, Adobe Photoshop

\section{PROFESSIONAL REFERENCES}

Latrica E. Best, PhD.

Associate Professor of Sociology \& Pan-African Studies

University of Louisville

Latrica.best@1ouisville.edu

502-852-5123

David Roelfs, $\mathrm{PhD}$.

Assistant Professor of Sociology

University of Louisville

Djroe101@louisville.edu

502-852-8038

Lauren Heberle, $\mathrm{PhD}$.

Associate Professor of Sociology \& Director of the Center for Environmental Policy and Management

University of Louisville

lauren.heberle@1ouisville.edu

502-852-4749

Patricia Gagne, $\mathrm{PhD}$.

Professor of Sociology \& Director of Graduate Studies in the Department of Sociology

University of Louisville

gagne@louisville.edu

502-852-8014

Allison F. Smith, PhD.

Urban Planner \& Brownfields Program Manager

Louisville Metro Government

Allison.Smith@louisvilleky.gov

502-574-1569 